University of Louisville

ThinkIR: The University of Louisville's Institutional Repository

Electronic Theses and Dissertations

$12-2013$

\title{
Pulsatile flow does not improve efficacy in ex vivo lung perfusion.
}

Keith A. Zoeller

University of Louisville

Follow this and additional works at: https://ir.library.louisville.edu/etd

Part of the Biomedical Engineering and Bioengineering Commons

\section{Recommended Citation}

Zoeller, Keith A., "Pulsatile flow does not improve efficacy in ex vivo lung perfusion." (2013). Electronic Theses and Dissertations. Paper 1651.

https://doi.org/10.18297/etd/1651

This Master's Thesis is brought to you for free and open access by ThinkIR: The University of Louisville's Institutional Repository. It has been accepted for inclusion in Electronic Theses and Dissertations by an authorized administrator of ThinkIR: The University of Louisville's Institutional Repository. This title appears here courtesy of the author, who has retained all other copyrights. For more information, please contact thinkir@louisville.edu. 


\title{
PULSATILE FLOW DOES NOT IMPROVE EFFICACY IN EX VIVO LUNG PERFUSION
}

\author{
By \\ Keith A. Zoeller \\ B.S., University of Louisville, 2013

\begin{abstract}
A Thesis
Submitted to the Faculty of the

University of Louisville

J.B. Speed School of Engineering

as Partial Fulfillment of the Requirements

for the Professional Degree
\end{abstract}

MASTER OF ENGINEERING

Department of Bioengineering

December 2013 


\title{
PULSATILE FLOW DOES NOT IMPROVE EFFICACY IN EX VIVO LUNG PERFUSION
}

\author{
Submitted by: \\ Keith A. Zoeller \\ A Thesis Approved On \\ (DATE)
}

by the Following Reading and Examination Committee:

Guruprasad Giridharan Ph.D., Thesis Director

Steven C. Koenig Ph.D.

Gail W. Depuy Ph.D.

Victor H. van Berkel, M.D., Ph.D. 


\section{DEDICATION}

This thesis is dedicated to

Kevin George 


\section{ACKNOWLEDGEMENTS}

I would like to thank Dr. Mark Slaughter and Dr. Steven Koenig of Advanced Heart Failure Research (AHFR) for the opportunity to work in this exciting field. Your trust and guidance made this all possible and enabled us to take this project to where it is today. I would also like to thank Dr. Victor van Berkel for his invaluable tutelage and unwavering enthusiasm throughout the ups and downs of this project. I would like to thank Dr. Gretel Monreal, Dr. Guruprasad Giridharan, Dr. Gail Depuy, and Dr. Kevin Soucy for the expertise they were so gracious as to share with me at every stage of this study. I would like to thank Dr. Paul Linsky and Dr. Erin Schumer for the great times during the long hours in the lab. Thank you for your friendship as well as your mentorship. I would like to thank the entire research team at AHFR for their invaluable support. Mary Anne Hauck, Regina Turner, Karen and Laura Lott, Cary Woolard, Todd Adams, Jon-Aaron Moody, Young Choi, and Steven Carnahan: I am glad to call you friends and colleagues. I would like to thank the RRC staff for the phenomenal support throughout the entire study. I would like to thank Dr. Rebecca Barnett for her invaluable consultation regarding our ELISA protocol. Lastly, I would like to give special 


\section{ACKNOWLEDGEMENTS (CONT)}

thanks to Mike Sobieski of AHFR for the mentorship and expertise that made this project possible. Whether it be post-op, surgery, or in the lab, my time at AHFR has been some of the most valuable, rewarding, and engaging I can remember.

Most importantly, thank you Mom, Dad, Kyle, Erin, and Smokey. 


\begin{abstract}
Introduction Ex vivo lung perfusion (EVLP) has the potential to increase the donor pool for lung transplantation by facilitating extended evaluation of marginal organs. Current methodology employs continuous flow pumps for perfusion. In vivo, continuous flow has been shown to increase pulmonary vascular resistance (PVR). Thus, pulsatile flow EVLP may reduce PVR and improve organ preservation by providing physiologic flow morphology.
\end{abstract}

Methods Lung blocks harvested from male, Yorkshire pigs were allocated into continuous $(\mathrm{CF}, \mathrm{n}=3)$ and pulsatile flow $(\mathrm{PF}, \mathrm{n}=4)$ groups. Lungs were ventilated at 4-5 $\mathrm{mL} / \mathrm{kg}, 30 \% \mathrm{FiO}_{2}$ and perfused with an acellular, albumin-based solution corrected for osmolarity, acid/base balance, and $\mathrm{CO}_{2}$ concentration ( $\leq 19$ hours at $\left.30^{\circ} \mathrm{C}\right)$. Prostaglandin E2 and 30\% albumin were infused continuously at $250 \mathrm{vg} / \mathrm{hr}$ and $100 \mathrm{~mL} / \mathrm{hr}$, respectively. Hemodynamic, respiratory, and blood gas parameters were recorded hourly. Parenchymal biopsies were used for quantification of wet: dry ratio and IL-6, IL8 , and TNF- $\alpha$ using ELISA. 


\begin{abstract}
CONT)
Results $\Delta \mathrm{PO}_{2} / \mathrm{FoO}_{2}$ in $\mathrm{mmHg}$ was $261 \pm 47$ and $313 \pm 37$ at baseline and $174 \pm 36$ and $152 \pm 36$ at hour 12 for $\mathrm{CF}$ and $\mathrm{PF}$, respectively. Wet: dry ratio was $5.53 \pm 0.56$ and 6.06 \pm 0.09 at baseline and 5.27 \pm 0.48 and 5.12 \pm 0.40 at hour 12 for $\mathrm{CF}$ and $\mathrm{PF}$, respectively. Average PVR in Woods Units was $15.17 \pm 1.33$ and $13.60 \pm 1.91$ over the 12 hour test period for $\mathrm{CF}$ and PF groups, respectively. Peak airway pressure (PAWP) in cm $\mathrm{H}_{2} \mathrm{O}$ was $17 \pm 1.15$ and $16 \pm 0.75$ at baseline and $21 \pm 1.67$ and $21 \pm 0.41$ at hour 12 for $\mathrm{CF}$ and PF, respectively. There were no discernable differences in TNF- $\alpha$, IL-6, and IL-8 concentrations, PVR, $\Delta \mathrm{PO}_{2} / \mathrm{FiO}_{2}$, wet: dry ratio, and PAWP between CF and PF.
\end{abstract}

Conclusion EVLP system successfully maintained lungs up to 19 hours using a modified perfusate. These data suggest PF does not offer benefits over CF for prolonged ex vivo lung preservation. 
TABLE OF CONTENTS

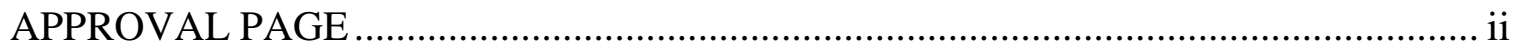

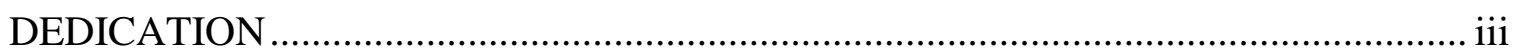

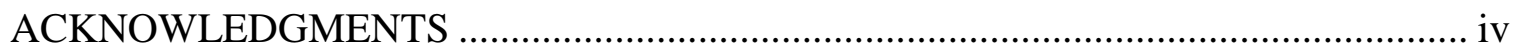

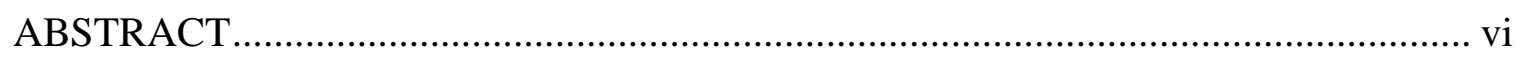

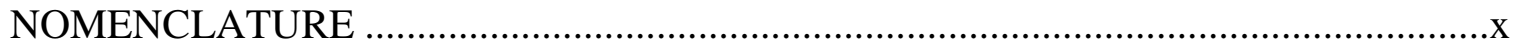

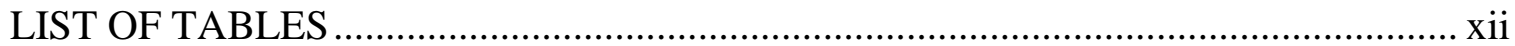

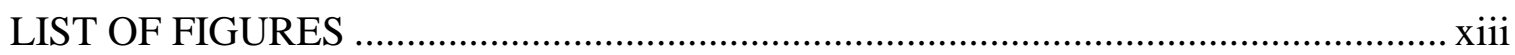

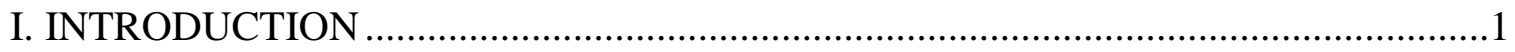

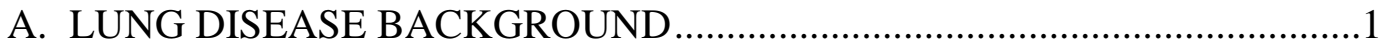

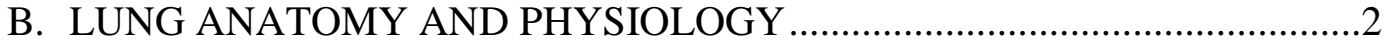

C. PULSATILITIY AND THE VASCULAR ENDOTHELIUM...........................

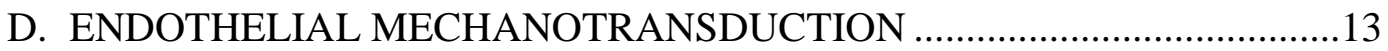

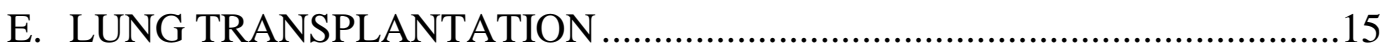

F. SINGLE FLUSH HYPOTHERMIC PRESERVATION ...................................16

G. ISCHEMIC EFFECTS ON TISSUES AND ORGANS …….........................17

H. EX VIVO LUNG PERFUSION ...................................................................18

I. PERFUSATE COMPOSITION IN EX VIVO LUNG PERFUSION .............19

J. VENTILATION AND PERFUSION STRATEGIES IN EX VIVO LUNG

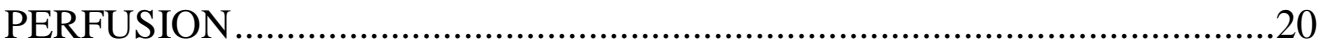

K. CLINICAL TRANSLATION OF EVLP .................................................21

L. PAST, PRESENT AND FUTURE DIRECTIONS IN EVLP ........................22

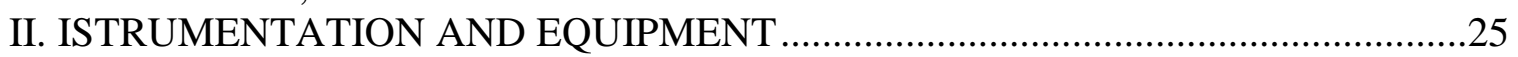

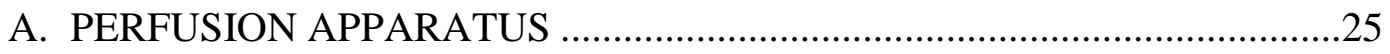

B. VENTILATION AND PERFUSION STRATEGY ……............................26

C. INSTRUMENTATION AND DATA ACQUISITION ...............................27

D. ENZYME-LINKED IMMUNOSORBENT ASSAY (ELISA) ........................28

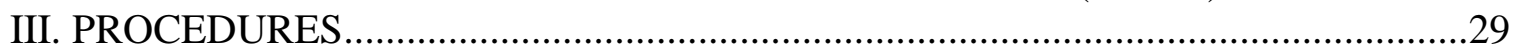

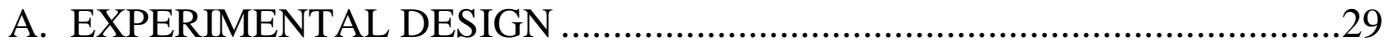

B. PREPARATION OF PERFUSATE ……………...................................

C. SET-UP OF PERFUSION APPARATUS ................................................... 
TABLE OF CONTENTS (CONT)

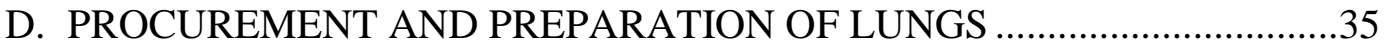

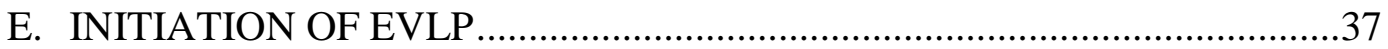

F. VENTILATION AND PERFUSION STRATEGY ……................................39

G. PERFUSATE WITHDRAWAL AND INFUSION SRATEGY ....................40

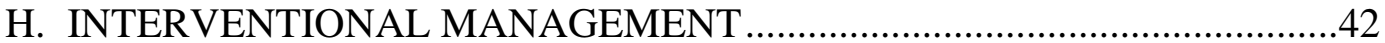

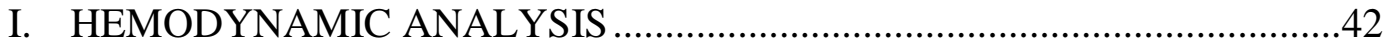

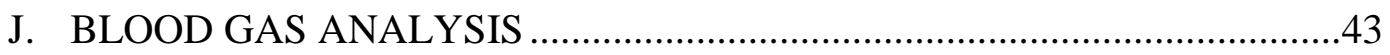

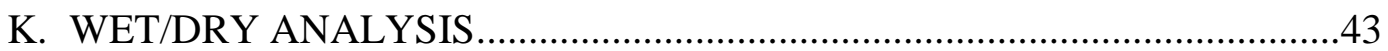

L. ENZYME-LINKED IMMUNOSORBENT ASSAY ANALYSIS .................44

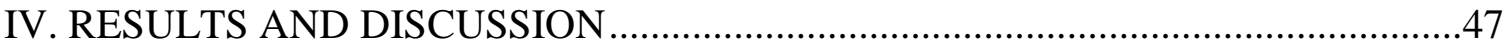

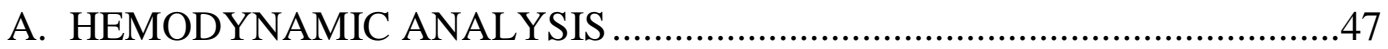

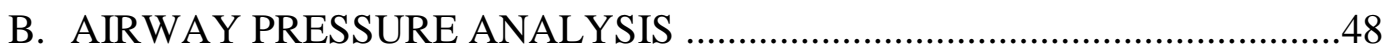

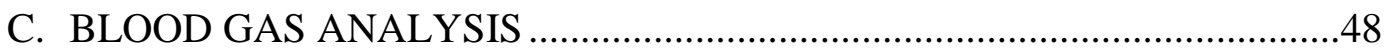

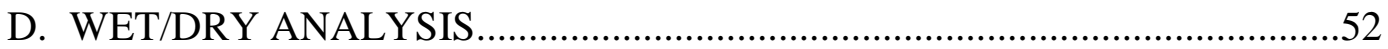

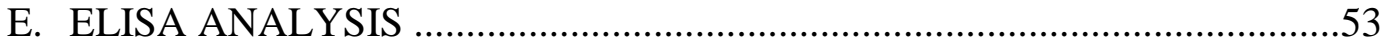

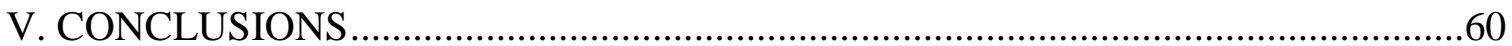

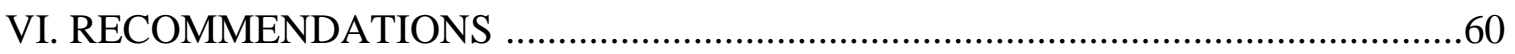

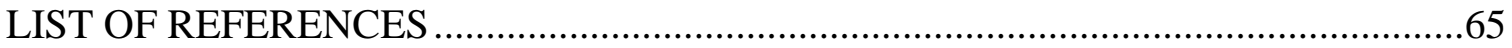

APPENDIX I: CALIBRATION STANDARDS FOR ELISA CONCENTRATION

QUANTIFICATION

APPENDIX II: UNPAIRED T-TEST RESULTS

APPENDIX III: CYTOKINE DATA TABLE 
NOMENCLATURE

EVLP $=E X$ VIVO LUNG PERFUSION

PA = PULMONARY ARTERY

$\mathrm{PAF}=\mathrm{PULMONARY} \mathrm{ARTERY} \mathrm{FLOW}$

PAP $=$ PULMONARY ARTERY PRESSURE

LAP $=$ LEFT ATRIAL PRESSURE

PAWP = PEAK AIRWAY PRESSURE

$\Delta \mathrm{PO}_{2} / \mathrm{FiO}_{2}=\mathrm{OXYGENATION} \mathrm{CAPACITY}$

PVR $=$ PULMONARY VASCULAR RESISTANCE

$\mathrm{PO}_{2}=$ PARTIAL PRESSURE OF OXYGEN

$\mathrm{PCO}_{2}=$ PARTIAL PRESSURE OF CARBON DIOXIDE

PEEP $=$ POSITIVE END EXPIRATORY PRESSURE

eNOS $=$ ENDOGENOUS NITRIC OXIDE SYNTHASE

NO = NITRIC OXIDE

ELISA $=$ ENXYME-LINKED IMMUNOSORBENT ASSAY

DAQ $=$ DATA ACQUISITION UNIT

TNF- $\alpha=$ TUMOR NECROSIS FACTOR ALPHA 
NOMENCLATURE (CONT)

\author{
IL-6 = INTERLEUKIN-6 \\ IL-8 = INTERLEUKIN-8 \\ IL-10 $=$ INTERLEUKIN-10 \\ SHE $=$ SURPLUS HEMODYNAMIC ENERGY \\ EEP $=$ ENERGY EQUIVALENT PRESSURE \\ ZART $=$ VASCULAR INPUT IMPEDANCE
}




\section{LIST OF TABLES}

TABLE I - PROSTACYCLIN RELEASE BY ENDOTHELIAL CELLS SUBJECTED

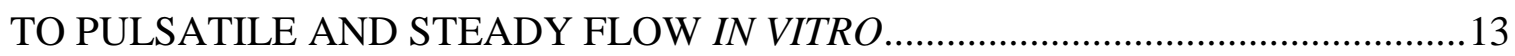

TABLE II - STANDARD (“IDEAL”) LUNG DONOR CRITERIA ……........................15 TABLE III - COMPARISON OF PARAMETERS BETWEEN LUND AND TORONTO

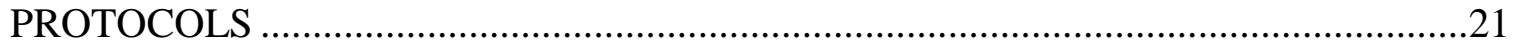

TABLE IV - RECENT CLINICAL TRIAL DATA FOR EVLP ..................................22

TABLE V - COMPOSITION OF 10X STOCK KREBS PERFUSION SOLUTION.......31

TABLE VI - COMPOSITION OF WORKING PERFUSION SOLUTION ......................31

TABLE VII - COMPOSITION OF STATIC PRESERVATION SOLUTION ..................31

TABLE VIII - VENTILATION AND PERFUSION SPECIFICATIONS...............40 


\section{LIST OF FIGURES}

FIGURE 1-DEATHS BY LUNG DISEASE: PERCENT BY SUBGROUP 1

FIGURE 2-A) SURFACE VIEW OF CAPILLARIES IN AN ALVEOLAR WALL AND B) CROSS-SECTIONAL VIEW OF ALVEOLAR WALLS AND THEIR VASCULAR

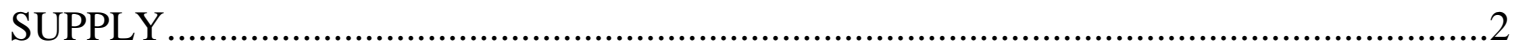

FIGURE 3-ILLUSTRATION OF CELL TYPES IN THE ALVEOLUS .......................4

FIGURE 4-BLOOD FLOW IN THE PULMONARY CIRCULATION .........................5

FIGURE 5-STRUCTURE OF THE ALVEOLI-CAPILLARY INTERFACE .................6

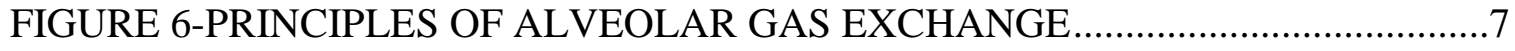

FIGURE 7-NORMAL $\mathrm{PO}_{2}-\mathrm{PCO}_{2}, \dot{\mathrm{V}}_{\mathrm{A}} / \mathrm{Q}$ DIAGRAM.............................................

FIGURE 8-PULSATILITY OF PRESSURE AND FLOW IN EACH LEVEL OF THE

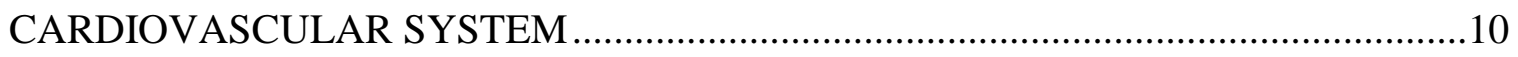

FIGURE 9-HISTOLOGICAL CROSS SECTIONS OF AN ARTERY AND VEIN........11 
LIST OF FIGURES (CONTINUED)

FIGURE 10-MECHANICAL FORCES PRESENT IN LUMEN OF VESSEL

FIGURE 11- DISTRIBUTION OF DECEASED ORGAN DONORS IN THE UNITED

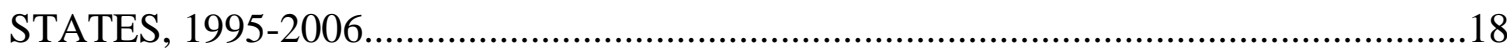

FIGURE 12- EVLP SYSTEM IN THE A) PULSTILE CONFIGURATION WITH THORATEC PVAD (PLEASONTON, CA) AND B) CONTINUOUS CONFIGURATION WITH LEVACOR CENTRIFUGAL PUMP (SALT LAKE CITY, UT)

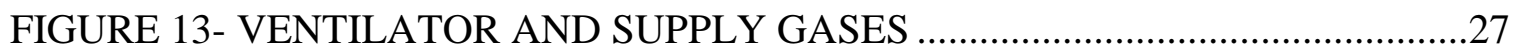

FIGURE 14- SPECTRAMAX M2 MICROPLATE READER ...........................................28

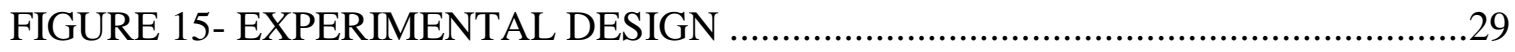

FIGURE 16-SCHEMATIC OF EVLP CIRCUIT .............................................................32

FIGURE 17-PLEURAL SPACE REVEALED BY MEDIAN STERNOTOMY ...............34

FIGURE 18-SUTURE PLACED IN PULMONARY ARTERY ……………………........34 
LIST OF FIGURES (CONTINUED)

FIGURE 19-INTRAOPERATIVE PARENCHYMAL SAMPLES

FIGURE 20-HEART AND LUNGS EN BLOC .36

FIGURE 21-SEWING THE FUNNELING CANNULA (VITROLIFE) TO THE LEFT

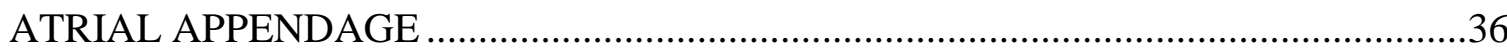

FIGURE 22-LUNGS PRIMED FOR CONNECTION TO EVLP SYSTEM ……….........37

FIGURE 23-PULMONARY ARTERY FLOW RAMP PHASE …………………….......38

FIGURE 24-CONTINUOUS INFUSIONS OF 30\% BOVINE SERUM ALBUMIN AND

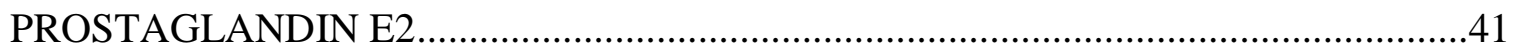

FIGURE 25-HOMOGENIZING TISSUE SAMPLES FOR ELISA …………………......45

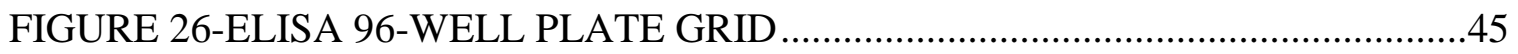

FIGURE 27-PULMONARY VASCULAR RESISTANCE IN A) WOODS UNITS AND B) DYNES/S/CM ${ }^{5}$ OVER 12-HOUR TEST PERIOD ..................................................... 
LIST OF FIGURES (CONTINUED)

FIGURE 28-PEAK AIRWAY PRESSURE OVER 12-HOUR TEST PERIOD. .48

FIGURE 29-APO2/FIO2 OVER 12-HOUR TEST PERIOD

FIGURE 30- $\triangle \mathrm{PO} / \mathrm{FIO} 2$ OVER 12-HOUR TEST PERIOD FOR CONTINUOUS FLOW EVLP GROUP .50

FIGURE 31- $\triangle$ PO2/FIO2 OVER 12-HOUR TEST PERIOD FOR PULSATILE FLOW EVLP GROUP .50

FIGURE 32-LACTATE CONCENTRATION OVER 12-HOUR TEST PERIOD .51

FIGURE 33-GLUCOSE CONENTRATION OVER 12-HOUR TEST PERIOD .51

FIGURE 34- $\triangle$ PH OVER 12-HOUR TEST PERIOD .52

FIGURE 35- WET/DRY RATIO OVER 12-HOUR TEST PERIOD. .53

FIGURE $36-T N F-\alpha$ MICROPLATE AFTER INCUBATION WITH DETECTION ANTIBODY .54 
LIST OF FIGURES (CONTINUED)

FIGURE 37-TNF- $\alpha$ CONCENTRATION OVER 12-HOUR TEST PERIOD .54

FIGURE 38-IL-6 MICROPLATE AFTER INCUBATION WITH DETECTION

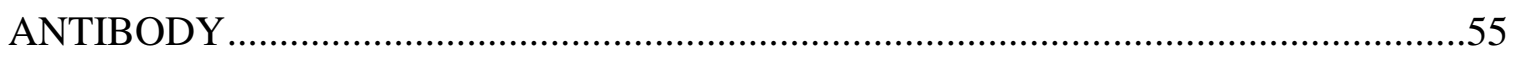

FIGURE 39-IL-6 CONCENTRATION OVER 12-HOUR TEST PERIOD ......................56

FIGURE 40-IL-8 MICROPLATE AFTER INCUBATION WITH DETECTION

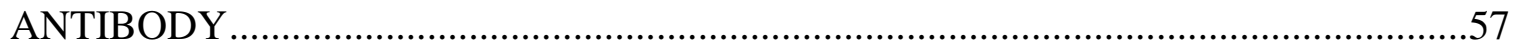

FIGURE 41-IL-8 CONCENTRATION OVER 12-HOUR TEST PERIOD ......................57

FIGURE 42-IL-10 MICROPLATE AFTER INCUBATION WITH DETECTION

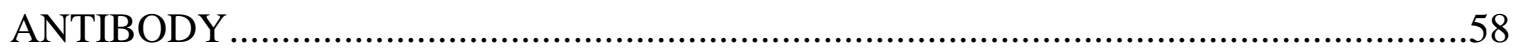

FIGURE 43-IL-10 CONCENTRATION OVER 12-HOUR TEST PERIOD ....................59 


\section{INTRODUCTION}

A. Lung Disease Background

The term lung disease can be used to describe any number of chronic pathologies of the lung that can be idiopathic in nature or genetically or environmentally acquired. Lung disease is the number three killer in the U.S. (behind heart disease and cancer), accounting for between 250,000 and 400,000 deaths per year or 1 out of every 6 deaths [2-4].

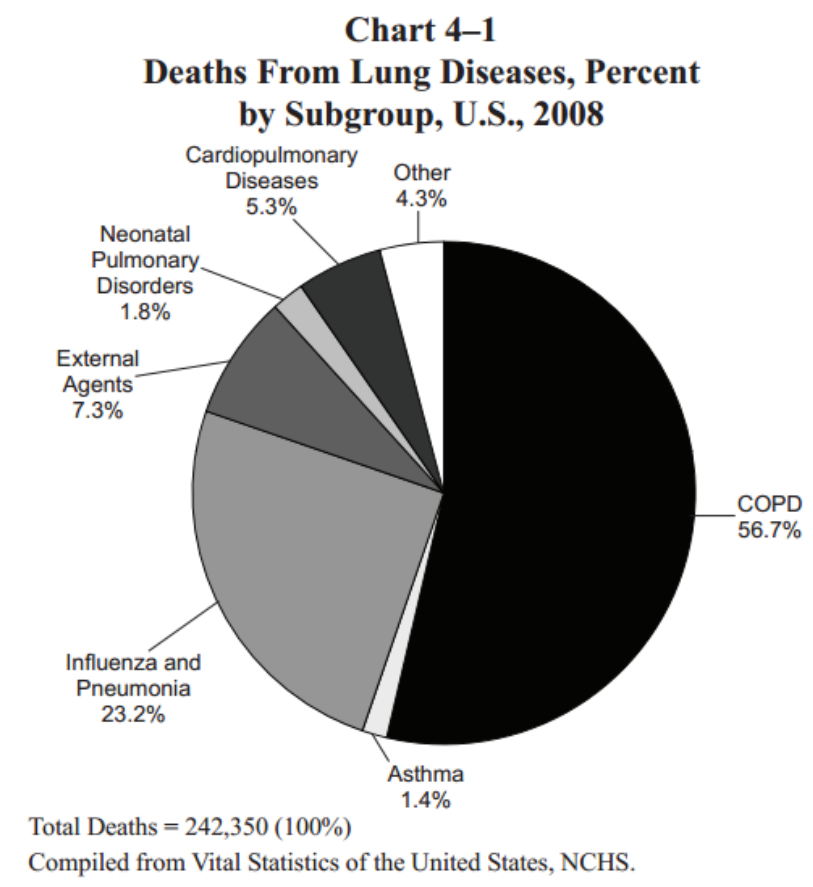

Figure 1: Deaths from lung disease by subgroup [2]

35 million Americans currently live with chronic lung disease [5]. Lung diseases can affect 1) the airways of the lung, including the trachea and bronchi, 2) the site of gas exchange, otherwise known as the alveoli, and 3) the pulmonary interstitium [6]. 
Disorders affecting the airways include asthma, chronic obstructive pulmonary disease (COPD), bronchitis, and cystic fibrosis. Disorders affecting the alveoli include pneumonia, tuberculosis, pulmonary edema, acute respiratory distress syndrome and pneumoconiosis. Disorders affecting the interstitium include sarcoidosis, idiopathic pulmonary fibrosis, and autoimmune disease. Disorders such as lung cancer, emphysema, and pulmonary fibrosis can affect one or more of these regions.

\section{B. Lung Anatomy and Physiology}

Lungs are complex organs that are made up of multiple tissue types and over 40 distinct cell types [7]. Much of the lung is composed of thin-walled alveoli, which

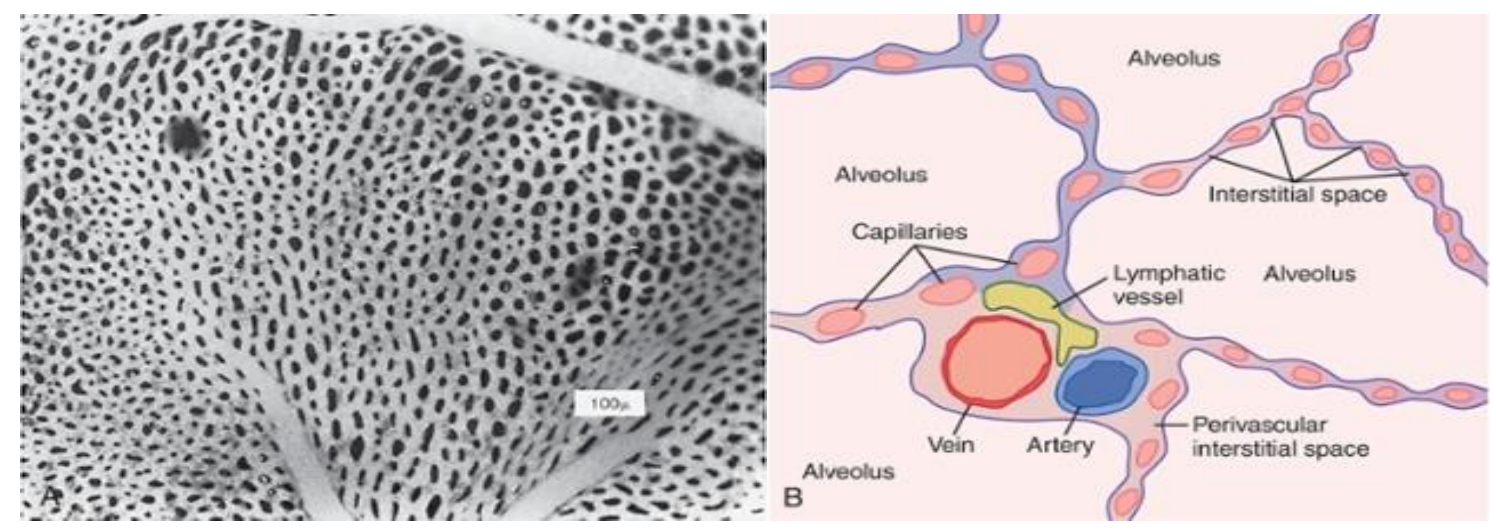

Figure 2: A) Surface view of capillaries in an alveolar wall and B) cross-sectional view of alveolar walls and their vascular supply[8]

are made up of a monolayer of squamous epithelium. A thin layer of connective tissue may be found between the alveoli. Capillaries composed of simple squamous epithelium interface with the alveoli. The interior lining of the bronchioles are composed of ciliated columnar epithelium in the larger airways, and cuboidal epithelium in the smaller airways. 
Interspaced disks of hyaline cartilage make up the trachea. The lumen of the trachea is lined with pseudostratified ciliated columnar epithelium. Mucous-secreting goblet cells are found in this layer. The mucous traps foreign particles and sweeps them up and out of the airway. A thick basement membrane lies beneath the epithelium. Moving from the trachea to the lowest airways, there is a progressive loss of cartilage, goblet cells, cilia and smooth muscle. Smooth muscle is found enveloping the bronchi and in the tunica media of the vasculature. The blood vessels are lined with a specialized endothelium that has secretory and regulatory functions. These functions will be discussed in greater detail in this text.

Type I and Type II pneumocytes make up part of the alveoli and help maintain them by functioning in gas exchange, secretion of pulmonary surfactant, and regeneration. Type I pneumocytes are squamous epithelium that cover $97 \%$ of the alveolar surface and specialized to function in gas exchange [9]. Type II pneumocytes are commonly located near the "corners" of the alveoli, near the alveolar-septal junction and secrete phospholipid-based surfactant. Surfactant functions to reduce the alveolar surface tension and aid in gas exchange. Lastly, lung tissue contains a number of cell types involved in mounting an immune response. These cell types include alveolar macrophages, neutrophils, and leukocytes that continuously mitigate the threat of bacterial and fungal contamination at the alveolar interface [10]. 


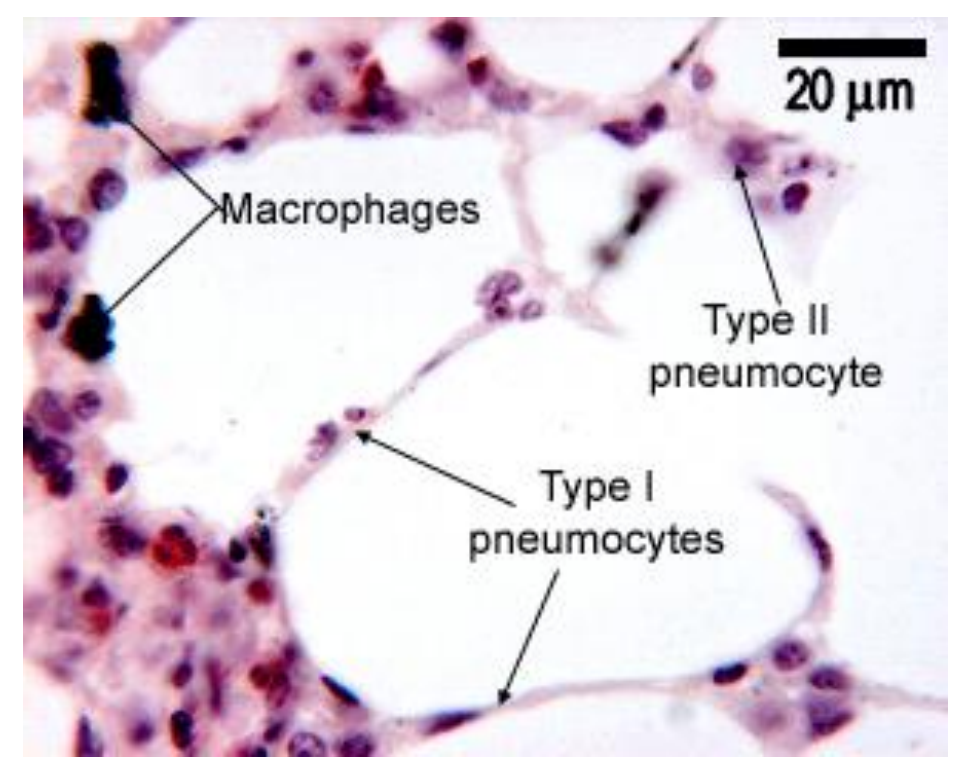

Figure 3: Illustration of cell types in the alveolus [11]

Vital functions of the lungs include serving as the site of gas exchange, regulating blood pressure and $\mathrm{pH}$, and removing foreign bodies [8]. Grossly, the right and left human lungs consist of three and two lobes, respectively. Air enters the lungs by first passing through the nasal or oral cavity and traveling through the pharynx, larynx and trachea before diverging down either the left or right bronchus. The respiratory tree, as it is called can consist of up to 28 generations of branches [12]. Beginning with the trachea, it branches bilaterally into the main bronchi, lobar bronchi, segmental bronchi, conducting bronchioles, terminal bronchioles, respiratory bronchioles, alveolar ducts, alveolar sacs and finally ending at the alveoli [13]. The most distal divisions (below the respiratory bronchioles) are specialized for gas exchange, while the more proximal segments are simply conducting segments. 
As for the pulmonary circulation, deoxygenated blood is pumped into the lungs from the right ventricle through the pulmonary semilunar valve via the pulmonary artery (PA).

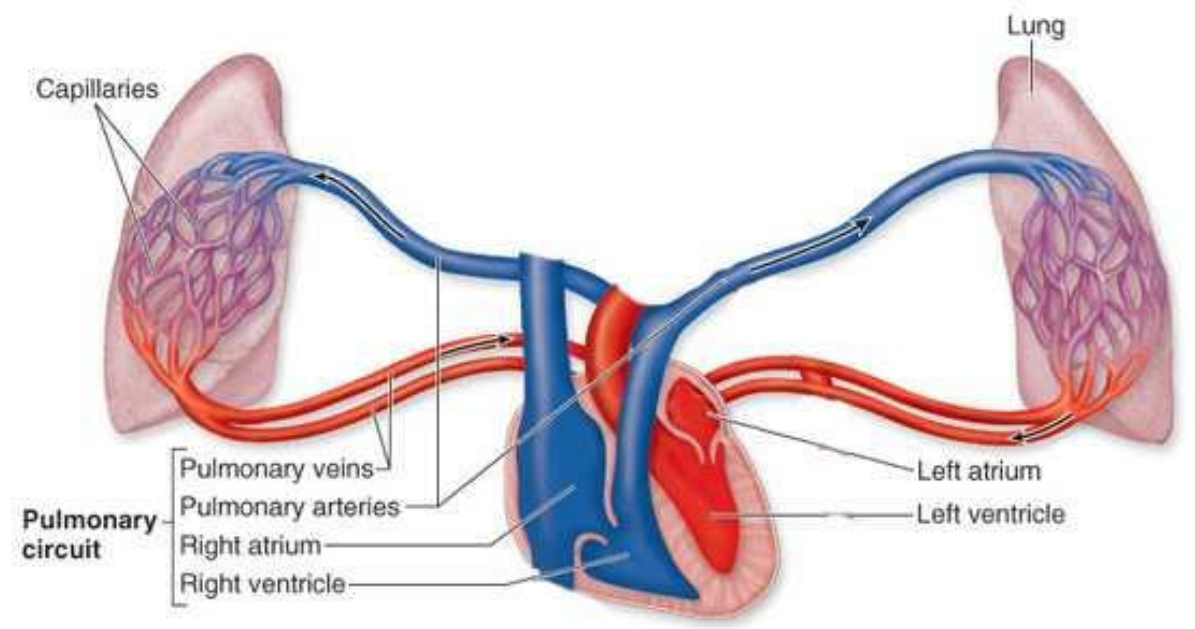

Figure 4: Blood flow in the pulmonary circulation [14]

The PA is approximately $5 \mathrm{~cm}$ long and $3 \mathrm{~cm}$ in diameter before branching into the right and left pulmonary arteries. The average mean PA pressure is $9-18 \mathrm{mmHg}$ with a systolic pressure of 15-30 $\mathrm{mmHg}$ and a diastolic pressure of 4-12 $\mathrm{mmHg}$. The pulmonary arteries diverge into progressively smaller branches of arterioles, intimately associating with the alveoli at the level of the capillary bed. The interface of these monolayer structures serves as the site of gas exchange. The lung is also supplied in part by the bronchiole arteries that originate from the aorta. These vessels, however, are not crucial for lung viability and are left transected and not anastomosed in lung transplantation. 


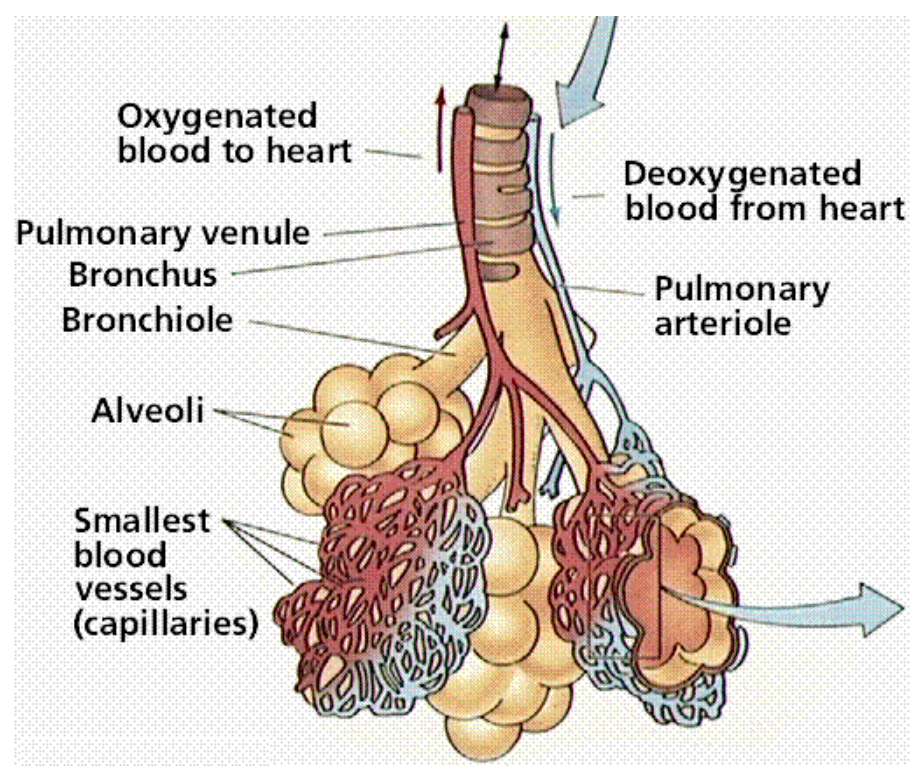

Figure 5: Structure of the alveoli-capillary interface [15]

Pulmonary gas exchange is explained by the principles derived by Adolf Fick in 1855 [16]. Fick's First Law relates the diffusive flux to the concentration under the assumption of steady state and is described by:

$$
\begin{gathered}
J=-D \frac{\delta \varphi}{\delta x} \quad \text { Eq.1 } \\
\text { where: } \\
\mathrm{J}=\text { Diffusion flux }\left(\mathrm{mol} / \mathrm{m}^{2} \mathrm{~s}\right) \\
D=\text { Diffusion Coefficient }\left(\mathrm{m}^{2} / \mathrm{s}\right) \\
\varphi=\text { concentration }\left(\mathrm{mol} / \mathrm{m}^{3}\right) \\
\mathrm{x}=\text { length of diffusion }(\mathrm{m})
\end{gathered}
$$

Fick's Second Law predicts how diffusion causes the concentration to change with time and is described by:

$$
\begin{gathered}
\frac{\delta \varphi}{\delta t}=D \frac{\delta^{2} \varphi}{\delta x^{2}} \quad \text { Eq. } 2 \\
\text { where: } \\
\text { t=time }
\end{gathered}
$$


Diffusion is an ATP-independent process dependent on 1) surface area available for gas exchange, 2) the diffusion distance of the gas molecules, and 3) the concentration gradient. The ventilation/perfusion ratio also plays a factor in human alveolar gas exchange. A large surface area in pulmonary gas exchange $\left(70-100 \mathrm{~m}^{2}\right)$ is facilitated by the numerous branches of the respiratory tree and large number of terminal alveoli[8]. Due to the interfacing of the pulmonary capillaries with the alveoli, the diffusion distance for gas is only 2 cell layers thick, or about $0.7 \mu \mathrm{m}$. Lastly, the concentration gradients for $\mathrm{O}_{2}$ and $\mathrm{CO}_{2}$ remain high because of the metabolic consumption of oxygen and production of carbon dioxide. Blood draining into the right atrium via the vena cava is in its most deoxygenated state, having passed through the capillary beds, supplying tissues with $\mathrm{O}_{2}$ and removing $\mathrm{CO}_{2}$. At this point, the partial pressures of $\mathrm{CO}_{2}$ and $\mathrm{O}_{2}$ are $45 \mathrm{mmHg}$ and $40 \mathrm{mmHg}$, respectively. Alveolar air, having passed through the respiratory tree and been

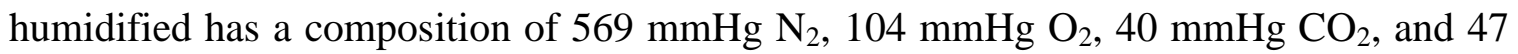
$\mathrm{mmHg} \mathrm{H}_{2} \mathrm{O}$. As can be seen in Figure 6, there are concentration gradients of
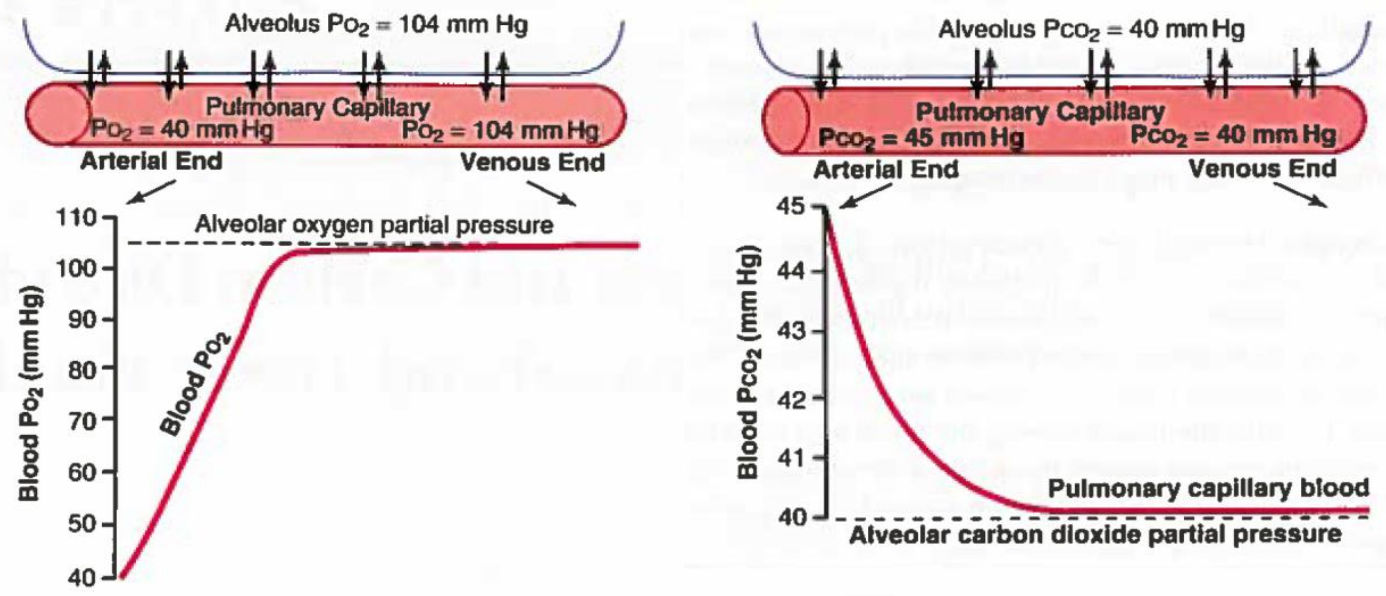

Figure 6: Principles of alveolar gas exchange[8] 
$64 \mathrm{mmHg}$ and $5 \mathrm{mmHg}$ for $\mathrm{O}_{2}$ and $\mathrm{CO} 2$, respectively, which serve to drive $\mathrm{O}_{2}$ into the blood and $\mathrm{CO}_{2}$ into the alveolar space to be expelled. Thus, blood entering the left atrium to be pumped to the systemic circulation by the left ventricle has a $\mathrm{P}_{\mathrm{CO} 2}$ of $40 \mathrm{mmHg}$ and a $\mathrm{P}_{\mathrm{O} 2}$ of $104 \mathrm{mmHg}$.

The ventilation/perfusion ratio is a concept developed to quantitatively assess respiratory exchange in terms of the air reaching the alveoli $(\dot{V})$ and the blood reaching the alveoli ( $\dot{\mathrm{Q}})$ [8]. Gravity affects the $\dot{\mathrm{V}} / \dot{\mathrm{Q}}$ ratio by causing 1) an increase in pleural pressure that reduces the alveolar volume and 2) increase in hydrostatic pressure and excessively high flows at the base of the lung. The converse can be said about the apex of the lungs. When the $\dot{\mathrm{V}} / \dot{\mathrm{Q}}$ ratio is below normal $(<1)$, then a physiologic shunt is developed, where there is inadequate ventilation to fully oxygenate the capillary blood. If the $\dot{V} / \dot{Q}$ ratio is greater than normal $(>1)$, then physiologic dead space develops and much of the work of ventilation is wasted.

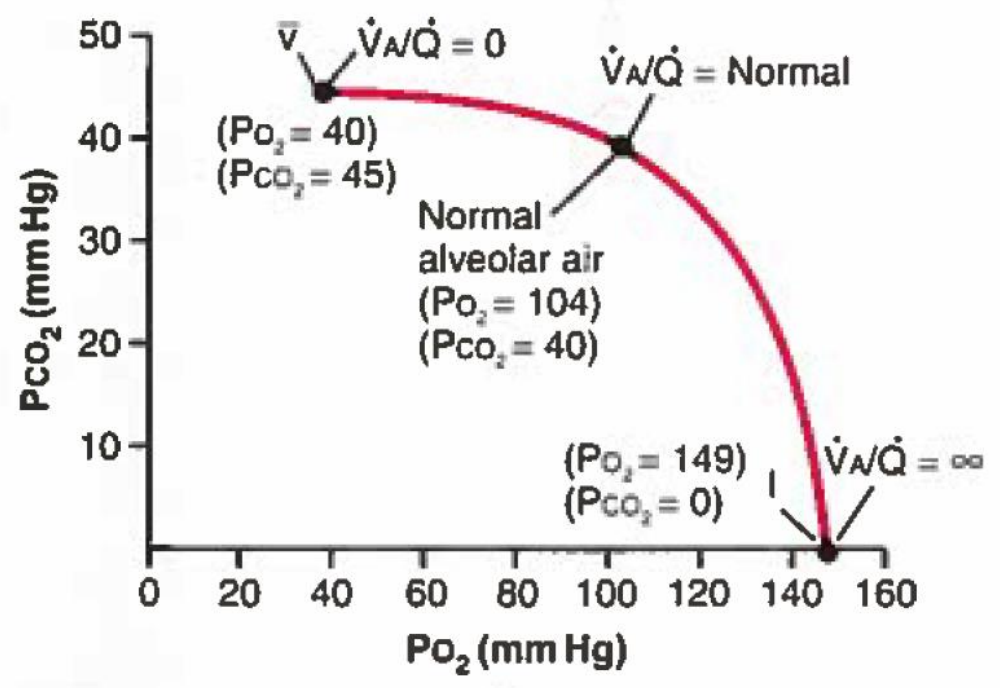

Figure 7: Normal $\mathrm{pO}_{2}-\mathrm{pCO}_{2}, \dot{\mathrm{V}}_{\mathrm{A}} / \dot{\mathrm{Q}}$ diagram [8] 


\section{Pulsatility and the Vascular Endothelium}

The physiologic importance of pulsatility is not completely understood. However, blood flow characteristics such as shear stress have been shown to be important in endothelial organization and function [17-19]. In one in vitro study, endothelial cells exhibited physiologic alignment at a shear rate of 22 dynes $/ \mathrm{cm}^{2}$ but were randomly oriented and dysfunctional when exposed to no flow [20]. Some likely benefits of pulsatility include the movement of lymph throughout the body, prevention of edema, prevention of "sludging" in the capillaries, maintenance of flow in the microcirculation, playing roles in physiologic signaling pathways, and increasing end-organ perfusion [21]. Attenuation of pulsatility has also been shown to contribute to pulmonary endothelial dysfunction in late Fontan-type procedures, presumably as a result of changes in exogenous nitric oxide (NO) expression [22]. One study found that continuous flow (CF) support increased vascular resistance, decreased surplus hemodynamic energy (SHE), and decreased compliance in heart failure patients, when compared to pulsatile flow (PF).

Pulsatility is greatest in the arterial tree and diminishes as it passes through the arteries, capillary bed and into the venous circulation. The compliance of the veins, when compared to arteries accounts for the decrease in pulsatility at the post-capillary side of the pulmonary circulation. Pulmonary vascular resistance (PVR) is defined (in dynes $\cdot \mathrm{s} / \mathrm{cm}^{5}$ ) by dividing the pressure drop across the lungs by the pulmonary artery flow [23]. To define this value in Woods Units, the ratio is divided by 80 [24]. In vivo, average values for PVR range from 20-130 dynes $/ \mathrm{s} / \mathrm{cm}^{5}$ but are typically elevated in ex vivo lung perfusion (EVLP) $[25,26]$. 

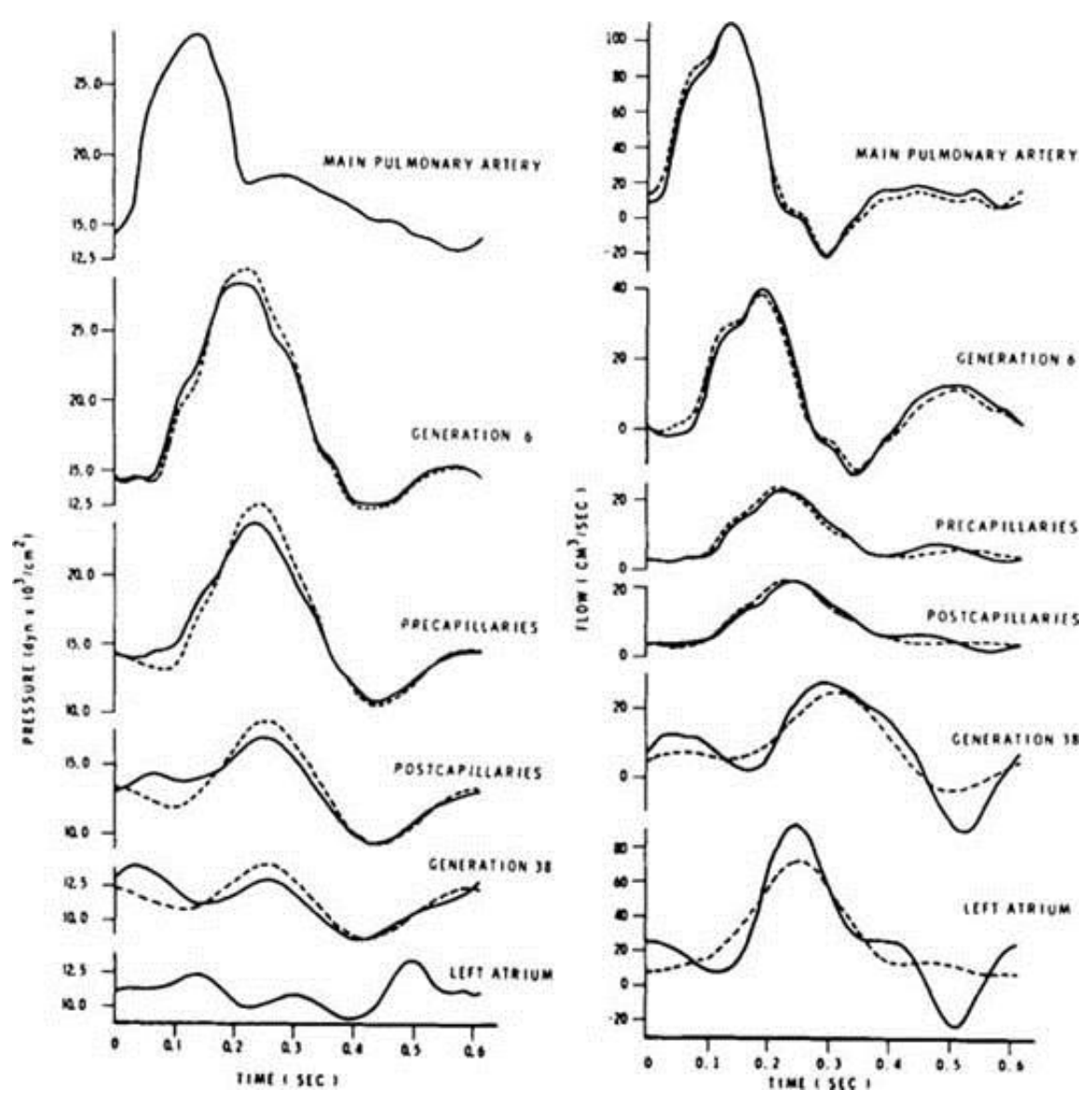

Figure 8: Pulsatility of pressure and flow in each level of the pulmonary circulation [27]

Starting at the most luminal layer and moving superficially, the layers of the blood vessels are the tunica intima, tunica media, and tunica adventitia. The innermost tunica intima is made up of the endothelium, which transmit signals from the lumen of the vessel to the surrounding tissues. By doing so, the endothelium acts as a signal transducer of physical and chemical signals.

The second layer, the tunica media, consists of a layer of concentric smooth muscle that can react to signals transmitted by the endothelium with contractile, dilatory, and secretory effects. Lastly, the tunica adventitia consists of longitudinally-arranged collagen fibers and serves as a durable sheath. These structures can vary markedly 
between large arteries, arterioles, capillaries, venules, and veins. As can be seen in Fig. 9, the tunica media of the artery is substantially larger than that of the vein, while the opposite is true of the tunica adventitia.

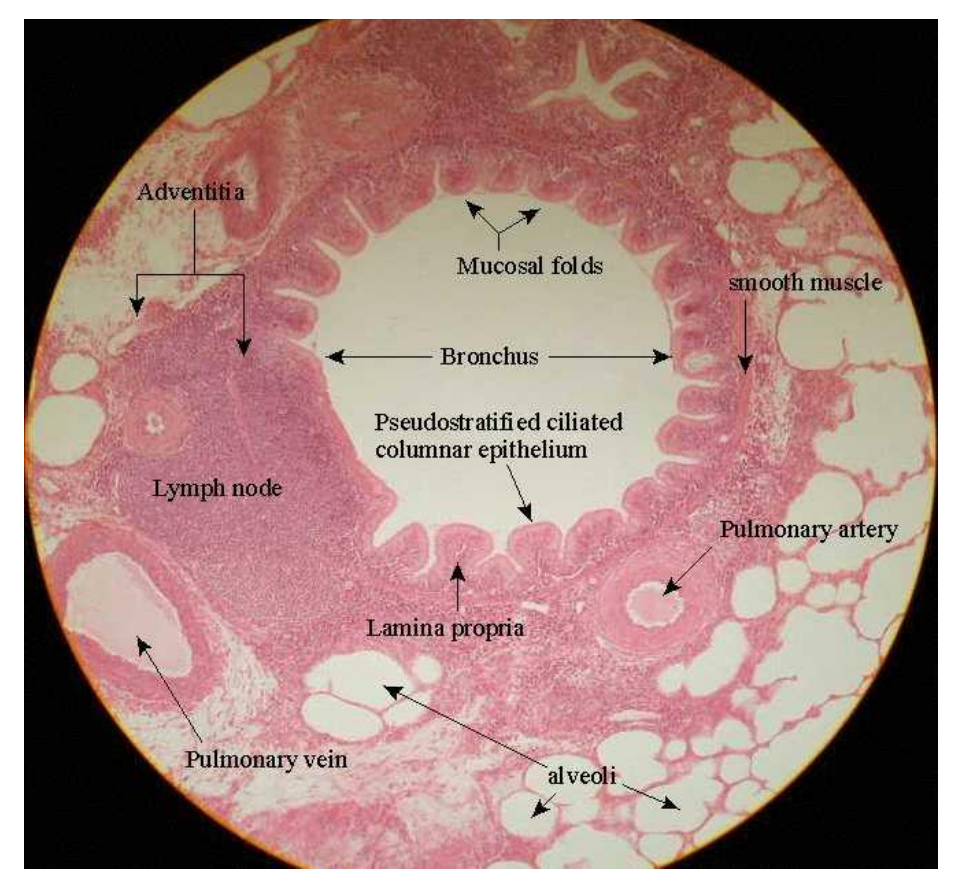

Figure 9: Histological cross sections of an artery and vein[28]

The vascular endothelium serving as a transduction mechanism for mechanical signals has important implications in choice of perfusion mode. The endothelium senses the hemodynamic environment in terms of blood pressure (circumferential stretch), shear stress, and flow disturbances [29]. Fig. 10 illustrates the directional forces present in on the vessel wall. Shear stress $(\tau)$ is described as the frictional force per unit area from flowing blood, of which the direct effects are restricted to the endothelium. This stress is an order of magnitude larger in the arteries than in the veins. The hydraulic pressure developed from the pumping heart exerts a force normal to the vessel wall that results in a circumferential tensional force. It has been suggested that the cyclic stretching of the 
artery walls promotes a quiescent, contractile state in which the vascular smooth muscle cells produce a physiologic normal range of differentiation markers[30].

Mean wall shear stress has been found to be a function of maximum flow $\left(\mathrm{Q}_{\max }\right)$ [31]. Thus, even with a comparable mean flow, pulsatile flow generates a larger shear stress than continuous flow.

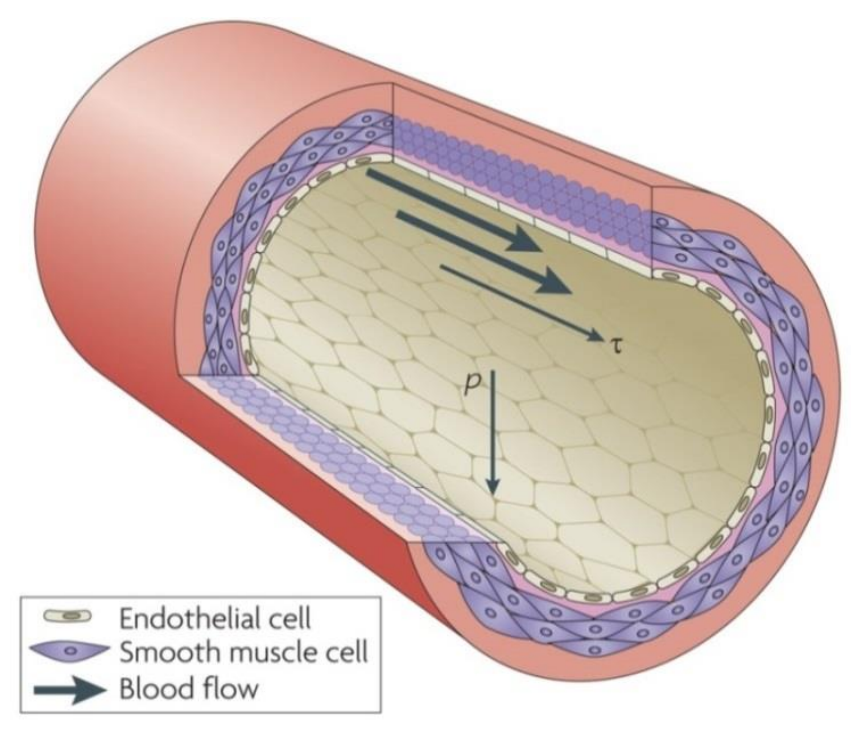

Figure 10: Mechanical forces present in lumen of blood vessel[29]

Though one study reported no relationship between pulse frequency and shear stress, a similar study reported maximum endothelial-dependent relaxation at a frequency of $4 \mathrm{~Hz}$ $[32]$.

Hyperpolarization is an important mechanism contributing to vasorelaxation by making the vascular smooth muscle cells less likely to activate the voltage-dependent calcium channels that open when the cell depolarizes [29]. This hyperpolarized state is believed to result from stimulation by such mediators as NO, prostacyclin, and other 
arachidonic acid metabolites. Pulsatile flow has been shown to enhance endotheliumderived NO release in the peripheral vasculature $[33,34]$ and therefore has implications in the improvement of EVLP outcomes via the reduction of pulmonary vascular resistance. Prostacyclin is another vasoactive, endothelial-derived compound that is influenced by flow characteristics. In one in vitro study, the steady state production of prostacyclin was more than doubled in endothelial cells exposed to pulsatile flow, when compared to continuous flow [35]. The results in terms of prostacyclin production rate are shown in table I.

\begin{tabular}{|c|c|c|c|}
\hline \multirow{2}{*}{$\begin{array}{l}\text { Shear } \\
\text { stress }\end{array}$} & \multicolumn{2}{|c|}{ Production rate } & \multirow{2}{*}{$\begin{array}{c}\text { Decay } \\
\text { constant } \\
\text { (minutes) }\end{array}$} \\
\hline & Steady state & Peak & \\
\hline $\begin{array}{l}\text { Pulsatile } \\
\text { Steady } \\
\text { (Ratio)* } \\
\text { Near-zero }\end{array}$ & $\begin{array}{c}161 \pm 56 \\
66 \pm 18 \\
(2.4) \\
11 \pm 0.5\end{array}$ & $\begin{array}{c}412 \pm 155 \\
368 \pm 120 \\
\text { (1.1) }\end{array}$ & $\begin{aligned} & 7.4 \pm 5.6 \\
& 25.8 \pm 10.4 \\
&(0.28)\end{aligned}$ \\
\hline
\end{tabular}

*Ratio of pulsatile and steady shear stress values.

Table I- Prostacyclin release by endothelial cells subjected to pulsatile and steady flow in vitro[35]

\section{Endothelial Mechanotransduction}

Physiological functions of the endothelium include anticoagulation response, control of luminal diameter, regulation of vascular permeability, and the inflammatory response [36]. Mechanotransduction is made possible by specific molecules present on the luminal surface of endothelial cells capable of converting physical stresses into biochemical signals [29]. Examples of these molecules include ion channels, integrins, receptor tyrosine kinases, the apical glycocalyx, primary cilia, heterotrimeric G proteins, plateletendothelial cell adhesion molecule-1 (PECAM-1), and VE-cadherin [29]. Two theories 
exist as to the mechanism of this transduction [29, 37-39]. In the Centralized Theory, physical forces are felt by luminal molecules which directly result in cellular biochemical changes to take place. In the Decentralized Theory, however, these forces are thought to be transmitted to distant regions of the endothelial layer and the tunica media via cell to cell attachments, focal adhesions, the nuclear membrane, and the cortical cytoskeleton.

The luminal glycocalyx in a carbohydrate-rich structure that extends about 100 microns into the lumen and senses drag, which is relayed by the cortical cytoskeleton [36]. The adhesion receptor, PECAM-1 is involved in Src family activation when exposed to a force and transmits it to the lateral aspects of the cell. The resultant cascade leads to AKT-dependent phosphorylation of endothelial NO-synthase and conformational activation of integrins at the basal surface [40]. Blood pressure plays a major role in the activation of tension-gated mechanosensative ion channels in the lipid bilayer. When activated by changes in membrane fluidity, an inward-rectifying $\mathrm{K}+$ channel induces vasodilation via rapid hyperpolarization-induced cessation of vascular smooth muscle contraction [41]. Heterotrimeric G proteins are activated due to flow-induced plasma membrane fluidity either directly or indirectly via ligand-independent conformational effects on the bradykinin receptor [42]. Primary cilia may play a role in mechanotrasduction due to low-level shear sensing by Polycytin 1 and 2. These ciliaassociated proteins are found in great abundance in the kidney but are also expressed on endothelial cells and respond to shear stresses localizing to cell-cell junctions by localizing to cell-cell junctions and regulating calcium retention [43]. 


\section{E. Lung Transplantation}

Lung transplantation is a preferred treatment for many end-stage lung diseases. Since the first successful transplant in 1963, over 32,000 procedures have been performed worldwide [44]. In 2010, idiopathic pulmonary fibrosis and chronic obstructive pulmonary disease (COPD) each accounted for about a third of the total number of lung transplantations and cystic fibrosis accounted for another 15\% [44]. However, even as more and more organ transplantations are performed, the demand for solid organs still far outweighs the supply. In 2006, there were about 29,000 solid organ transplantations and as of June 2007, there were 97,000 people on the waiting list [1]. As of 2008, more than 2,100 patients were on the waiting list for lung transplant in the United States. Of these, only 1,466 received a suitable allograft and 276 patients died on the waiting list[45]. The challenge of meeting lung donor criteria has resulted in a 15-20\% utilization rate and a subsequent waiting list mortality of up to $35 \%$ [46, 47].

\begin{tabular}{c}
\hline STANDARD ("IDEAL") LUNG DONOR CRITERIA \\
Age $<55 \mathrm{yr}$ \\
Clear serial chest X-ray \\
Normal gas exchange $\left(\mathrm{Pa}_{\mathrm{O}_{2}}>300 \mathrm{~mm} \mathrm{Hg}\right.$ on $\mathrm{Fi}_{\mathrm{O} 2}=1.0$, PEEP $\left.5 \mathrm{~cm} \mathrm{H}_{2} \mathrm{O}\right)$ \\
Absence of chest trauma \\
No evidence of aspiration or sepsis \\
Absence of purulent secretions at bronchoscopy \\
Absence of organisms on sputum gram stain \\
No history of primary pulmonary disease or active pulmonary infection \\
Tobacco history < 20 pack-years \\
ABO compatibility \\
No prior cardiopulmonary surgery \\
Appropriate size match with prospective recipient \\
\hline
\end{tabular}

Table II: Standard (“ideal”) lung donor criteria [45]

The need for these criteria is not unfounded, however. The majority of donor lungs come from patients who are brain dead as a result of a cerebrovascular accident. Thus, contraindicative damage to the lungs can result from direct trauma, resuscitation 
maneuvers, neurogenic edema, aspiration of blood or gastric content, or ventilatorassociated trauma and pneumonia [45]. Of 2,139 cadaveric donors reported to Eurotransplant in 2007 , only $23.5 \%$ served as lung donors compared to $90.2 \%$ for kidney, $73.3 \%$ for liver, and $28 \%$ for heart [45]. Additionally, whereas more robust organs, such as the kidneys, can survive outside of the body for up to 30 hours, the absolute maximum preservation time for lungs is only 5-10 hours.

\section{F. Single Flush Hypothermic Preservation}

Since lung transplantation was realized in the 1960's, multiple techniques have been examined to extend preservation times. Examples include single flush hypothermia, mechanical perfusion, in situ donor core-cooling, and normothermic autoperfusion [48]. To date, single flush hypothermia is the standard method of preservation. This protocol involves antegrade perfusion with a preservation solution such as Celsior, Wisconsin Solution, Euro-Collins Solution or Perfadex and cooling to $4-7^{\circ} \mathrm{C}$ [49]. This method takes advantage of hypothermia-induced metabolic inhibition which slows enzymatic reaction rates and thus the 1)depletion of ATP and 2)metabolite accumulation that results in tissue dysfunction and failure. Reaction rate as a function of temperature is shown in the Arrhenius equation [50]:

$$
\begin{gathered}
\text { Rate }=A e^{-\frac{E}{R T}} \quad \text { Eq. } 3 \\
\text { where: } \\
\text { A is a constant, } \\
\mathrm{T}=\text { absolute temperature }(\mathrm{K}) \\
\mathrm{R}=\text { universal gas constant }(8.31 \mathrm{~J} / \mathrm{mol} / \mathrm{K}) \\
\mathrm{E}=\text { activation energy }(\mathrm{J} / \mathrm{mol}) \\
\mathrm{e}=\text { Euler's constant }(2.718)
\end{gathered}
$$


The limitation of hypothermic inhibition is that even at $0^{\circ} \mathrm{C}$, oxygen consumption and metabolism still occur at about $5 \%$ of the rate seen at $37^{\circ} \mathrm{C}$ [51]. Furthermore, the complex effects of hypothermia are not uniform for all enzymatic rates and can even uncouple reactions, leading to harmful consequences [52]. Lastly, hypothermia affects the mitochondria, suppressing the translocation rate of adenine nucleotides across their inner membrane, decreasing ATP synthesis subsequently slowing oxidative phosphorylation [50].

\section{G. Ischemic Effects on Tissues and Organs}

The effects of ischemia can vary between organs but the general biochemical events that occur as a result are the 1) decline of high energy phosphates, 2) onset of intracellular acidosis, 3) increase in osmolar load resulting in cell swelling, 4) generation of oxygen free radicals, 4) stiulation of intracellular lysosomal enzymes, and 5) damage to the mitochondria [50]. Ischemia results in the depetion of oxygen and utilization of ATP within a few seconds or minutes. The cessation of oxidative phosphorylation prompts a compensatory increase in anaerobic respiration that leads to insufficent energy production and the accumulation of metabolic wastes such as lactate, protons, and NADH [53]. This accumulation leads to an intracellular acidosis that perpetuates cellular dysfunction. The loss of oxidative phosphorylation and $\mathrm{pH}$ imbalance results in an enzymatic insufficiency, where the protein channels and pumps involved in volume regulation become dysfunctional and osmolar control is lost. This progressive intracellular dysfuction leads to the formation of oxygen free radicals and intracellular lysosome production, which break down cellular machinery [54]. Oxygen depletion reults 
in a complete loss of aerobic respiration in the mitochondria, causing them to become irreveribly damaged and dysfunctional.

\section{H. Ex vivo Lung Perfusion (EVLP)}

EVLP has recently emerged as an alternative platform for the preservation and evaluation of donor lungs. EVLP adapts the principles of cardiopulmonary bypass and mechanical ventilation to support donor lungs at normothermic or slightly hypothermic temperatures. EVLP potentiates treatment and rehabilitation of lungs otherwise deemed suboptimal for transplant. The conditions by which donor lungs become available depend on the mode of death of the donating individual. In donation after brain death (DBD), the patient can remain on life support while the transplant surgeon asesses the lungs in question. In donation after cardiac death (DCD), the organs are retrieved after all

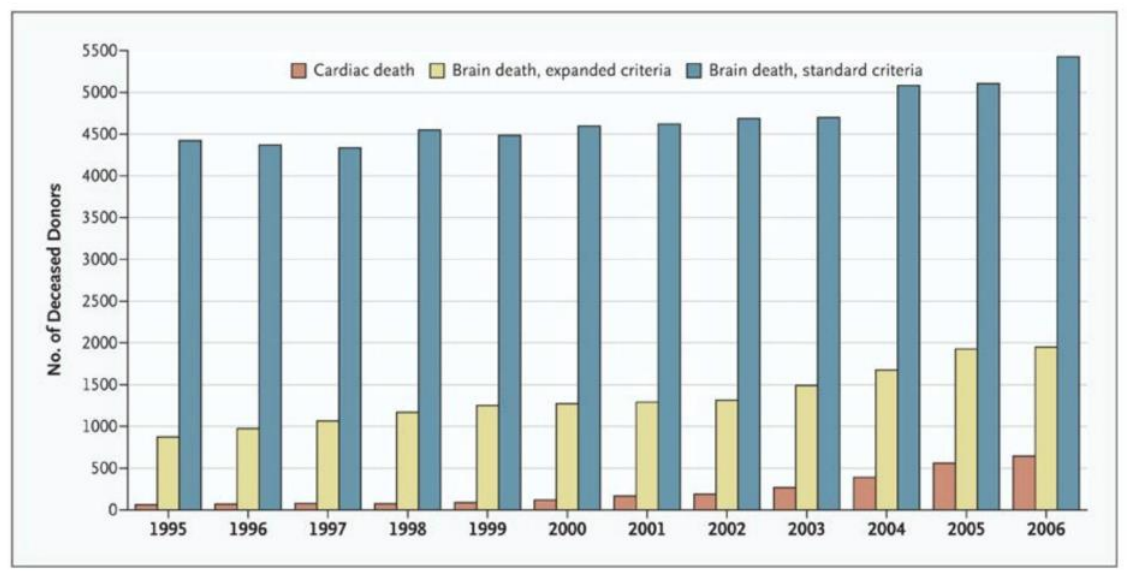

Figure 11-Distribution of Deceased Organ Donors in the United States, 1995-2006 [1]

cardiopulmonary function ceases, limiting the time for evaluation. In 2006, the DCD category acounted for $8 \%$ of all deceased donors [1]. EVLP may be used to expand the donor pool for lung transplantation by enabling the resuciatation of lungs from the DCD category. 
EVLP seeks to not only preserve lungs, but to promote healing and to give the transplant surgeon a window of oppurtunity for extended evaluation and treatment. Rather than statically cooling the lungs, they are dynamically perfused with a specialized perfusate and ventilated at low tidal volumes. This potentiates intravenous and bronchial drug administration, assesment and lavage of airways, and reversal of edema and atalectasis formation.

The fundamental aspects of EVLP are similar to cardiopulmonary bypass. A blood reservoir contains the perfusate, which passes through a mechanical blood pump and membrane oxygenator/heat exchanger. Oxygen and a venous gas mixture are fed into membrane gas exchanger both to 1) support the lungs and 2) simulate the blood gas composition of the pulmonary artery. The perfusate passes through a leukocyte filter before entering the lungs via the PA. A funneling cannula sutured into the left atrial cuff serves as the venous return, which flows back into the reservoir. The flows and pressures are carefully monitored over the course of the experiment.

\section{Perfusate Composition in EVLP}

Initially, cellular perfusates were considered for EVLP for their innate oxygen carrying capacities and superior buffering capabilities [55]. However, numerous studies in support of acellular perfusates have led to their nearly universal adoption. Studies have examined blood-based perfusates and acellular perfusates, with the acellular Steen's Solution emerging as the current standard [56]. Clinical trials are currently underway in the United States and market approval is pending. Steen's Solution is a hypokalemic, hyperoncotic, high-dextran containing perfusate[57]. The extracellular electrolyte 
composition contains a low concentration of potassium to minimize the formation of free radicals and to avoid vascular spasm[58]. A high albumin content provides oncotic pressure , minimizing edema formation in the interstium and airways. In a rabbit model, perfusate with an albumin concentration of $5 \mathrm{~g} / \mathrm{dL}$ was found to minimize edema formation when compared to $0.1 \mathrm{~g} / \mathrm{dL}[59]$. The high dextran content is believed to coat and protect the vacular endothelium, inhibiting excessive leukocyte interaction and thrombogenesis[60].

\section{J. Ventilation and Perfusion Strategies in EVLP}

Using a rat model of EVLP, it was shown that low flow perfusion of $12 \mathrm{~mL} / \mathrm{g} / \mathrm{min}$ was superior to high flow perfuion of $25 \mathrm{~mL} / \mathrm{g} / \mathrm{min}$ in terms of pulmonary edema formation [61]. A similar study using rabbits showed that pulmonary artery pressures greater than $20 \mathrm{mmHg}$ and lower than $5 \mathrm{mmHg}$ were associated with increased edema formation and impaired lung function, while pressures in the range of $10-15 \mathrm{mmHg}$ were not [62]. In swine studies performed by Cypel et al., the total flow is increased to $40 \%$ of the predicted cardiac output and mechanical ventilation is performed at a tidal volume of 6-8 $\mathrm{mL} / \mathrm{kg}[26]$.

Clinically, the two most practiced P/V protocols are the Lund and Toronto protocols [56, 63, 64]. In the Lund protocol, the lungs are removed from ice and gradually warmed to normothermic temperatures based on setpoints of temperature. The target maximum flow rate in this scheme is $100 \%$ of the estimated cardiac output. Ventilation is initiated at $32^{\circ} \mathrm{C}$ and the tidal volume is calculated based on the weight of the donor and gradually increased at set temperatures. The Lund protocol advocates a 
$\mathrm{FiO}_{2}$ of $50 \%$. In the Toronto protocol, the lungs are gradually warmed over the first hour of perfusion. During this time, the flow is increased to $40 \%$ of the predicted cardiac output. Ventilation is initiated at 20 minutes, with a fixed tidal volume of $6-8 \mathrm{~mL} / \mathrm{kg}$, respiratory rate of 7 breaths per minute, and a $\mathrm{FiO}_{2}$ of $21 \%$. Both protocols limit perfusion based on a threshold maximum pulmonary artery pressure of $<20 \mathrm{mmHg}$. Additionally, it is widely accepted that high oxygen concentrations is detrimental over time and that the ventilatory strategy should be protective in nature.

\begin{tabular}{|c|c|c|}
\hline & Lund's protocol & Toronto's protocol \\
\hline \multicolumn{3}{|l|}{ Flow } \\
\hline Target total & 100\% Cardiac output & $40 \%$ Cardiac output \\
\hline Start perfusion & $100 \mathrm{ml} / \mathrm{min}$ & $150 \mathrm{ml} / \mathrm{min}$ \\
\hline \multicolumn{3}{|l|}{ Ventilation } \\
\hline Mode & Volume control & Volume control \\
\hline $\mathrm{VT}$ & $5-7 \mathrm{ml} / \mathrm{kg}$ & $7 \mathrm{ml} / \mathrm{kg}$ \\
\hline Frequency & $20 \mathrm{bpm}$ & $7 \mathrm{bpm}$ \\
\hline PEEP & $5 \mathrm{~cm} \mathrm{H}_{2} \mathrm{O}$ & $5 \mathrm{~cm} \mathrm{H}_{2} \mathrm{O}$ \\
\hline $\mathrm{FiO}_{2}$ & $50 \%$ & $21 \%$ \\
\hline Start ventilation & $32^{\circ} \mathrm{C}$ & $32^{\circ} \mathrm{C}$ \\
\hline \multicolumn{3}{|l|}{ Pressure } \\
\hline Pulmonary artery & Under $20 \mathrm{mmHg}$ & Under $15 \mathrm{mmHg}$ \\
\hline Left atrium & $\mathrm{OmmHg}$ & $3-5 \mathrm{mmHg}$ \\
\hline \multicolumn{3}{|l|}{ Temperature } \\
\hline Start perfusion & $25^{\circ} \mathrm{C}$ & $25^{\circ} \mathrm{C}$ \\
\hline Start evaluation & $37^{\circ} \mathrm{C}$ & $37^{\circ} \mathrm{C}$ \\
\hline Perfusate & Steen solution + red cells (Hto $14 \%$ ) & Steen solution \\
\hline Perfusion time (h) & Up to $2 \mathrm{~h}$ & Up to $12 \mathrm{~h}$ \\
\hline
\end{tabular}

Table III: Comparison of parameters between Lund and Toronto protocols [63]

\section{K. Clinical Translation of EVLP}

Clinical trials evaluating EVLP with Steen's Solution are currently underway in at least 8 institutions in the United States [65]. In a retrospective analysis of 317 lung transplants that included 50 EVLP reconditioned lungs, comparable 1 and 3 year survival rates were reported when compared to lungs stored under cold, static preservtion[64]. 
Another group reported a higher incidence of acute rejection in standard lungs when compared to EVLP reconditioned lungs at 3 and 12 months post-transplant [64]. Table 4 displays all the clinical studies that investigate EVLP as a safe and efficient technique for lung preservation.

\begin{tabular}{llcccc}
\multicolumn{1}{c}{ Author } & Year Number of Lungs on EVLPTransplanted lungs & Type of perfusate & Supporting/Against EVLP Quantifying efficiency \\
\hline Dark J.H & 2012 & 18 & 7 & Acellular & + \\
Aigner C & 2012 & 10 & 6 & Acellular & + \\
Cypel M.; & 2012 & 18 & - & - & + \\
GeorgeT.J. & 2012 & 7 & - & - & + \\
Wallinder A. & 2012 & 10 & 7 & - & + \\
Bonato R.; & 2012 & 6 & 5 & - & + \\
Medeiros I.L. & 2012 & 16 & 3 & Acellular & + \\
Zych B; & 2012 & 13 & 6 & Acellular & + \\
Egan T. & 2012 & 15 & 0 & Cellular & + \\
KoikeT; & 2011 & 28 & 24 & Acellular & + \\
Fildes J.E.; & 2011 & 8 & 8 & - & + \\
Sadaria MR & 2011 & 7 & - & Acellular & + \\
Slama A. & 2011 & 12 & 8 & Acellular & + \\
Medeiros I.L. & 2011 & 16 & - & Acellular & + \\
Cypel M. & 2011 & 26 & 23 & Acellular & + \\
& & & & & + \\
& & & & & +
\end{tabular}

Table IV: Recent clinical trial data for EVLP [64]

\section{Past, Present, and Future Directions in EVLP}

Studies have indicated cytokine accumulation as a potential mechanism for graft dysfunction [66, 67]. Interleukin-6 (IL-6) and tumor necrosis factor- $\alpha$ (TNF- $\alpha$ ) are both associated with the inflammatory response and have been shown to increase after 6 hours of EVLP [68]. As an approach to mitigating this issue, one group used an adsorbent membrane to supress inflammatory cytokines [68]. Despite both TNF- $\alpha$ and IL-8 concentrations being lower in the membrane group, no differences existed in lung function. Another study noted the upregulation of IL-6, IL-8, granulyte colonystimulating factor, and monocyte chemomtactic protein-1, the downregulation of macrophage colony-stimulating factor, and an undetectable change in IL-1 $\beta$, IL-4, IL-7, IL-12, interferon- $\gamma$, macrophage inflammatory protein 1- $\beta$, and tumor necrosis factor- $\alpha$ [69]. This group went on to report excellent lung function post-EVLP. 
Gene vector therapy using engineered adenoviral vectors has also been considered as a method of prolonging graft viability. In one study, the ex vivo administration of an adenoviral vector gene resulted in decreased vector-associated inflammation both pre- and post- lung trasnplantation in a pig model[70]. Another group used a modified adenovirus to deliver IL-10 gene therapy and reported favorable results in terms of a shift from a pro-inflammatory to an antiinflammatory state, as well as improvements in pulmonary vascular resistance and oxygenation [71].

NO has also been evaluated as a treatment in EVLP due to its role in activating endothelium-derived relaxing factor. NO-donating compounds such as nitrite, sodium nitroprusside, nitroglycerin, and inhaled NO have been shown to protect the vasculature during ex vivo perfusion [72-74]. However, whereas NO does provide favorable outcomes by maintaining flow in the microcirculation, the effects are not totally understood and may still be detrimental $[75,76]$.

Prostaglandins are routinely given during the retrieval period in lung donation[77]. Prostacylin $\left(\mathrm{PCI}_{2}\right)$ and Prostaglandin $\mathrm{E}_{1}\left(\mathrm{PGE}_{1}\right)$ are two examples that have potent vasodilatory, anti-thrombogenic, and inhibitory effects on complement activation[78]. The most tangible benefit of arachadonic acid metabolites like $\mathrm{PCI}_{2}$ and PGE are their reduction of PVR which helps to maintain flow in the microcirculation. They may also have immunosuppresive effects, as well as effects on the permeability of the vasculature [79]. 
Other therapies such as steroids treatment with methylprednisolone are commonly used in EVLP but their effect on outcomes is still unclear[80, 81]. An adenosine A2A agonist has also been shown to improve lung funcion during EVLP[82]. The antiinflammatory effects of adenosine resulted in a decrease in IL-1, IL-6, and IL-8 but statistical sgnificance was not demonstrated. 


\section{INSTRUMENTATION AND EQUIPMENT}

\section{A. Perfusion Apparatus}

The EVLP apparatus used components from donated cardiovascular procedure kits (Terumo Medical Corporation, Somerset, NJ) and was designed to simulate the pressure and flow conditions of the pulmonary circulation. The arterial side is constructed using $3 / 8$ " tubing while the venous side is constructed using $1 / 2$ " tubing to accommodate a reduction in resistance. Two configurations were examined to compare continuous and pulsatile flow in an EVLP model. In the continuous flow configuration, a Levacor centrifugal pump circulated perfusate with no compliance chamber in-line. In the pulsatile configuration, a PVAD (Thoratec, Pleasanton, CA) circulated the perfusate. A compliance chamber was located 3-5 inches distal to the pulsatile pump. All other aspects of the perfusion apparatus remained the same between the two configurations. Traveling anterograde from the pump, perfusate flowed through a Capiox D membrane oxygenator (Terumo Medical Corporation, Somerset, NJ) and leukocyte depletion filter, before entering the pulmonary artery of the lungs via a specialized cannula (XVIVO Perfusion, Göteborg, Sweden). Perfusate exited the lungs via a specially designed, funneling cannula for the left atrial cuff. This design prohibits the left atrial cuff from collapsing due to low pressures. The perfusate exiting through the left atrial cuff cannula drained directly into a blood reservoir. The height of the reservoir could be adjusted to raise or lower the pulmonary venous pressure. A variable resistor is located in between the pump and oxygenator in the continuous configuration or between the compliance chamber and oxygenator in the pulsatile configuration. In addition, the lungs were enclosed in a specially designed dome equipped with an outflow drain. Any perfusate that leaks from 

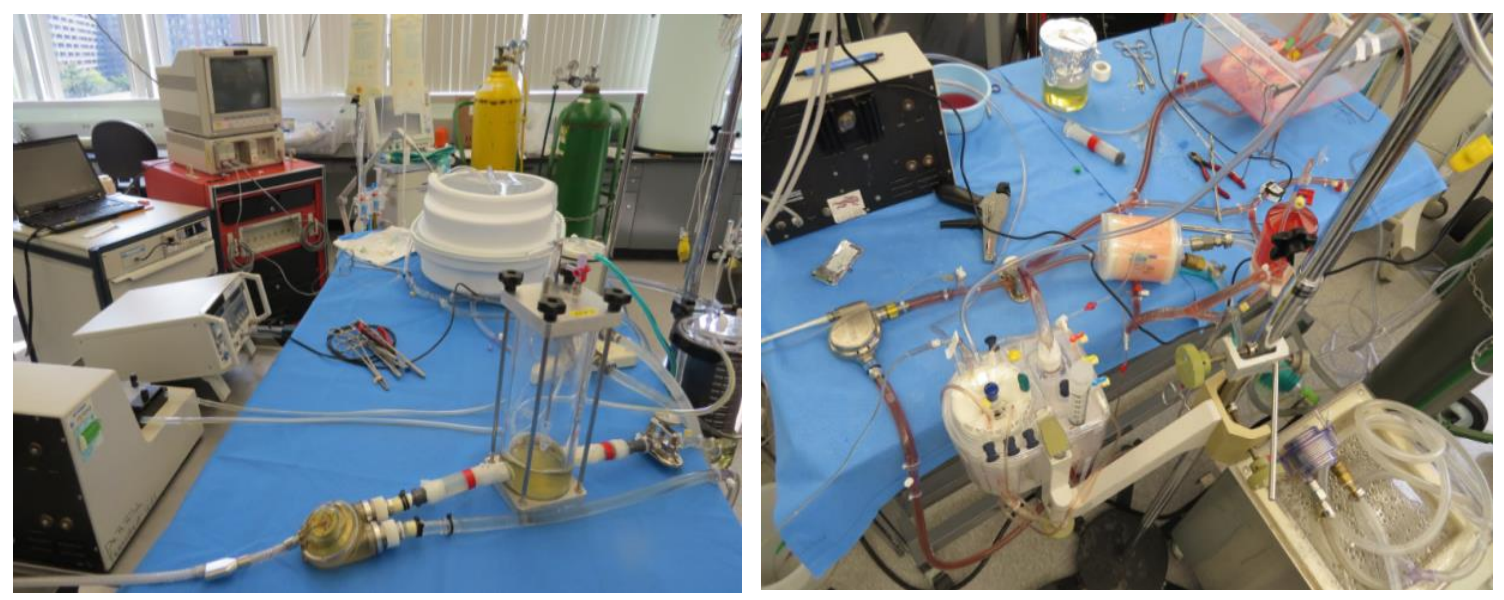

Figure 12: EVLP system in the A) pulsatile configuration with Thoratec PVAD (Pleasonton, CA) and B) continuous configuration with Levacor centrifugal pump (Salt Lake City, UT)

the cannulation sites is sequestered and pumped back into the reservoir using a S Series varistaltic pump (Manostat, Woodstock, NY)

\section{B. Ventilation and Perfusion}

Ventilation of the lungs was achieved using a Servo $i$ ICU ventilator (Maquet, Rastatt Germany) operating on medical air. A 28 French endotracheal tube (ID $7.0 \mathrm{~mm}$, OD $9.3 \mathrm{~mm}$ ) placed in the trachea delivered air to the lungs via a volume control strategy. Venous blood conditions were simulated using a specialty gas mixture $\left(6 \% \mathrm{O}_{2}, 8 \% \mathrm{CO}_{2}\right.$, and $86 \% \mathrm{~N}_{2}$, Welder's Supply, Louisville, KY). Gas entered the perfusate via the membrane oxygenator at a rate of $0.5 \mathrm{~L} / \mathrm{min}$ and was titrated to maintain a $\mathrm{pCO}_{2}$ of $40-45$ mmHg. A GEM 4000 blood gas analyzer (Instrumentation Laboratory, Zaventem, Belgium) provided data on the composition of the perfusate. The GEM 4000 measured $\mathrm{pH}, \mathrm{pCO}_{2}, \mathrm{pO}_{2}, \mathrm{Na}+, \mathrm{K}+, \mathrm{Mg} 2+, \mathrm{Cl}-, \mathrm{HCO} 3-, \mathrm{Ca} 2+$, glucose, lactate, and base excess. 


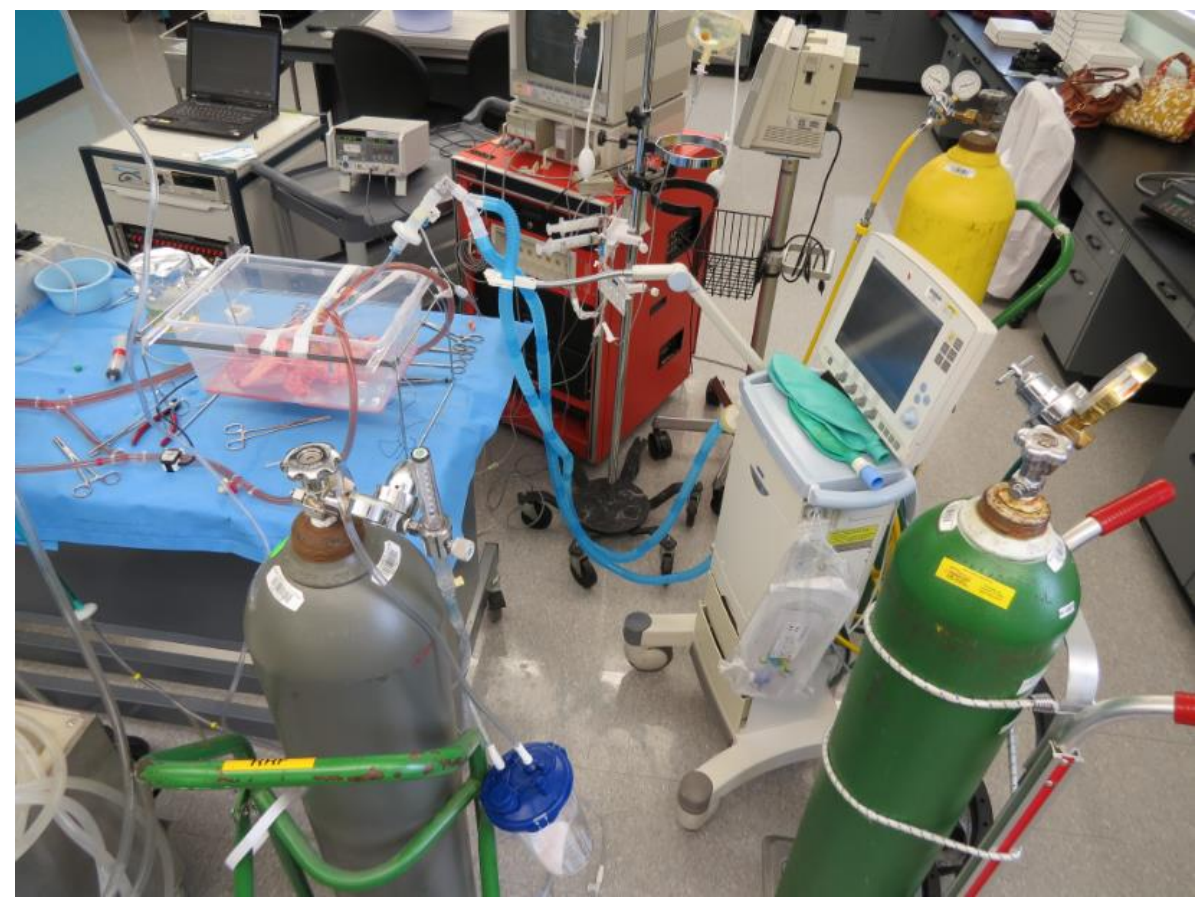

Figure 13: Ventilator unit and gas supply

C. Instrumentation and Data Acquisition

Hemodynamic pressure monitoring was achieved using fluid-filled and air-filled pressure transducers (BD Biosciences, San Jose, CA). Pulmonary artery pressure (PAP) was monitored proximally to the PA cannula and left atrial pressure (LAP) was monitored distally to the left atrial cuff cannula via the ports built in the cannulae. Peak airway pressure was measured with a transducer placed on the elbow of the endotracheal tube. These three metrics were fed into a Phillips Agilent patient monitor (Phillips Healthcare, Andover, MA) with BNC cables. This information was then fed into the data acquisition unit (DAQ), which was built in-house. Pulmonary artery flow was measured using an ultrasonic flow meter (Transonic Systems, Ithaca, NY) clamped proximally to the pulmonary artery cannula. The flow meter was configured to $1 / 4$ flow scale to output the flow in $\mathrm{mL} / \mathrm{min}$ due to the low flow scenario in EVLP. This data was also output to 
the DAQ. In addition to discrete measurements, continuous monitoring of the pressure and flow data was stored in the DAQ as DAT files.

D. Enzyme-Linked Immunosorbent Assay (ELISA)

Cytokine concentration was measured via immunoassay using Quantikine ELISA kits (R\&D Systems, Minneapolis, MN) following manufacturer's instructions and formulated for the detection of TNF- $\alpha$, IL-6, IL-8, and IL-10. A model 985370 tissue homogenizer (Biospec Products, Bartlesville, OK) was used for homogenization of parenchymal samples, which were stored in a Revco $-80^{\circ} \mathrm{C}$ freezer (Thermo Fisher Scientific, Waltham, MA). Concentration quantification was carried out using a Spectramax M2 multi-mode microplate reader using SoftMax Pro Data Acquisition and Analysis Software (Molecular Devices, Sunnyvale, CA).

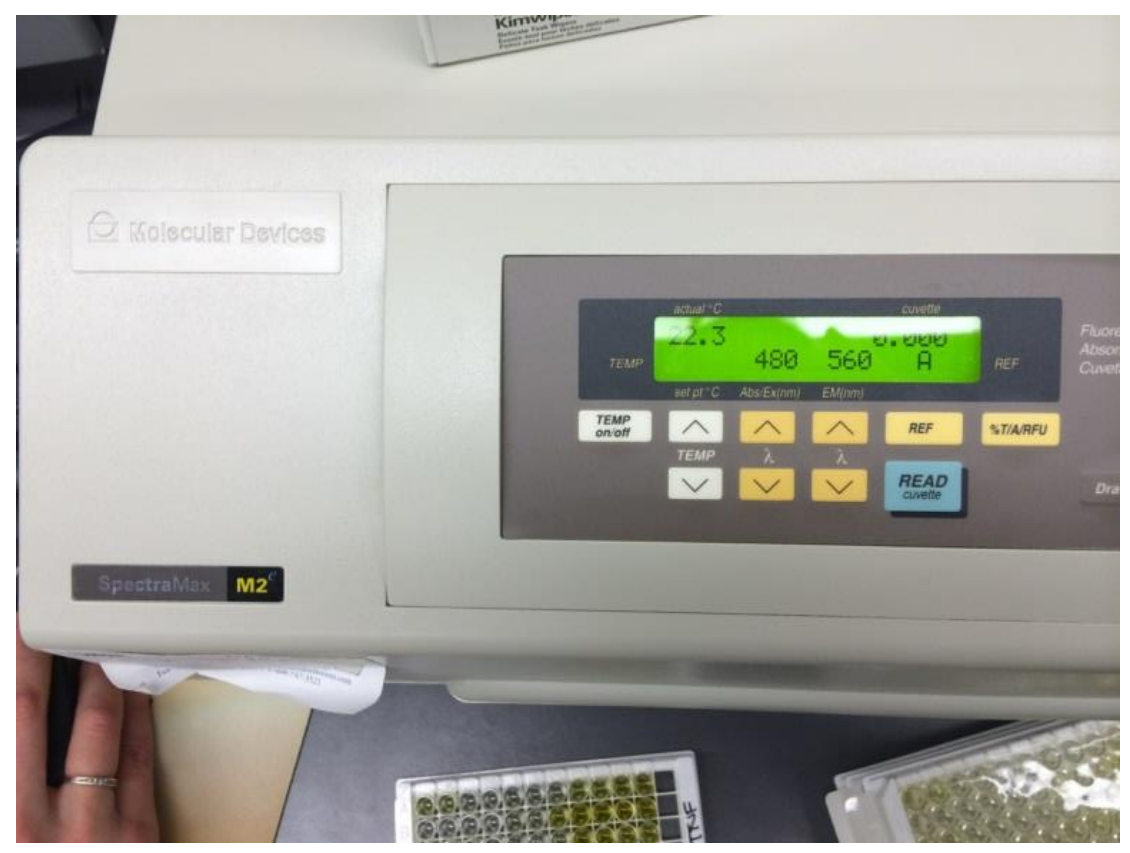

Figure 14-Spectramax M2 microplate reader 


\section{PROCEDURES}

\section{A. Experimental Design}

In this randomized study, lungs from 7 male Yorkshire pigs (weight $=45 \pm 5 \mathrm{~kg}$ ) were subjected to EVLP for durations greater than 12 hours. Fig. 14 shows the project

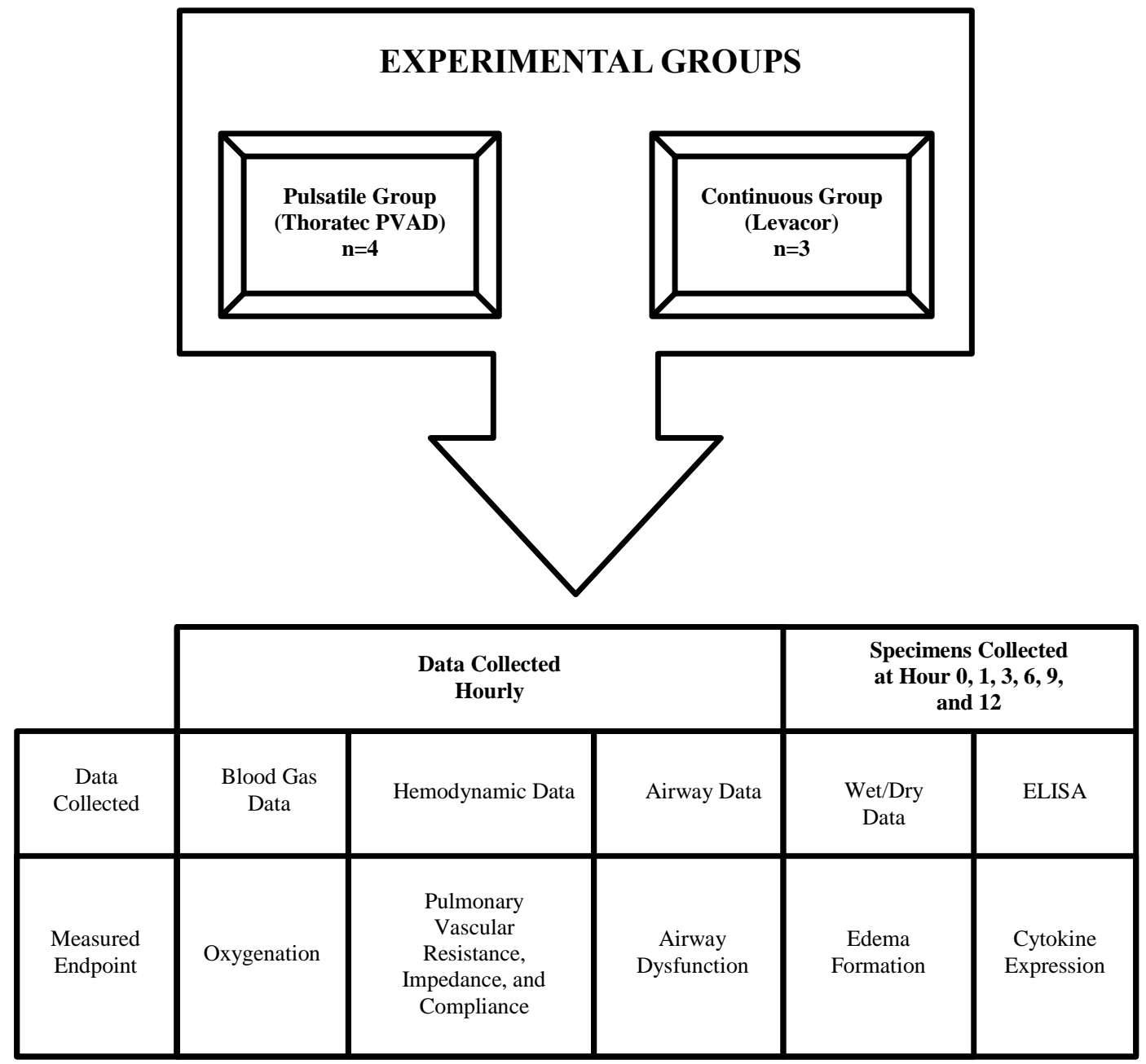

Figure 15: Experimental Design

organization in terms of the experimental groups compared and the endpoints that were examined. In the pulsatile group $(n=4)$, lungs were perfused using a PVAD (Thoratec, 
Pleasonton, CA). In the continuous group $(n=3)$, the lungs were perfused using a centrifugal pump (Levacor, Salt Lake City, UT).

Physical parameters of lung performance and tissue biopsies were analyzed to determine a quantitative and qualitative assessment of allograft viability over the course of the experiments. In this protocol, the lungs were fully supported by a modified cardiopulmonary bypass circuit for 50 minutes of every hour. This period was called the preservation period and was intended to increase the length of time that the lungs would remain viable. The fiftieth minute marks the start of the test period, where the oxygen flow is stopped and the specialty gas mixture is titrated to produce physiologic pulmonary artery partial gas pressures. During this period, the lungs were assessed based on their appearance, oxygenation capabilities, airway pressure, vascular resistance, wet/dry ratio, and cytokine expression.

\section{B. Preparation of Perfusate}

Two modified Krebs solutions were used for static and dynamic perfusion of the lungs. The static preservation fluid was used to flush the lung vasculature at the time of harvest and once again just prior to connection of the lungs to the EVLP system. The composition of the static perfusion solution and the perfusate differ only in their albumin concentrations. The compositions of these and the stock Krebs formulations are listed below: 


\section{0x Stock Krebs Perfusion Solution}

\begin{tabular}{cc}
\hline Compound & Amount \\
\hline $\mathrm{NaCl}$ & $261.8 \mathrm{~g}$ \\
$\mathrm{KCl}$ & $14.92 \mathrm{~g}$ \\
$\mathrm{KH}_{2} \mathrm{PO}_{4}$ & $5.44 \mathrm{~g}$ \\
$\mathrm{MgSO}_{4}$ & $5.80 \mathrm{~g}$ \\
$\mathrm{CaCl}_{2}$ & $7.36 \mathrm{~g}$ \\
\multicolumn{2}{c}{$\mathrm{QS}$ to $4000 \mathrm{~mL} \mathrm{DI} \mathrm{H}_{2} \mathrm{O}$} \\
\hline \multicolumn{2}{c}{$\mathrm{pH}$ of solution is about 5.6 } \\
\hline
\end{tabular}

Table V: Composition of 10x stock Krebs perfusion solution

\section{Working Perfusion Solution}

\begin{tabular}{cc}
\hline Krebs Stock Solution & $\mathbf{5 0 ~} \mathbf{~ m L}$ \\
\hline Glucose & $2.5 \mathrm{~g}$ \\
Dextran 40 & $2.5 \mathrm{~g}$ \\
30\% Bovine Serum Albumin & $117.6 \mathrm{~mL}$ \\
QS to $500 \mathrm{~mL}$ with DI $\mathrm{H}_{2} \mathrm{O}$ \\
Prior to use, add $\sim 1 \mathrm{~mL}$ of $1 \mathrm{M}$ Tris solution to reach a pH of \\
7.6 \\
\hline
\end{tabular}

Table VI: Composition of working perfusion solution

\section{Static Preservation Solution}

\begin{tabular}{cc}
\hline Krebs stock solution & $\mathbf{5 0 ~} \mathbf{~ L L}$ \\
\hline Glucose & $2.5 \mathrm{~g}$ \\
$30 \%$ Bovine Serum Albumin & $50 \mathrm{~mL}$ \\
QS to $500 \mathrm{~mL}$ with $\mathrm{DI} \mathrm{H}_{2} \mathrm{O}$ \\
Prior to use, add $\sim 1 \mathrm{~mL}$ of $1 \mathrm{M}$ Tris solution to reach a $\mathrm{pH}$ of \\
7.6 \\
\hline
\end{tabular}

Table VII: Composition of static preservation solution
C. Set up of perfusion apparatus

Fig. 15 displays a schematic view of the EVLP apparatus. Prior to set-up, the pump (and compliance chamber, if applicable) was cleaned by running it in a mild bleach 
solution (10 mL bleach: $\left.1 \mathrm{~L} \mathrm{DI} \mathrm{H}_{2} \mathrm{O}\right)$ and rinsing thoroughly in sterile saline. Sterile tubing components from donated cardiovascular procedure kits (Terumo) were used to build the circuit. The circuit was set up according to specifications outlined in

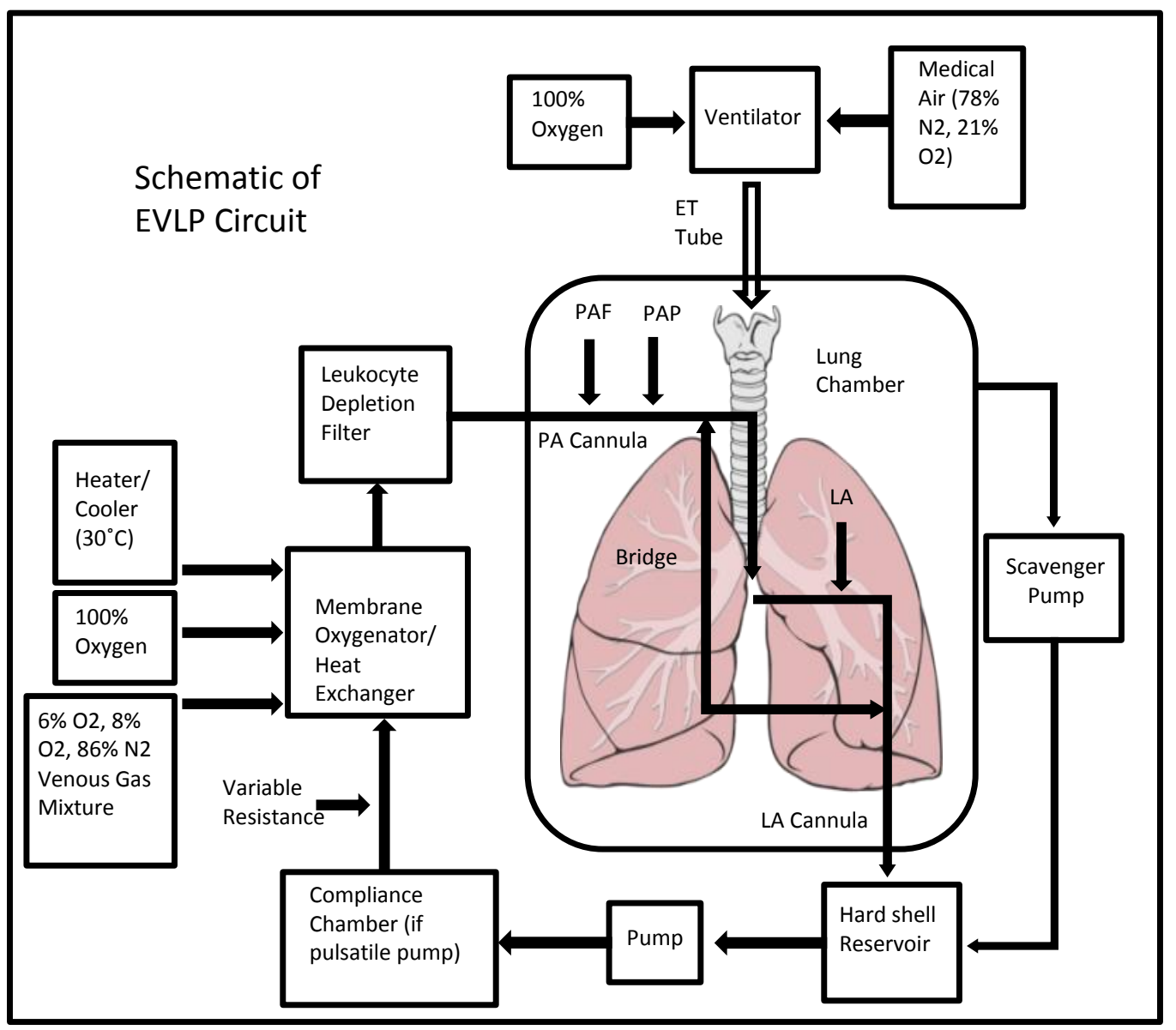

Figure 16: Schematic of EVLP Circuit

Section IIA of this text. Care was taken to keep any perfusate-contacting surfaces as clean as possible. The heat exchanger was primed with water before loading the perfusate. Prior to organ procurement, the system was primed with perfusate and balanced for $\mathrm{pH}$ and gas composition. During this time, perfusate was allowed to circulate through the bridge and the arterial and venous lines were clamped. The PA flow probe, PAP, LAP, and PAWP pressure transducers were calibrated and the outputs were 
verified on the DAQ. The pumps were then tuned to provide $100-200 \mathrm{~mL} / \mathrm{min}$ of flow through the bridge. The scavenger pump that returns perfusate collected in the lung basin to the reservoir was also inspected for operation.

Size $\mathrm{H}$ medical air and oxygen tanks were connected to the Servo $i$ ventilator (Maquet, Rastatt Germany) so that it could be performance tested before procurement. A specialty venous gas $\left(6 \% \mathrm{O}_{2}, 8 \% \mathrm{CO}_{2}\right.$, and $\left.86 \% \mathrm{~N}_{2}\right)$ was blended with an oxygen tank via a $\mathrm{Y}$ junction in the delivery line to the membrane oxygenator. This addition allowed for oxygen support during the preservation period while allowing for its removal during the test period. Omni-Flow 4000 infusion pumps (Abbott Park, IL) were primed and tested prior to use. $30 \%$ albumin and protaglandin E2 were loaded and set to infusion rates of $100 \mathrm{~mL} / \mathrm{hr}$ and $250 \mu \mathrm{g} / \mathrm{hr}$, respectively. Another pump was set to withdraw $100 \mathrm{~mL} / \mathrm{hr}$ from the circuit.

\section{Procurement and Preparation of Lungs}

Prior to the day of procurement, the pig was fasted for 18 hours to prevent intraoperative aspiration. The animal was placed in the supine position and a midline sternotomy was performed using electric cautery and sternal saw. The pleural space and pericardium were opened to reveal the heart, lungs and great vessels. 


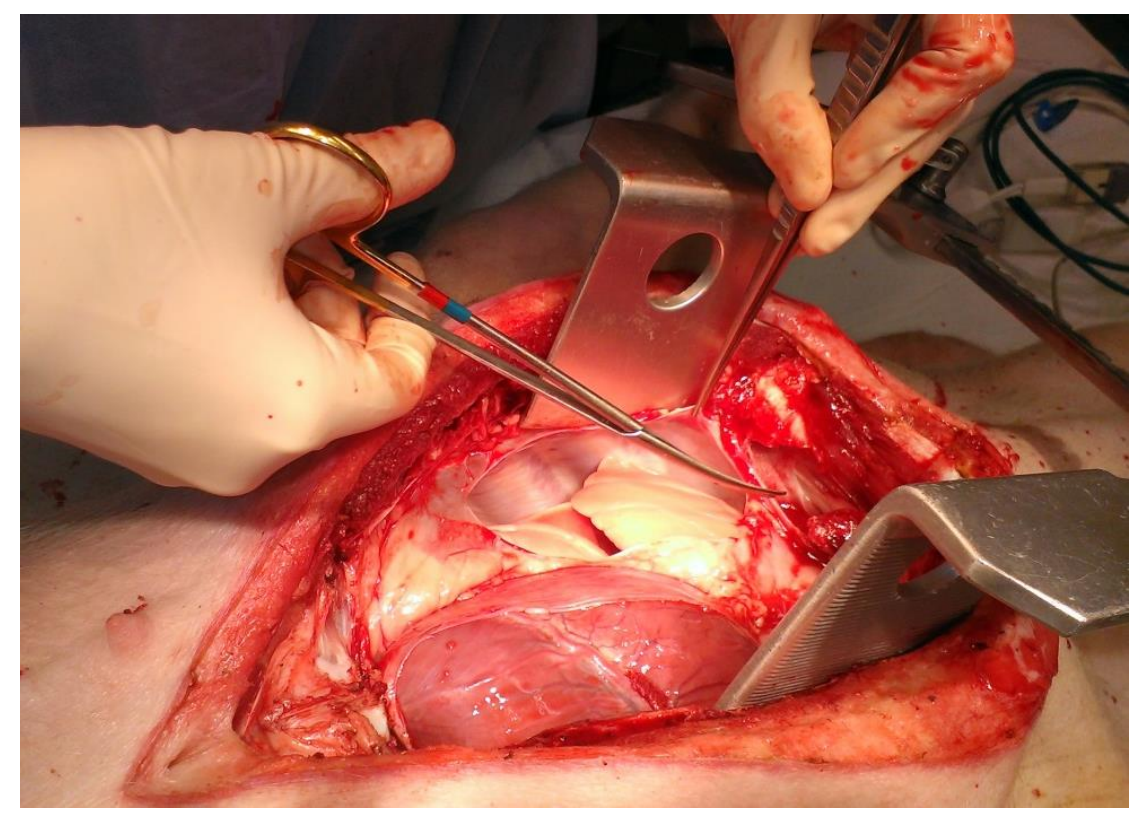

Figure 17-Pleural space revealed by median sternotomy

The pulmonary artery was dissected free of the aorta and sutures were placed in the PA in preparation for cannulation. The inferior pulmonary ligaments were

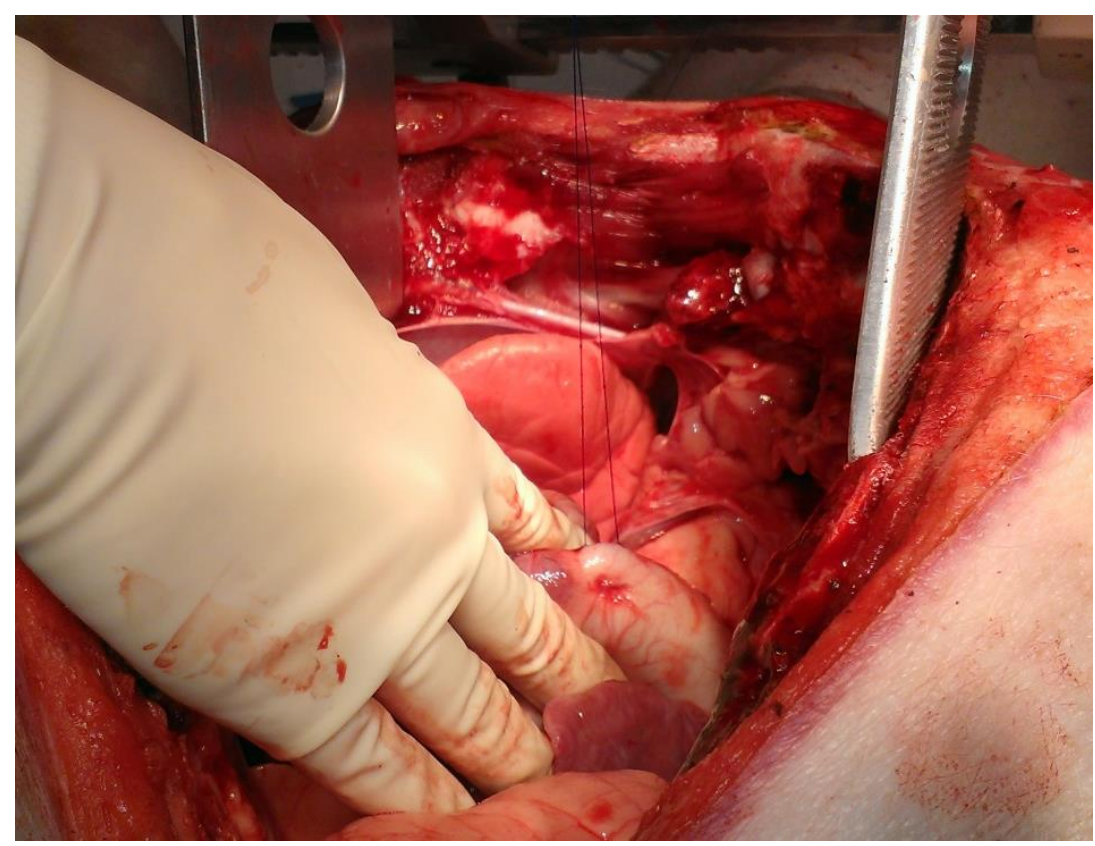

Figure 18-Suture placed in pulmonary artery 
identified and transected. The donor was then infused with 10,000 units of heparin, which was allowed to circulate for 3 minutes. Parenchymal biopsies were excised by tying a portion of the lung with a suture and excising with a scalpel or fine scissors.

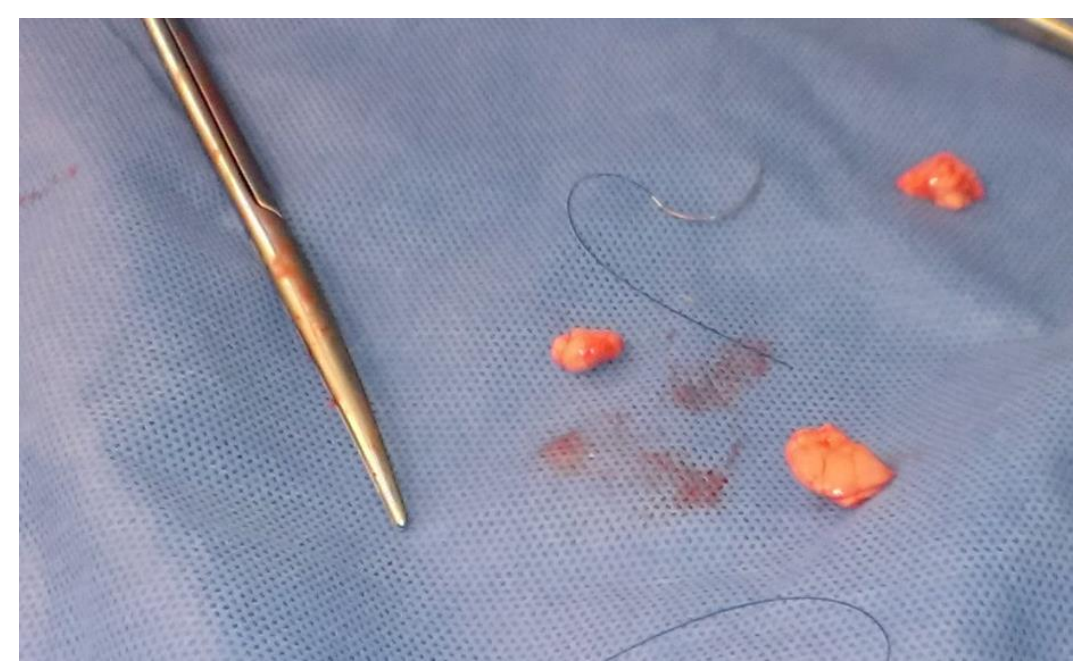

Figure 19-Intraoperative Parenchymal Samples

At this point, $250 \mathrm{mcg}$ Prostin VR was loaded into the cold flush bag containing the static preservation solution. A stab incision was made in the PA and dilated to allow placement of a 32 French cannula. This was secured and infusion of the perfusate was initiated. The aorta was cross-clamped, the right atrium and SVC were cut to vent. Ice was placed in the thoracic cavity during the infusion and subsequent dissection of the great vessels. Once infusion was completed, the trachea was dissected free and isolated. Ventilation ceased once the trachea had been clamped while the lungs were in the inflated state. The heart and lungs were removed en bloc to be placed in cold saline on ice.

Once the heart and lungs were removed en bloc, they were transported on ice to the EVLP facility and immediately back tabled. The heart and esophagus were dissected free, taking care to leave the left atrial cuff intact. The left atrial cuff was then cannulated with 


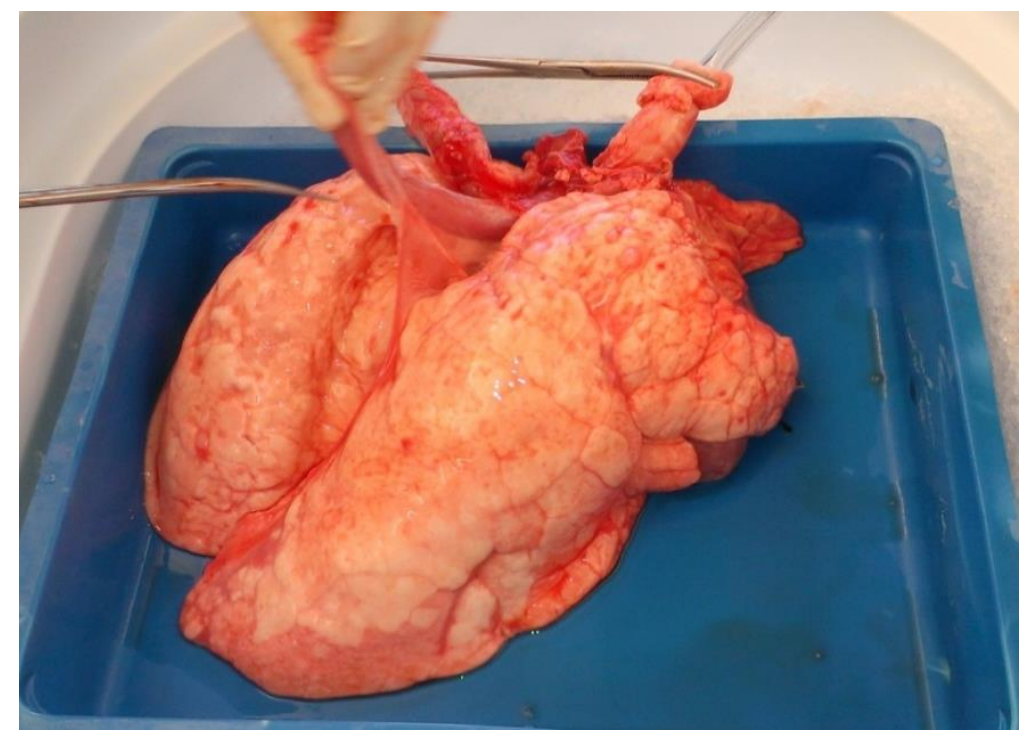

Figure 20-Heart and lungs en bloc

a specialized funneling cannula (XVIVO). Two sets of sutures were used to ensure patency of the anastomosis. The pulmonary artery was cannulated (XVIVO) and secured

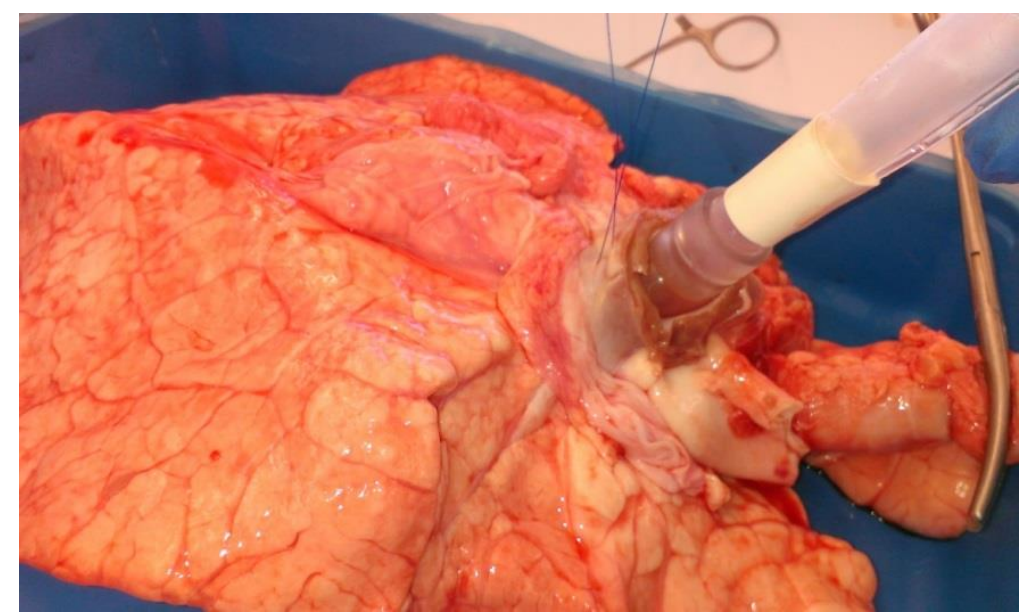

Figure 21-Sewing the funneling cannula (Vitrolife) to the left atrial appendage

with a purse string suture. At this time, another $1 \mathrm{~L}$ of static preservation solution was infused into the lungs to ensure adequate flushing of the vasculature. The lungs were then moved onto the EVLP apparatus. 


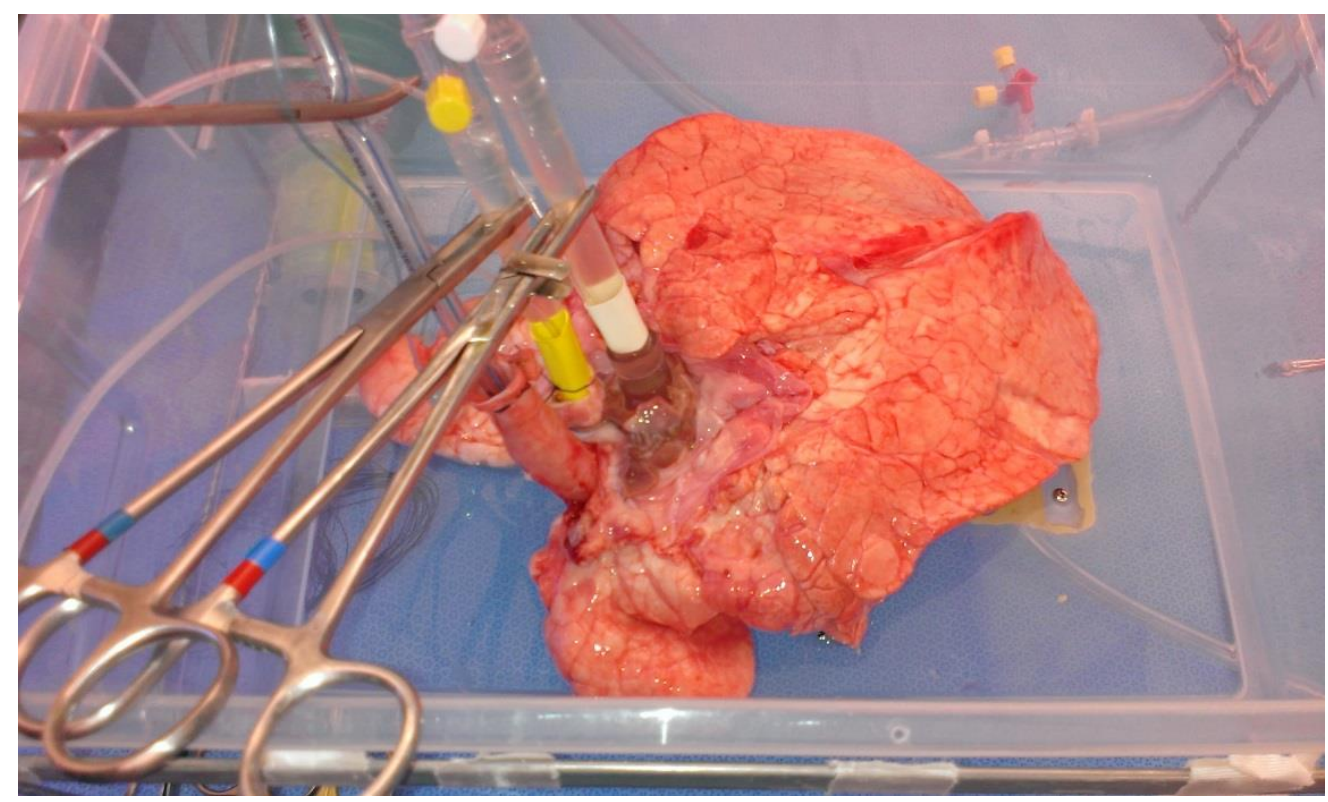

Figure 22-Lungs primed for connection to the EVLP system

\section{E. Initiation of EVLP}

While the lungswere being prepared for EVLP on the back table, $500 \mathrm{mg}$ methylpredisolone, $1 \mathrm{~g}$ cefazolin and 10,000 units of heparin were loaded into the circuit. The GEM 4000 was used to balance the perfusate gas composition to ensure a $\mathrm{pH}$ of 7.47.5, $\mathrm{pCO}_{2}$ between 40 and $45 \mathrm{mmHg}$, and $\mathrm{pO}_{2}>200 \mathrm{mmHg}$. A specialty gas mixture containing $6 \% \mathrm{O}_{2}, 8 \% \mathrm{CO}_{2}$, and $86 \% \mathrm{~N}_{2}$ (Welders Supply, Louisville, $\mathrm{KY}$ ) was fed into the membrane oxygenator and titrated to maintain the aforementioned partial gas pressures. While the specialty gas mixture was used to produce venous conditions during the test phase, oxygen was also fed into the oxygenator at a rate of $1 \mathrm{~L} /$ min during the preservation phase of EVLP. A heater/cooler (Sarns, Ann Arbor, MI) was used to maintain a perfusate temperature of $30^{\circ} \mathrm{C}$.

Once the lungs were loaded onto the EVLP platform, a wet to wet connection was made on the venous cannulation by clamping the return line to the reservoir and leaving 
the bridge unclamped. Retrograde perfusion at about $100 \mathrm{~mL} / \mathrm{min}$ was then initiated to de-air the PA cannula. Once a wet to wet connection was made at the PA cannula, the return line to the reservoir was unclamped and the bridge was clamped to allow anterograde perfusion at a rate of $100 \mathrm{~mL} / \mathrm{min}$.

This protocol adapted elements of the Lund and Toronto protocols, with some modifications. The target maximum flow rate was based on animal weight and the physical principles of gas exchange. With this in mind, the maximum flow rate was kept in the range of $5-6 \mathrm{~mL} / \mathrm{kg} / \mathrm{min}$, such that adequate gas exchange could occur, while still maintaining a lower and thus more protective flow maximum. Thus, the flow is increased incrementally over the first hour until full perfusion is reached. Fig. 22 shows the ramping phase for the pulmonary artery flow.

\section{PA Flow Ramp Phase}

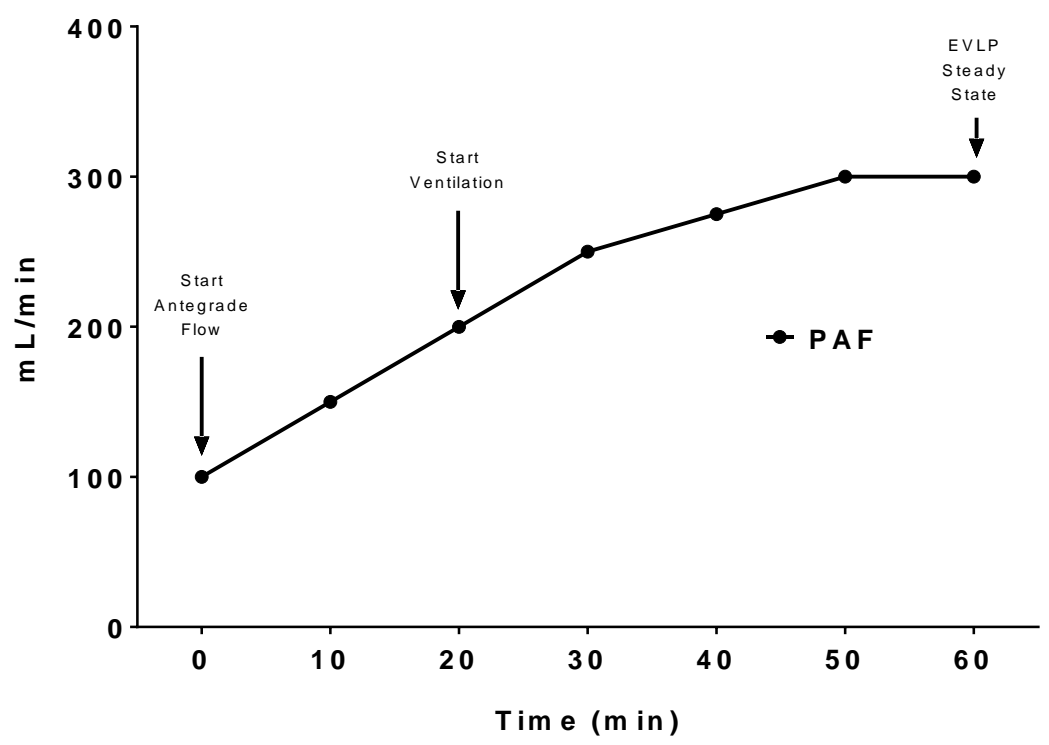

Figure 23: Pulmonary artery flow ramp phase 
Also unlike these protocols, the perfusate temperature is kept at $30^{\circ} \mathrm{C}$ during the entire experiment. It is believed that mild hypothermia promoted a moderate depression in enzymatic activity, decreasing metabolite accumulation while still permitting reparative processes to occur.

This protocol paralleled the Toronto in terms of when ventilation was started. Ventilation was initiated after 20 minutes of EVLP. Until this point, the lungs were kept in the inflated state by clamping the ET tube. Since oxygenation is not as affected by tidal volume as compared with ventilation, the ventilator was set for a low tidal volume of 20$40 \%$ of that used intraoperatively. It was also postulated that a low tidal volume would serve to protect the lung by avoiding barotrauma. Positive end expiratory pressure was kept at about 3-5 $\mathrm{cm} \mathrm{H}_{2} \mathrm{O}$ to promote oxygenation. The fraction of inspired oxygen was initially set to $30 \% \mathrm{O}_{2}$ but was increased to $35 \%$ at hour $4,40 \%$ at hour $6,45 \%$ at hour 9 and $50 \%$ at hour 12 of EVLP.

\section{F. Ventilation and Perfusion Strategy}

Once anterograde perfusion was initiated at $100 \mathrm{~mL} / \mathrm{min}$, it was incrementally increased to $250-300 \mathrm{~mL} / \mathrm{min}$ over the first hour. Once this threshold was reached, the lungs were considered to be in steady state. The pulmonary vascular resistance was monitored over the course of the experiment. If PVR began to increase, troubleshooting in the form of 1) acidosis correction with sodium bicarbonate, 2) prostaglandin E2 titration to encourage vasorelaxation, or 3) changes to the pump settings was employed to stay within specifications. 
Once ventilation was initiated, the tidal volume was adjusted to maintain a peak airway pressure $<20 \mathrm{cmH}_{2} \mathrm{O}$. However, this specification could be superseded if low tidal volumes were hindering adequate ventilation. Positive end expiratory pressure was set to 3-5 $\mathrm{cmH}_{2} \mathrm{O}$ and $\mathrm{FIO}_{2}$ was set to $30 \%$ to maintain adequate oxygenation.

\begin{tabular}{ccc}
\hline$\underline{\text { Parameter }}$ & Preservation Period (50 min) & $\underline{\text { Test Period (10 }}$ \\
\hline $\begin{array}{c}\text { Tidal Volume } \\
\text { Positive End Expiratory Pressure } \\
\text { (PEEP) }\end{array}$ & $4-5 \mathrm{~mL} / \mathrm{kg}$ & $4-5 \mathrm{~mL} / \mathrm{kg}$ \\
Respiratory Rate & $3 \mathrm{~cm} \mathrm{H} 20$ & $3 \mathrm{~cm} \mathrm{H} \mathrm{H}_{2} \mathrm{O}$ \\
Fraction of Inspired Oxygen $\left(\mathrm{FiO}_{2}\right)$ & $5 \mathrm{bpm}$ & $15 \mathrm{bpm}$ \\
$\mathrm{O}_{2}$ Flow Rate & $30-100 \%$ & $30-100 \%$ \\
$\mathrm{pCO}_{2}$ & $1 \mathrm{~L} / \mathrm{min}$ & $\mathrm{NA}$ \\
$\mathrm{pO}_{2}$ & $40-45 \mathrm{mmHg}$ & $45-50 \mathrm{mmHg}$ \\
$\mathrm{PAF}_{\text {Specific Gravity }}$ & $>200 \mathrm{mmHg}$ & $40-80 \mathrm{mmHg}$ \\
\hline
\end{tabular}

Table VIII: Ventilation and perfusion specifications

During the preservation period, the respiratory rate was set to $5 \mathrm{bpm}$, in accordance with our protective strategy. However, during the test period, the respiratory rate was increased to $15 \mathrm{bpm}$, to promote increased oxygenation. As has been mentioned, oxygen was cut off during the test period and the lungs were required to oxygenate on their own under venous conditions. Table VIII summarizes the ventilation/perfusion strategy.

\section{G. Perfusate Withdrawal and Infusion Strategy}

Throughout the procedure, perfusate was drawn from the circuit at a rate of 100 $\mathrm{mL} / \mathrm{hr}$ via a syringe pump to diminish the number of circulating inflammatory cells, reduce lactate levels, and replenish the glucose supply. In addition to the albumin in the perfusate, $30 \%$ albumin was directly infused into the reservoir at a rate of $100 \mathrm{~mL} / \mathrm{hr}$ via 
a syringe pump. Additionally, a $100 \mathrm{~mL}$ transfusion was performed every hour. Appropriate maintenance of albumin concentration was important to control the formation of pulmonary edema. Specific gravity was measured hourly to afford an approximation of the oncotic pressure of the perfusate. This analysis was done by simply weighing a $1 \mathrm{~mL}$ of perfusate and dividing it by the weight of $1 \mathrm{~mL}$ of water. A specific gravity between 1.4 and 1.8 is considered optimal for the reduction of edema.

Prostaglandin E2 was infused into the circuit to reduce pulmonary vascular resistance via vasodilation. Prostaglandin E2 may also reduce clotting by inhibiting platelet aggregation. $250 \mathrm{mcg}$ Prostaglandin E2 was administered intraoperatively during the

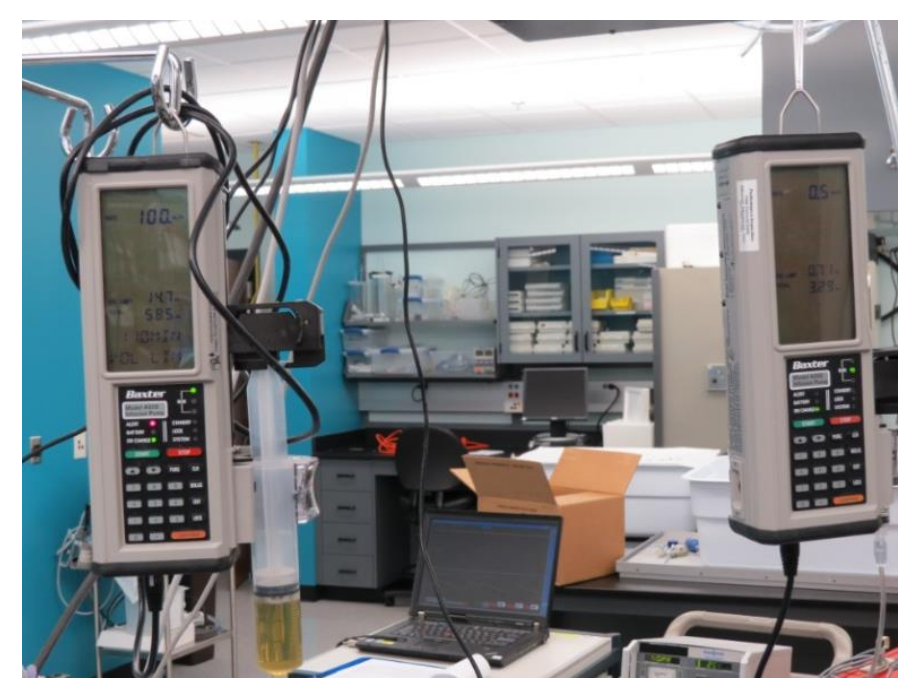

Figure 24: Continuous infusions of 30\% bovine serum albumin and prostaglandin E2

first static perfusate flush and another $250 \mathrm{mcg}$ was loaded into the second static perfusate flush just prior to EVLP cannulation. Protaglandin E2 was also loaded into a 5 $\mathrm{mL}$ syringe and set to infuse at a rate of $250 \mathrm{mcg} / \mathrm{hr}$ into the perfusion apparatus and titrated to maintain a pulmonary vascular resistance <20 Woods Units. If vasospasm 
occurred and the PVR began to increase, a bolus of 50-100 mcg was administered to protect the vasculature and preserve vascular patency.

\section{H. Interventional Management}

Interventional maneuvers were taken to protect the lung from acidosis, alkalosis, excessively high pulmonary vascular resistance, excessively high $\mathrm{pCO}_{2}$, edema accumulation, and blockage of the airway. Blood gasses were analyzed three times during the hour and also at the discretion of the technician. Acidosis was described as a perfusate $\mathrm{pH}$ lower than 7.4. If noted, sodium bicarbonate was given as a bolus into the reservoir. Alkalosis was less common and mitigated by adjusting the sweep gas flow and ventilation settings. Specific gravity readings were taken every hour as a rough marker for viscosity and oncotic pressure provided by albumin in the solution. If a specific gravity reading was less than 1.03 or edema was noted in the airways or interstitial space, albumin was given as a bolus into the reservoir. Excessively high pulmonary vascular resistance, defined as $>50$ Woods units, was treated by titrating or giving prostaglandin E2 as a bolus. Sodium nitroprusside was also used as a vasodilator to promote a reduction in PVR. Blockage of the airway or fluid accumulation was mitigated by introducing a suction catheter down the trachea. Occasional inspiratory holds at a peak airway pressure of $30 \mathrm{cmH}_{2} \mathrm{O}$ were also used to open the airway and prevent atelectasis. 10 second inspiratory holds were conducted hourly to PAWP of $30 \mathrm{~cm} \mathrm{H}_{2} \mathrm{O}$.

\section{Hemodynamic Analysis}

Pressure and flow data were recorded hourly as discrete measurements and continuous 30 second samples, and were stored in the data acquisition unit. Of the major 
end points, pulmonary vascular resistance (in Dynes $\cdot \mathrm{s} / \mathrm{cm}^{5}$ ) was derived from this data using the following formula:

$$
\begin{gathered}
P V R=\frac{P A P-L A P}{P A F} \quad \text { Eq. } 4 \\
\text { Where: } \\
\text { PAP }=\text { Pulmonary Artery Pressure }(\mathrm{mmHg}) \\
\mathrm{LAP}=\text { Left Atrial Pressure }(\mathrm{mmHg}) \\
\mathrm{PAF}=\text { Pulmonary Artery Flow }(\mathrm{L} / \mathrm{min})
\end{gathered}
$$

Hourly calculations of PVR from the discrete data collections were plotted as a function of time for analysis between the two groups. To obtain PVR in Woods Units, the result of this equation is divided by 80 .

\section{J. Blood Gas Analysis}

Blood gas analysis conducted on a GEM 4000 Analyzer provided data for the determination of oxygenation capacity of the lungs. Perfusate samples were taken from the arterial and venous sides and the $\Delta \mathrm{PO}_{2} / \mathrm{FIO}_{2}$ of the lungs was calculated. Additionally, the GEM 4000 measured $\mathrm{pH}, \mathrm{pCO}_{2}, \mathrm{pO}_{2}, \mathrm{Na}+, \mathrm{K}+, \mathrm{Mg} 2+, \mathrm{Cl}-\mathrm{HCO}-$, $\mathrm{Ca} 2+$, glucose, lactate, and base excess. These measurements enabled the diagnosis and treatment of metabolic and respiratory alkalosis and acidosis, as well as monitor for glucose consumption, hyperkalemia, hypernatremia, lactate accumulation and bicarbonate levels.

\section{K. Wet/Dry Analysis}

Wet/dry analysis was the predominant endpoint for determination of edema formation. Biopsies were taken by ligating a small section of lung parenchyma with a 
scalpel or fine scissors. The sample would then be weighed, dried at room temperature for 72 hours, and weighed again to provide a quantitative assessment of fluid accumulation and edema in the tissue. This was achieved by the ratio of the weight of the wet sample to the weight when dried.

\section{Enzyme-Linked Immunosorbent Assay (ELISA) for Cytokine}

Using the method of biopsy indicated above, parenchymal samples were excised, placed in a cryovial and flash frozen in liquid nitrogen. Following the experiment, the samples were transferred to a $-80^{\circ} \mathrm{C}$ freezer and stored until analysis. Tissue samples were removed from storage and each were weighed to obtain a sample weight of $0.75 \mathrm{~g}$. $1.5 \mathrm{~mL}$ of buffer with protease inhibitor was added to each sample in a cuvette and homogenized using a rotary homogenizer for 15 seconds. The samples were then centrifuged at 9000 RPM for 10 minutes. The supernatant was removed and transferred to clean $2 \mathrm{~mL}$ cryovials, flash frozen in liquid nitrogen, and stored at $-80^{\circ} \mathrm{C}$.

The homogenized samples were removed from freezer storage and thawed at room temperature. Reagents and standard dilutions were prepared per specifications provided by the manufacturer. $50 \mu \mathrm{L}$ of assay diluent was added to each well of the four Quantikine ELISA kits. Standards, controls, blanks, and samples (50 $\mu \mathrm{L}$ each) were loaded according to the grid shown in Fig. 26. 


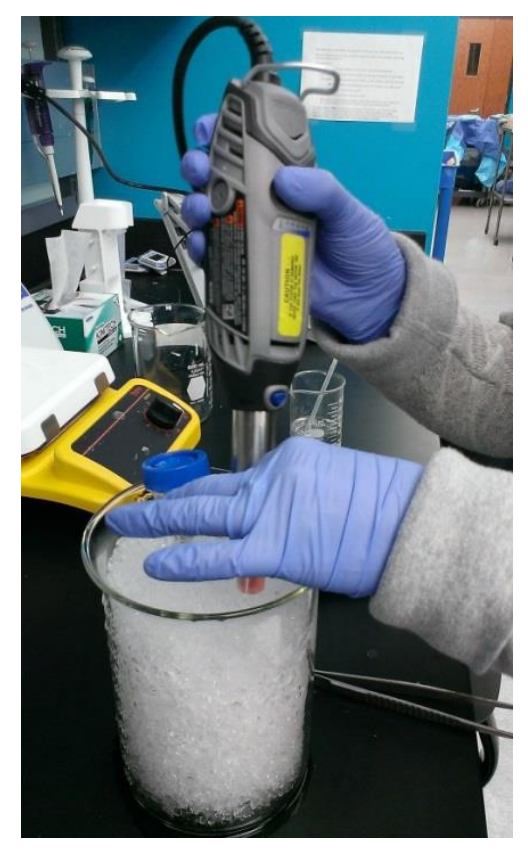

Figure 25-Homogenizing tissue samples for ELISA

The plates were sealed and allowed to incubate at room temperature for 2 hours. Each well was aspirated and washed 5 times with wash buffer. $100 \mu \mathrm{L}$ of conjugate antibody

\begin{tabular}{|r|r|r|r|r|r|r|r|r|r|r|r|r|}
\hline & 1 & 2 & 3 & 4 & 5 & 6 & 7 & 8 & 9 & 10 & 11 & 12 \\
\hline A & Confol & $p_{1}$ & on & $p_{1}$ & lh & $p_{1} 3 \mathrm{~h}$ & $p_{1}$ & $6 h$ & $p_{1}$ & $12 h$ & \\
\hline B & Brank & 2 & & 2 & & 2 & 2 & & 2 & & \\
\hline C & & & 3 & & 3 & & 3 & 3 & & 3 & & \\
\hline D & & 5 & 4 & & 4 & & 4 & 4 & & 4 & & \\
\hline & & 5 & & 5 & & 5 & 5 & & 5 & & \\
\hline F & & 6 & & 6 & & 6 & 6 & & 6 & & \\
\hline H & S & & 7 & & 7 & & 7 & 7 & & 7 & & \\
\hline
\end{tabular}

Figure 26-ELISA 96-well plate grid

The plates were sealed and allowed to incubate at room temperature for 2 hours. Each well was aspirated and washed 5 times with wash buffer. $100 \mu \mathrm{L}$ of conjugate antibody 
was added for each cytokine type and allowed to incubate again for 2 hours at room temperature. After aspirating and washing another 5 times, $100 \mu \mathrm{L}$ of substrate solution was added to each well and the plates were allowed to incubate in the dark for 30 minutes. Post-incubation, $100 \mu \mathrm{L}$ of stop solution was added to each well. Within 30 minutes of adding the stop solution, the plates were developed using a Spectramax M2microplate reader at $450 \mathrm{~nm}$ and analyzed with SoftMax Pro Data Acquisition and Analysis Software. 


\section{RESULTS AND DISCUSSION}

\section{A. Hemodynamic Analysis}

Hemodynamic data collected from pulsatile flow $(n=4)$ and continuous flow $(n=3)$ groups were used to calculate pulmonary vascular resistance using Eq. 4. Analysis between the two groups was accomplished using GraphPad Prism software. Fig. 27 plots PVR over the 12 hour test period in both Woods Units and dynes $/ \mathrm{s} / \mathrm{cm}^{5}$ for both groups. Average PVR in Woods Units was $15.17 \pm 1.33$ and $13.60 \pm 1.91$ over the 12 hour test period for $\mathrm{CF}$ and $\mathrm{PF}$ groups, respectively. Unpaired t-tests conducted between the two groups at each hour could not discern a statistical difference $(\alpha=0.05)$ over the 12-hour test period. However, a statistically significant difference was noticed in PVR at hour 9 but this was not true at any other time point. Additionally, the large variation in PVR at hour 12 for the CF group is believed to be a result of improper prostaglandin E2 dosing during at least one of the experiments.
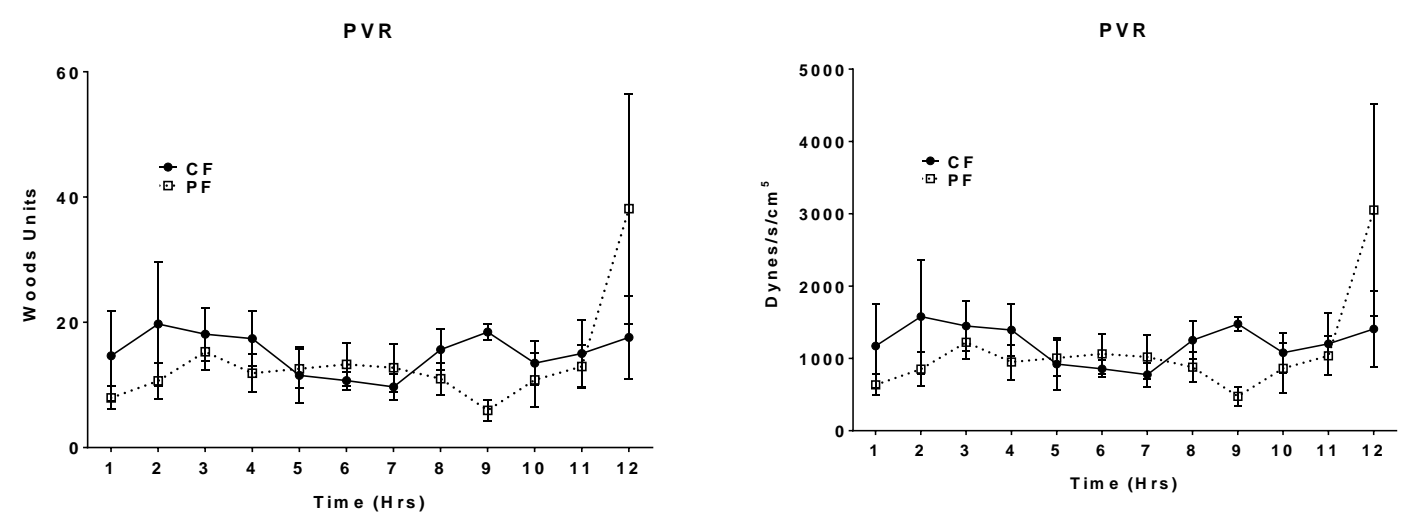

Figure 27-Pulmonary vascular resistance (PVR) in A) Woods Units, and B) Dynes $/ \mathrm{s} / \mathrm{cm}^{5}$ 


\section{B. Airway Pressure Analysis}

Airway pressure data was recorded in discrete measurements as well as 30 second continuous data samples at $400 \mathrm{~Hz}$ sampling frequency. Peak airway pressure was collected from the Maquet Servo i ventilator for both continuous and pulsatile groups and plotted a function of time. PAWP was observed to increase over the 12 hour test period for both groups. PAWP in $\mathrm{cm}_{2} \mathrm{O}$ was $17 \pm 1.15$ and $16 \pm 0.75$ at baseline and $21 \pm 1.67$ and $21 \pm 0.41$ at hour 12 for $\mathrm{CF}$ and PF, respectively. Unpaired t-tests conducted between the two groups could not discern a statistical difference $(\alpha=0.05)$ at any time point.

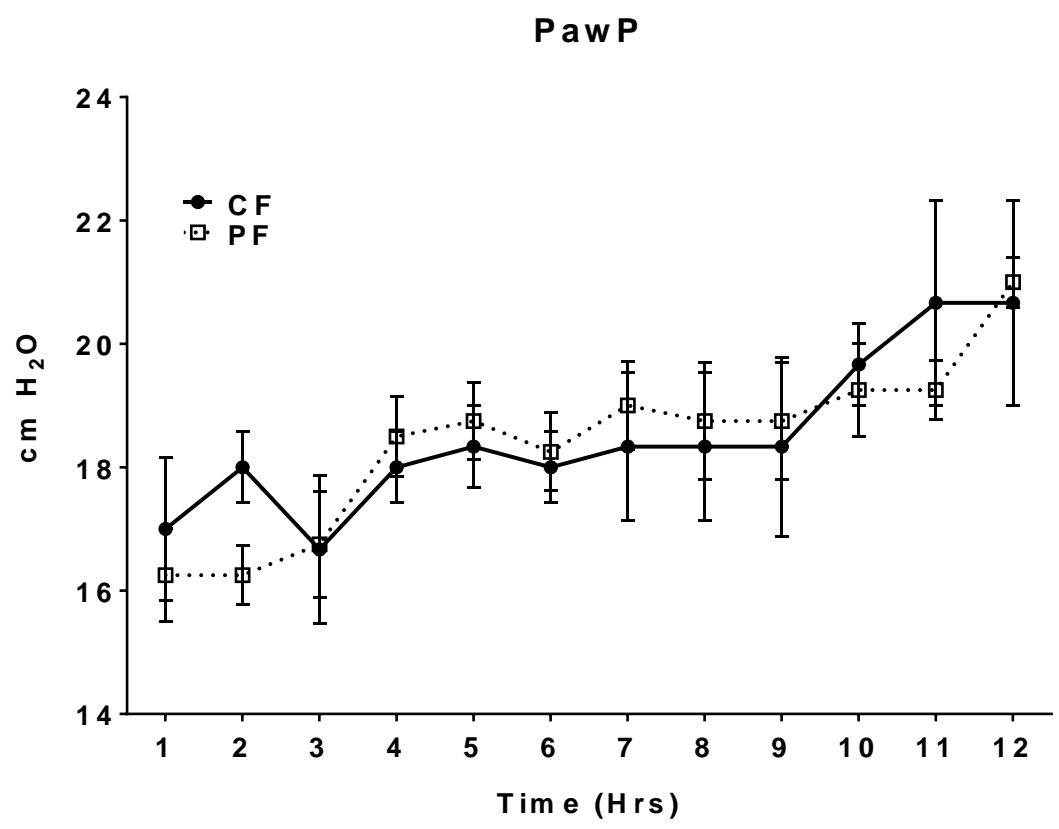

Figure 28-Peak airway pressure over 12-hour test period

\section{Blood Gas Analysis}

Perfusate samples were taken from the arterial and venous aspects of the lung and analyzed on a GEM 4000 Blood analyzer. Using Eq. 4, the oxygenation capacity of the 
lungs was calculated and plotted as a function of time. $\triangle \mathrm{PO} 2 / \mathrm{FIO} 2$ trends over the $12-$ hour test period for both $\mathrm{CF}$ and $\mathrm{PF}$ groups are shown in Fig. 29. $\Delta \mathrm{PO}_{2} / \mathrm{FiO}_{2}$ in $\mathrm{mmHg}$ was $261 \pm 47$ and $313 \pm 37$ at baseline and $174 \pm 36$ and $152 \pm 36$ at hour 12 for $\mathrm{CF}$ and PF, respectively. Unpaired t-tests conducted between the two groups were only able to discern a statistically significant difference at hour 9. However, over the course of the 12hour experiment, neither group could be proven to be better than the other.

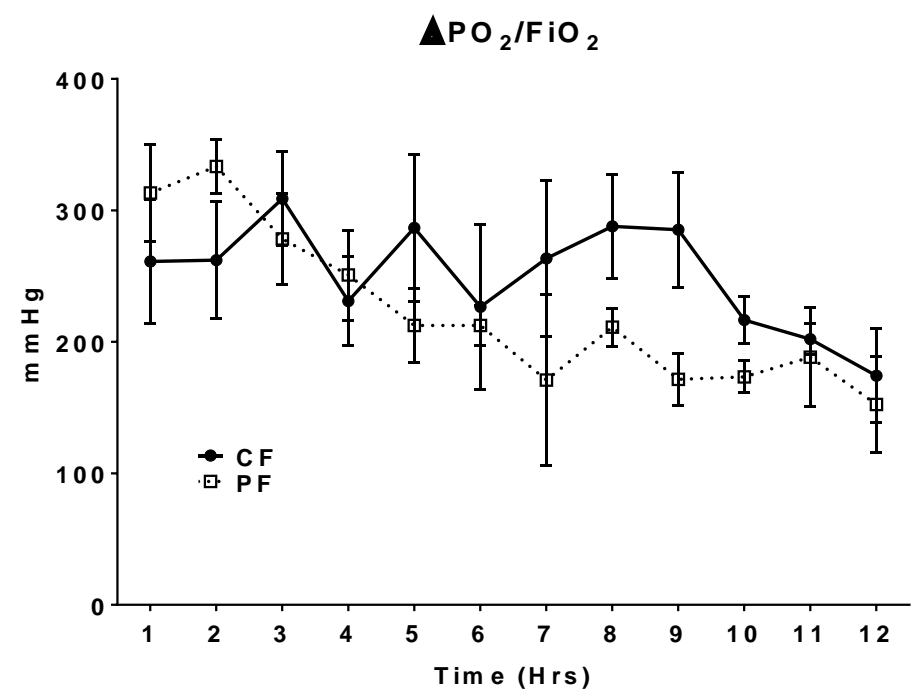

Figure 29- $\Delta \mathrm{PO}_{2} / \mathrm{FiO}_{2}$ over 12-hour test period

$\Delta \mathrm{PO} 2 / \mathrm{FIO}_{2}$ trends for individual runs for both $\mathrm{CF}$ and $\mathrm{PF}$ groups are shown in Fig. 30 and Fig. 31, respectively. As can be seen, the lungs from CF Run 1 were able to oxygenate at near-optimal levels up to 12 hours on $40 \% \mathrm{FiO}_{2}$. 


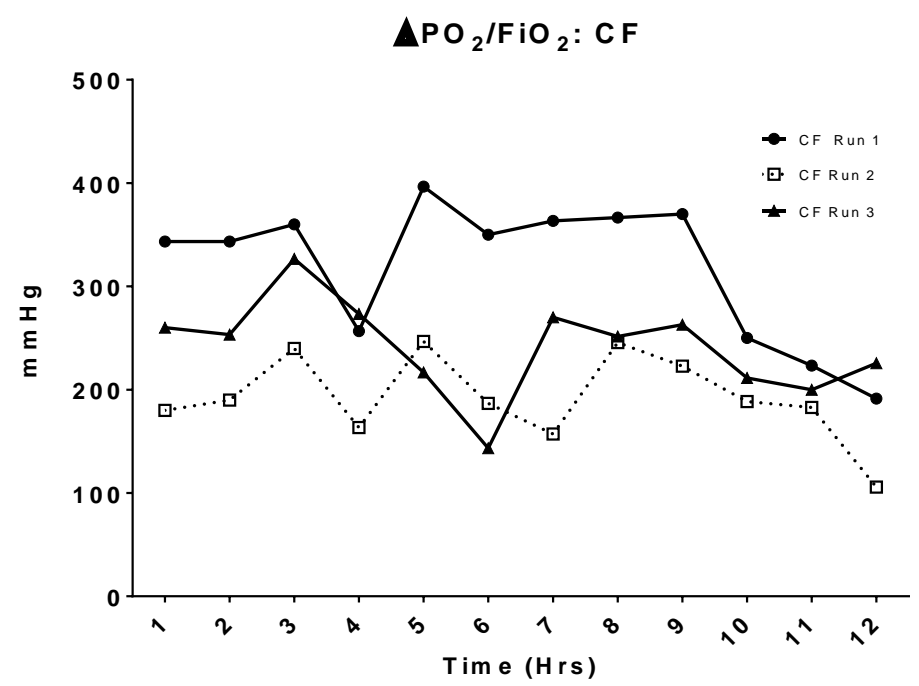

Figure 30- $\Delta \mathrm{PO}_{2} / \mathrm{FiO}_{2}$ over 12-hour test period for continuous flow EVLP group

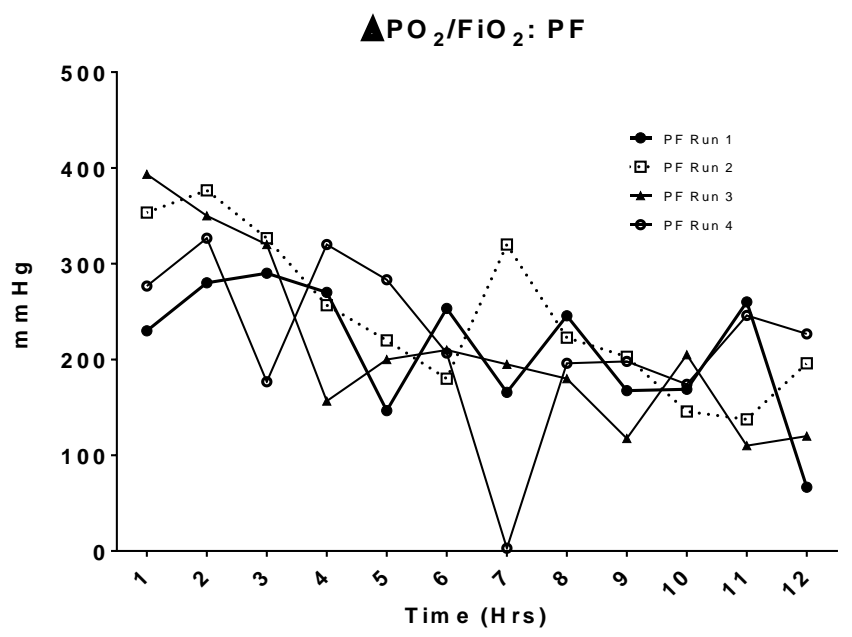

Figure 31-- $-\mathrm{PO}_{2} / \mathrm{FiO}_{2}$ over 12-hour test period for pulsatile flow EVLP group

Lactate concentration was observed to increase over the 12 hour test period for both groups. Lactate concentration in $\mathrm{mmol} / \mathrm{L}$ was $1.17 \pm 0.26$ and $0.85 \pm 0.09$ at baseline and $6.20 \pm 1.31$ and $5.68 \pm 1.02$ at hour 12 for $\mathrm{CF}$ and PF, respectively. Unpaired t-tests conducted between the two groups could not discern a statistical difference $(\mathrm{p}=0.05)$ at any time point. 


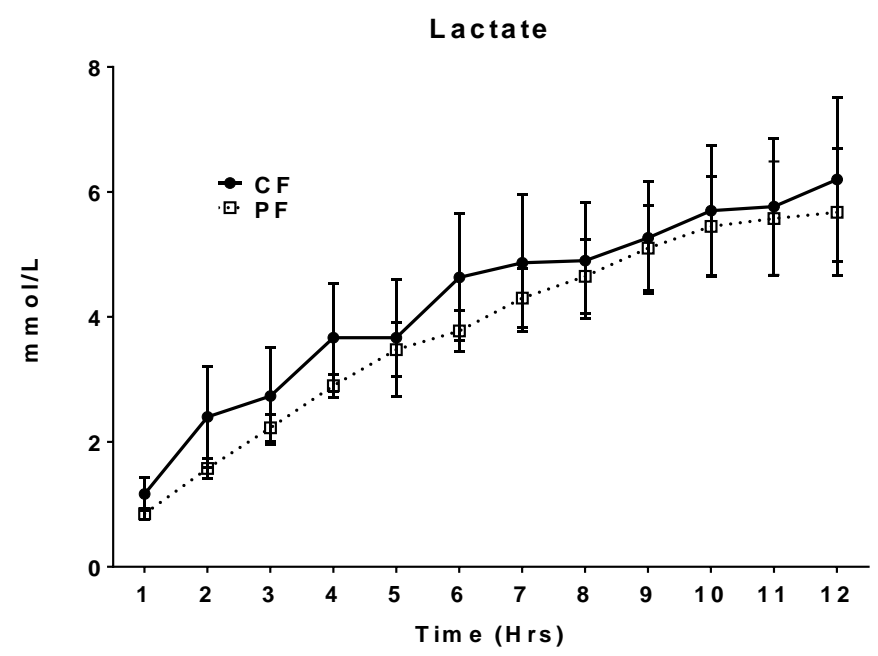

Figure 32-Lactate concentration over 12-hour test period

Glucose concentration was observed to decrease over the 12 hour test period for both groups. Glucose concentration in $\mathrm{mg} / \mathrm{dL}$ was $398 \pm 24.76$ and $421 \pm 26.51$ at baseline and $188 \pm 10.17$ and $174 \pm 22.90$ at hour 12 for $\mathrm{CF}$ and $\mathrm{PF}$, respectively. Unpaired t-tests conducted between the two groups could not discern a statistical difference $(\mathrm{p}=0.05)$ at any time point.

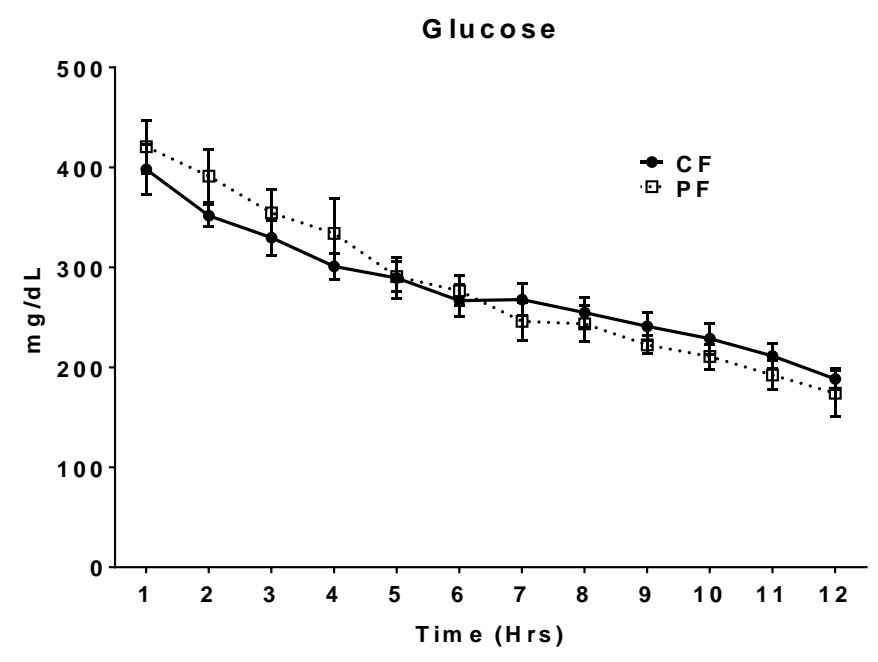

Figure 33-Glucose concentration over 12-hour test period 
Despite aggressive management with sodium bicarbonate, $\mathrm{pH}$ was observed to decrease over the 12 hour test period for both groups. In addition, the buffering capability of the lungs was observed to decrease.

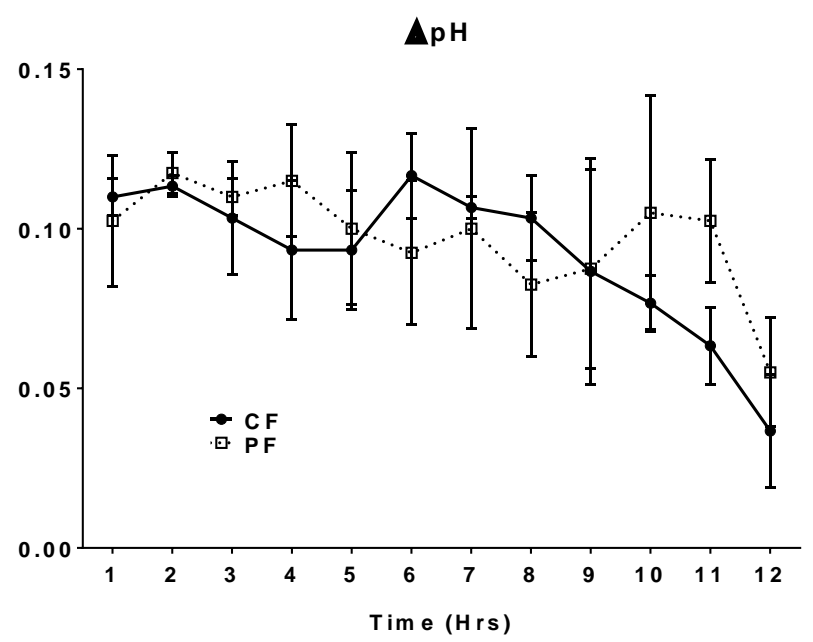

Figure $34-\mathrm{sH}$ over 12 -hour test period

The $\Delta \mathrm{pH}$ between the arterial and venous aspects of the lungs was $0.11 \pm 0.006$ and $0.10 \pm 0.021$ at baseline and $0.04 \pm 0.012$ and $0.055 \pm 0.017$ at hour 12 for $\mathrm{CF}$ and PF, respectively. Unpaired t-tests conducted between the two groups could not discern a statistical difference $(\mathrm{p}=0.05)$ at any time point.

\section{Wet/Dry Analysis}

Parenchymal biopsies were taken intraoperatively, as well as after 1, 3, 6, 9, and 12 hours of EVLP. Average values are plotted for both continuous and pulsatile groups as a function of time. Wet/dry ratio was $5.53 \pm 0.56$ and $6.06 \pm 0.09$ at baseline and $5.27 \pm 0.48$ and 5.12 \pm 0.40 at hour 12 for $\mathrm{CF}$ and PF, respectively. The average values for wet/dry ratio were $5.88 \pm 0.25$ and $5.44 \pm 0.14$ for $\mathrm{CF}$ and $\mathrm{PF}$ respectively. Unpaired t-tests 
conducted between the two groups could not discern a statistical difference $(p=0.05)$ at any time point.

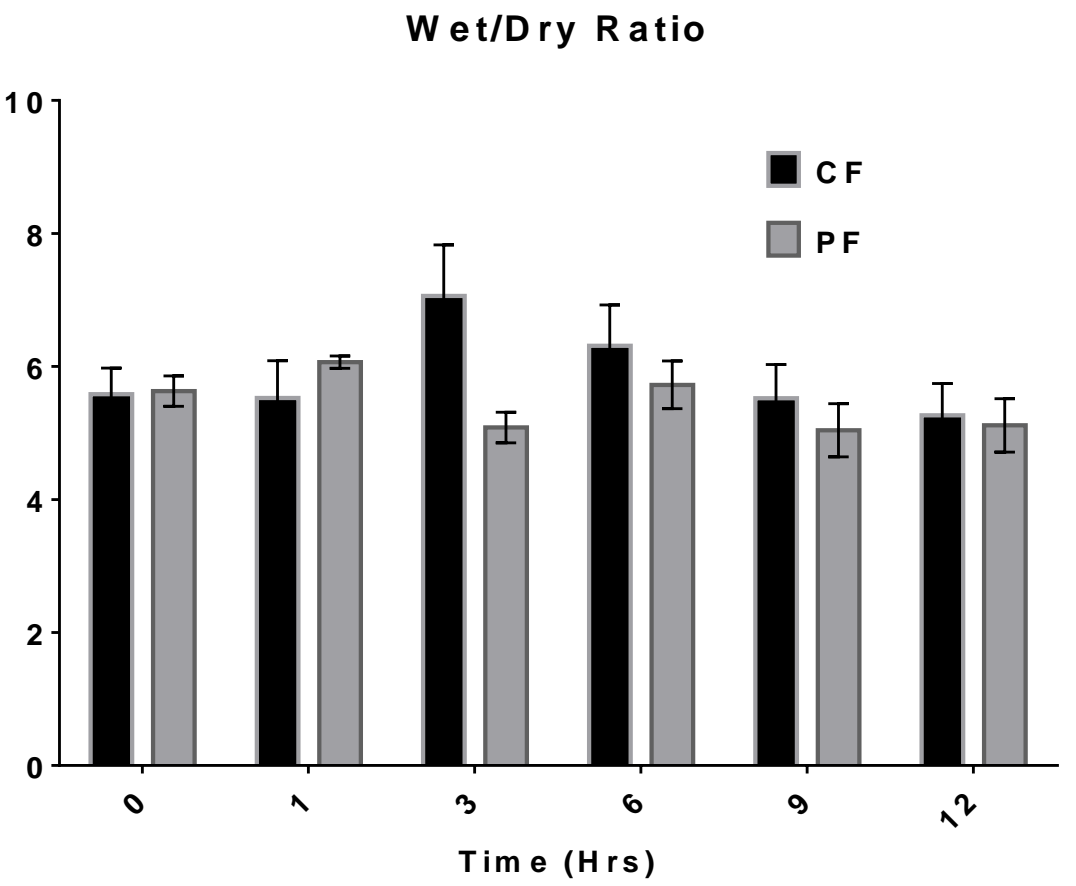

Figure 35-Wet/Dry Ratio over 12-hour test period

E. Enzyme-Linked Immunosorbent Assay (ELISA) Analysis

Parenchymal biopsies were taken intraoperatively, as well as after 1, 3, 6, 9, and 12 hours of EVLP. ELISA was carried out in 96 well plates to quantify IL-6, Il-8, IL-10, and TNF- $\alpha$ concentration at each of these time points. TNF- $\alpha$ concentration increased on a logarithmic scale over the 12 hour test period. TNF- $\alpha$ concentration was $16.305 \pm 4.76$ and $8.42 \pm 0.31 \mathrm{pg} / \mathrm{mL}$ at baseline and $705.86 \pm 0.43$ and $582.17 \pm 204.10 \mathrm{pg} / \mathrm{mL}$ at hour 12 for $\mathrm{CF}$ and PF, respectively. Fig. 36 shows the color change that accompanied incubation with the detection antibody. 


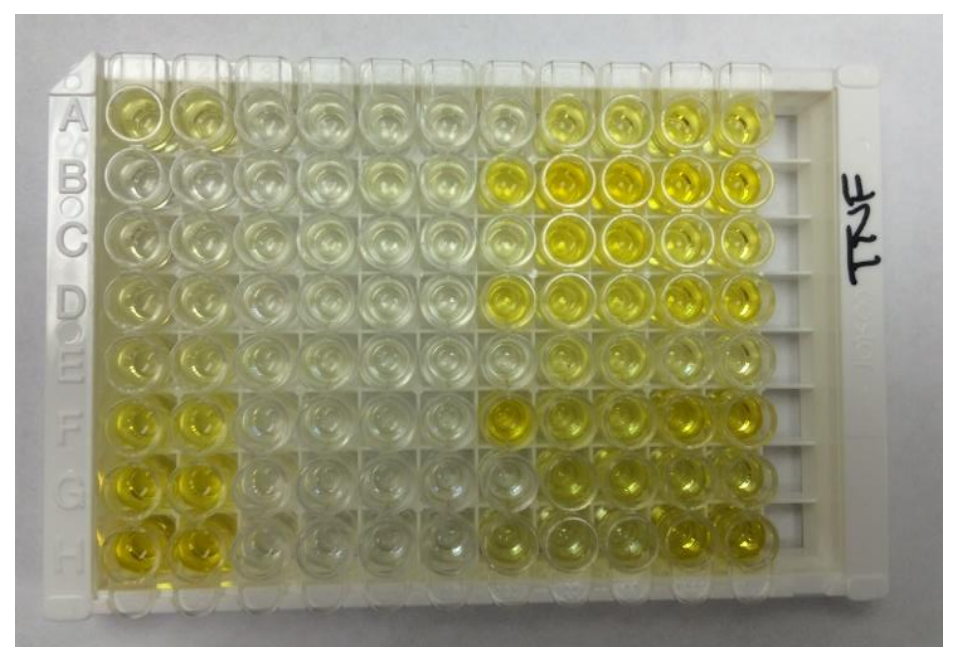

Figure 36-TNF- $\alpha$ microplate after incubation with detection antibody

Average values are plotted for both continuous and pulsatile groups as a function of time in fig. 37. Unpaired t-tests conducted between the two groups could not discern a statistical difference $(\mathrm{p}=0.05)$ at any time point.

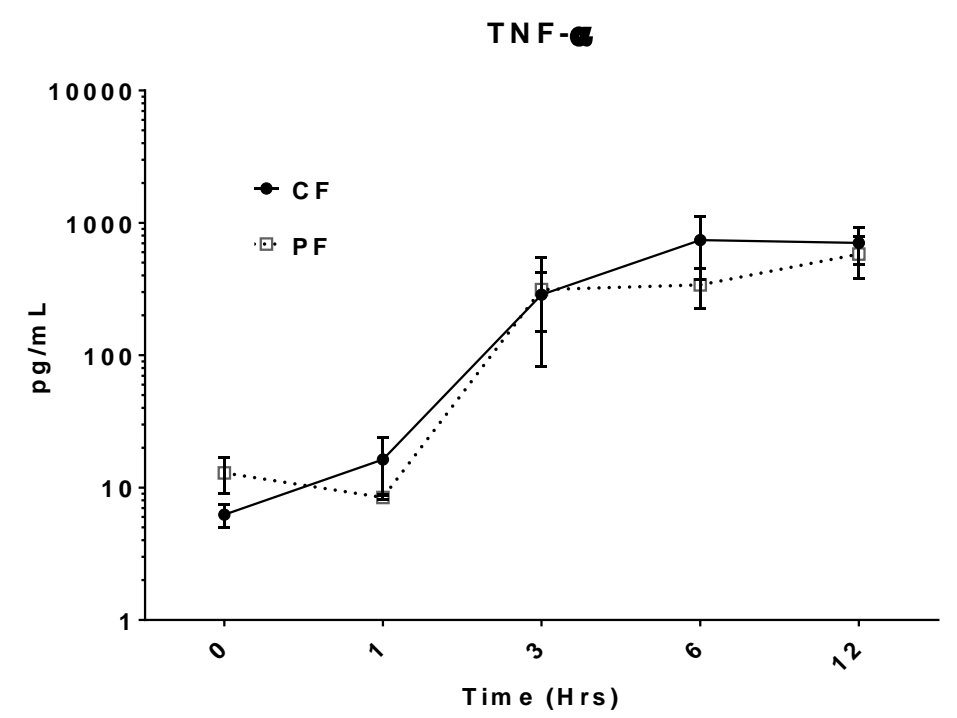

Figure 37-TNF- $\alpha$ concentration over 12-hour test period

Elevated TNF- $\alpha$ expression is indicative of tissue inflammation, sepsis, and initiation of the acute phase reaction. The increase in this cytokine suggests the activation of 
macrophages and cellular apoptotic pathways. Interestingly, the slope of the concentration over the first hour is negative for the PF group, while it is positive for the CF group. By hour 3, however, both slopes are positive and the concentrations are nearly identical.

IL-6 concentration increased on a logarithmic scale over the 12 hour test period. IL-6 concentration was $5.56 \pm 1.35$ and $6.34 \pm 1.17 \mathrm{pg} / \mathrm{mL}$ at baseline and $107.46 \pm 48.36$ and $156.29 \pm 64.68 \mathrm{pg} / \mathrm{mL}$ at hour 12 for $\mathrm{CF}$ and PF, respectively. Fig. 38 shows the color change that accompanied incubation with the detection antibody.

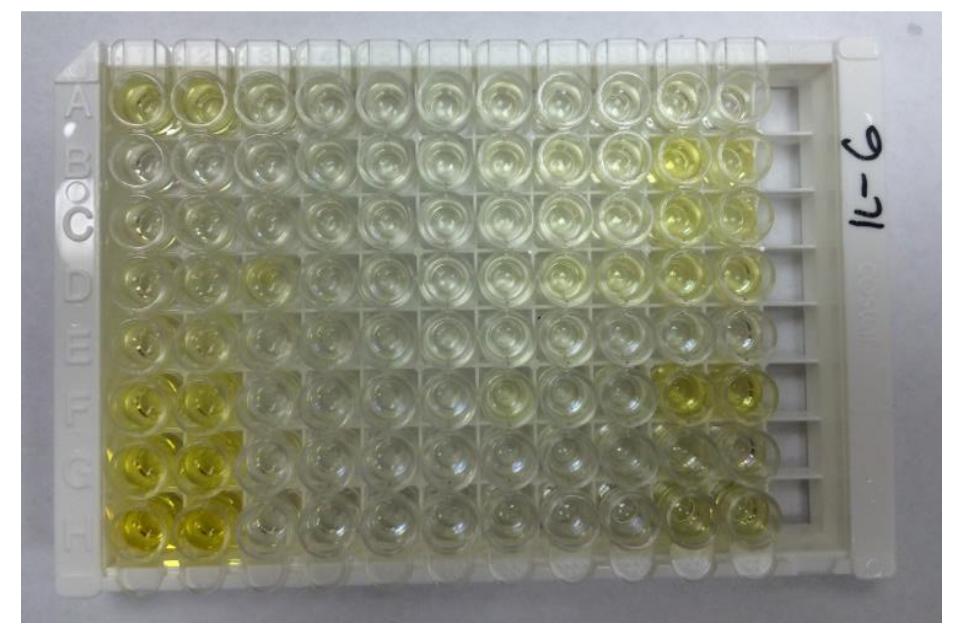

Figure 38-IL-6 microplate after incubation with detection antibody

Average values are plotted for both continuous and pulsatile groups as a function of time in Fig. 39. Unpaired t-tests conducted between the two groups could not discern a statistical difference $(\mathrm{p}=0.05)$ at any time point. Elevated IL-6 concentration is indicative of T-cell and macrophage recruitment and suggests the activation of the immune response. This response could be the result of sepsis, trauma during procurement, ischemia-reperfusion injury, or ventilator/bypass related trauma. Interestingly, the slope 
of the concentration over the first hour is negative for the PF group, while it is positive for the CF group. By hour 3, however, both slopes are positive and the concentrations are nearly identical.

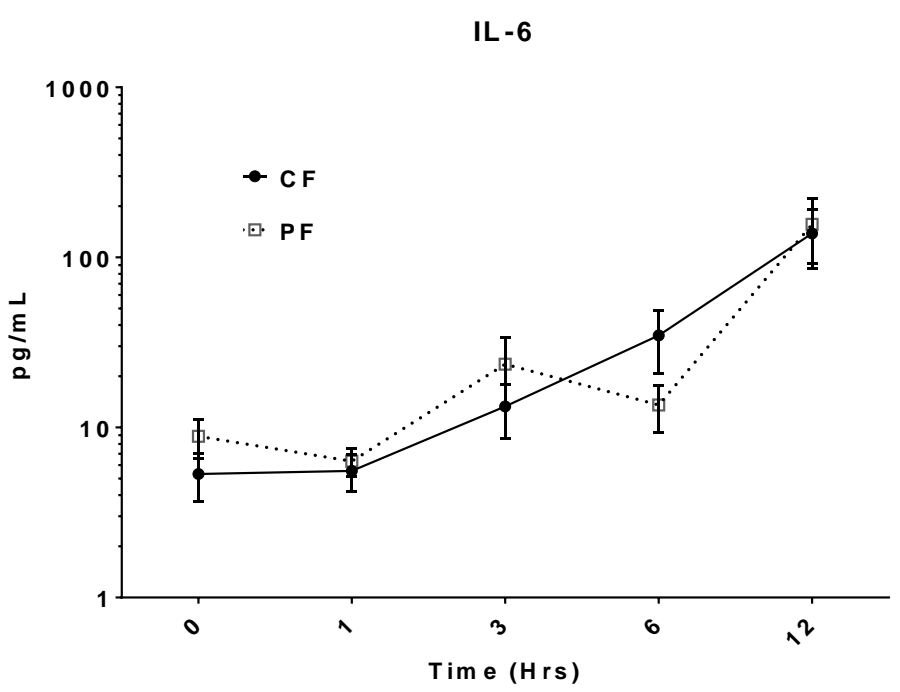

Figure 39-IL-6 concentration over 12-hour test period

IL-8 concentration increased on a logarithmic scale over the 12 hour test period. IL-8 concentration was $49.51 \pm 21.96$ and $48.57 \pm 10.42 \mathrm{pg} / \mathrm{mL}$ at baseline and 1620.80 \pm 796.70 and $774.38 \pm 271.92 \mathrm{pg} / \mathrm{mL}$ at hour 12 for $\mathrm{CF}$ and PF, respectively. Fig. 40 shows the color change that accompanied incubation with the detection antibody. 


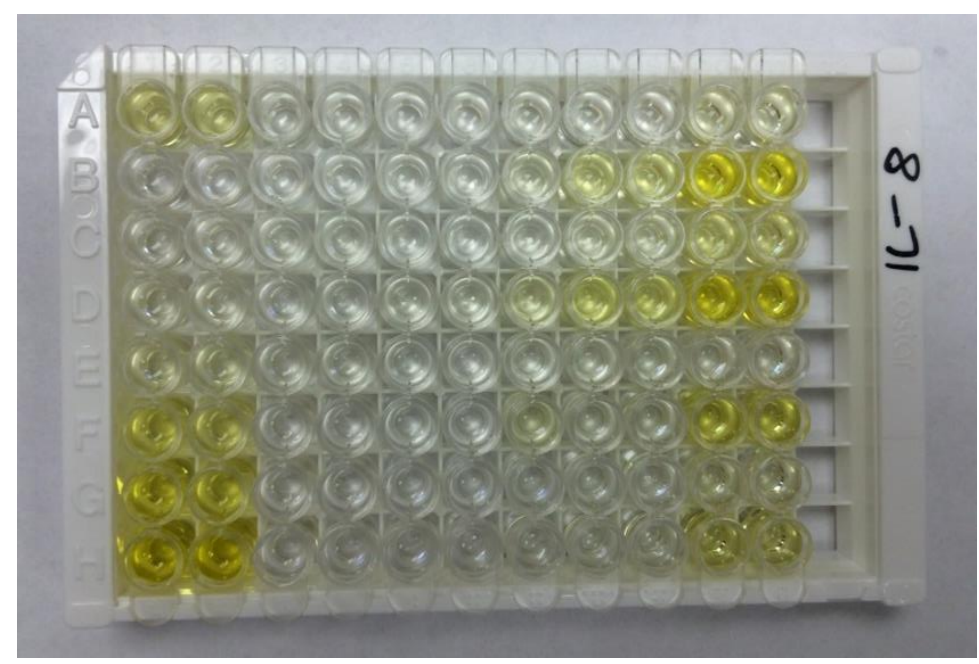

Figure 40-IL-8 microplate after incubation with detection antibody

Average values are plotted for both continuous and pulsatile groups as a function of time in fig. 41. Unpaired t-tests conducted between the two groups could not discern a statistical difference $(\mathrm{p}=0.05)$ at any time point. Elevated IL-8 concentration is indicative of the immune response being initiated in the epithelium, endothelium, and airway smooth muscle cells.

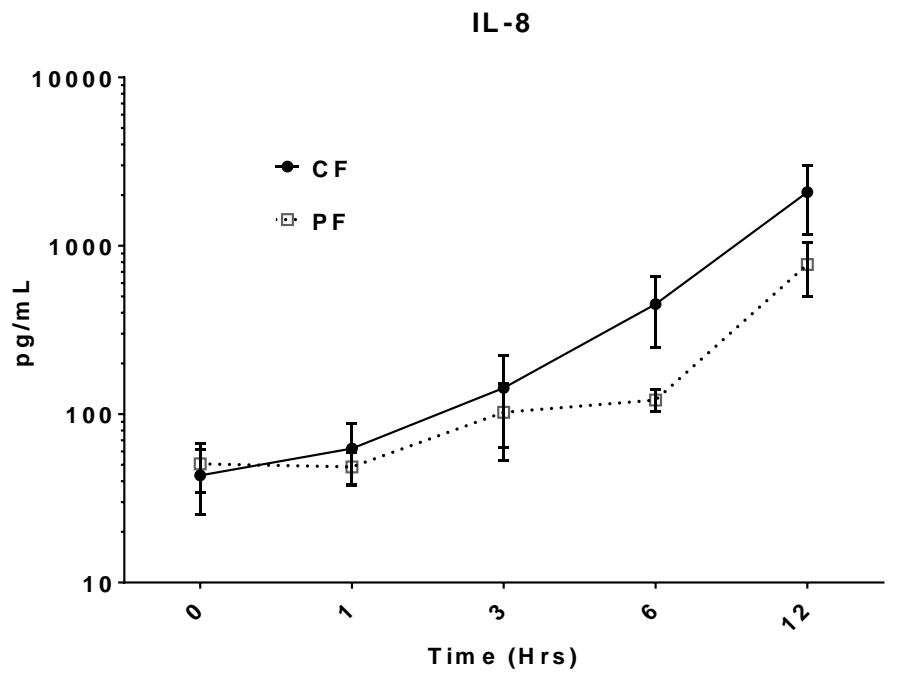

Figure 41-IL-8 Concentration over 12-hour test period 
IL-10 concentration was $11.94 \pm \mathrm{NA}$ and $1.71 \pm 0.72 \mathrm{pg} / \mathrm{mL}$ at baseline and 9.16 \pm 4.30 and $9.83 \pm 3.48 \mathrm{pg} / \mathrm{mL}$ at hour 12 for $\mathrm{CF}$ and $\mathrm{PF}$, respectively. However, only one well was successfully analyzed for the continuous baseline and therefore the measurement is not completely reliable. Fig. 42 shows the color change that accompanied incubation with the detection antibody.

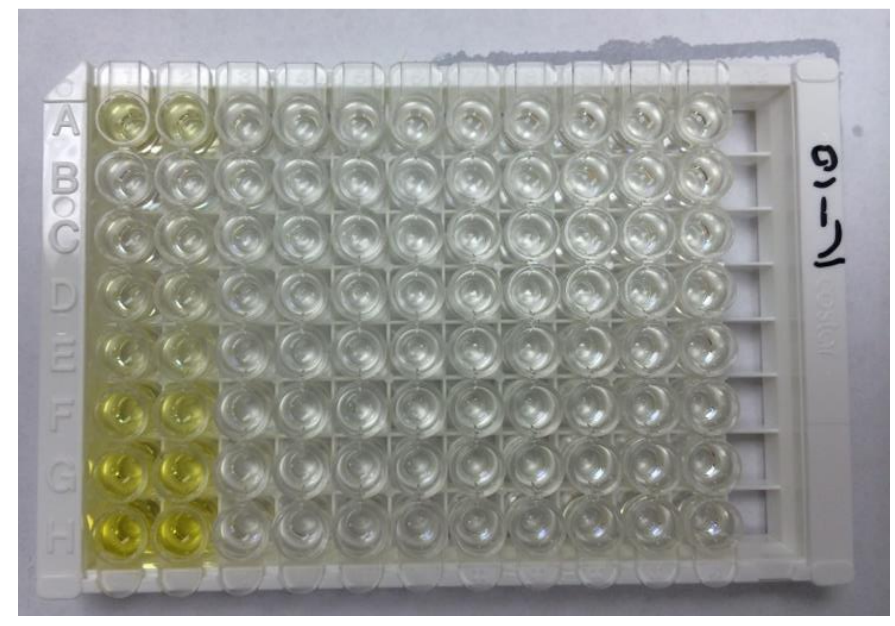

Figure 42-IL-10 microplate after incubation with detection antibody

Average values are plotted for both continuous and pulsatile groups as a function of time in fig. 43. As can be seen, only one of three wells was successfully measured for the continuous baseline concentration. Unpaired t-tests conducted between the two groups could not discern a statistical difference $(\mathrm{p}=0.05)$ at any time point. Since IL-10 is an anti-inflammatory cytokine, it is understandable that the concentration increased only slightly, while the other pro-inflammatory cytokines concentrations increased dramatically on a logarithmic scale. 


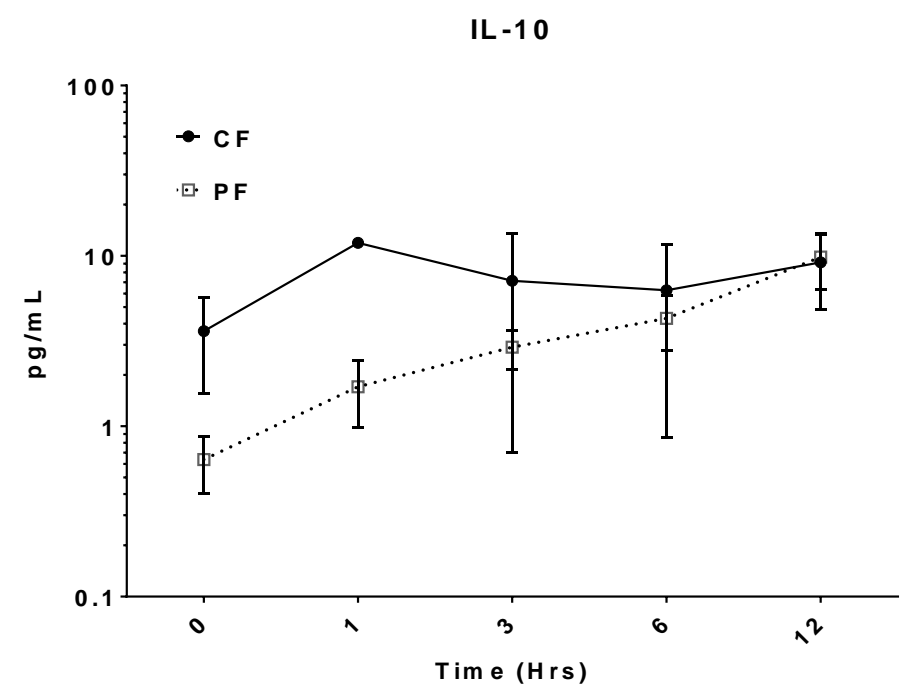

Figure 43-IL-10 concentration over 12-hour test period

The results from these cytokine assays suggest a generalized activation of the immune response. Though a statistical difference was not discerned between groups, it is interesting to note that pro-inflammatory cytokine concentratin (TNF- $\alpha$, IL-6, and IL-10) concentrations all decreased over the first hour of EVLP in the PF group and increased in the PF group. Despite this, cytokine concentration increased for both groups over the 12hour test period, reaching similar values by termination of EVLP. This initial decrease, however, could support a benefit to PF EVLP. Further study is necessary to statistically verify this observation. 


\section{CONCLUSIONS}

Swine lungs were successfully preserved ex vivo for $\leq 19$ hours using an albuminbased perfusate and a protective perfusion/ventilation strategy. During this time, minimal edema was observed and pulmonary vascular resistance was able to be controlled through the continuous infusion of prostaglandin E2. The data collected in this study suggest that PF does not offer benefits over CF in EVLP. There were no statistically significant differences in TNF- $\alpha$, IL-6, and IL-8 concentrations, PVR, $\Delta \mathrm{PO}_{2} / \mathrm{FiO}_{2}$, wet/dry ratio, and PAWP between CF and PF.

\section{RECOMMENDATIONS}

\section{A. Limiting Factors and Observations}

Though we were able to successfully sustain lungs for durations greater than 12 hours, some limitations still persist. For instance, though initially prepared with a 30\% albumin concentration of $117.6 \mathrm{~mL}$ per liter, the perfusate continually needed a supplemental infusion of about $100 \mathrm{~mL} / \mathrm{hr}$. This determination was made using specific gravity as a rough marker for viscosity/oncotic pressure. This raises questions on the mode of its consumption. It is hypothesized that the albumin could be being broken down due to multiple passes through the mechanical blood pumps. Another consideration is whether the albumin is properly buffered in the solution or if some stabilizing agent is required. It is recommended that this problem be addressed, as the accumulation of these breakdown products could be detrimental to the lung tissue.

To mitigate the increase in PVR that occurs, prostaglandin was continuously infused at a rate of $250 \mathrm{mcg} / \mathrm{hr}$. Using this initial dosage, the rate was titrated at about 
$0.5-0.7 \mathrm{~mL} / \mathrm{hr}$ to maintain a low resistance state of the lungs, defined as $<50$ Woods Units. Thus, further investigation of the mechanism behind this reduction in vascular resistance could be implicated in improving outcomes in terms of primary graft dysfunction in a chromic model of EVLP. Prostaglandin E2 is frequently given as a palliative therapy to maintain the patency of the ductus arteriosis in neonates. The mechanism of action is still under investigation but it is observed to cause vasodilation, inhibition of platelet aggregation, and stimulation of intestinal and uterine smooth muscles.

A persistent shift towards acidosis required continual $\mathrm{pH}$ management with sodium bicarbonate and adjustments in the P/V strategy. Paralleling this, despite periodic perfusate transfusions, lactate was observed to rise as well. Thus, a time-dependent shift towards increased anaerobic metabolism is suspected, despite the perfusate being fully oxygenated. Potential explanations for this phenomenon could include the damage to vital machinery in aerobic respiration and the electron transport chain over time. Additionally, dysfunction at the gas exchange barrier in the form of edema, structural, mechanical, or chemical damage could hinder mass transport of gas. Another suspected contributor to graft failure ex vivo is metabolite accumulation due to the absence of clearance via the kidneys. Thus, a potential improvement to the EVLP protocol could be the addition of a hemodialysis unit.

Atelectasis was also noted to develop in the lower lobes of the lungs intraoperatively. Despite multiple inspiratory holds, these regions would generally not recover ex vivo. It is possible that the lowered temperature inhibits reparative processes from occurring, despite the reestablishment of ventilation and perfusion. Delicate 
handling of the lungs during procurement minimized this formation. Another interesting observation was the change in perfusate color over time. $3 \mathrm{~L}$ of solution was used to flush the lungs before initiation of EVLP. Upon initiation, the perfusate would slowly change from a clear, golden color to deep red over the course of about 3 hours. The cause of this observation is currently unknown.

Lastly, it should be noted that during this experiment, a pulse pressure of $2 \mathrm{mmHg}$ was used. This was due to the protective, low flow scenario that we were employing. However, it is possible that the full benefits of pulsatility were not transmitted to the more superficial structures of the vasculature, due to the diminished circumferential stretch that accompanies a decrease in pressure. It is also possible that the magnitude of the maximum shear stress was not large enough the benefit the vascular endothelium. Thus, it is believed that more studies should be conducted to investigate the effects of pulsatility at more physiologic flows ( $\geq 40 \%$ cardiac output; using the Toronto protocol as a minimum).

\section{B. Future Improvement}

Continuous 30 second data samples were collected hourly for PAP, LAP, PAWP, and PAF at $400 \mathrm{~Hz}$ sampling frequency and stored in a DAQ unit. A significant observation of this study was the time-dependent change in morphology of the PAF waveform. Future plans for this data include analysis in Simulink MATLAB by plotting the first few harmonics of impedance: resistance, inductance, and capacitance. This analysis could lead to the discovery of novel, engineering-based metrics as indicators of vascular patency in EVLP. Other data left to be analyzed include frozen and formalin-fixed 
parenchymal samples. The frozen tissue is intended to be used for western blot detection of endothelium-derived, vasorelaxation-inducing proteins, such as eNOS and prostacyclin, to further elucidate any effects of pulsatility not discovered in this study. The formalin stored tissue is to be used in hematoxylin and eosin (H\&E) staining, as well immunohistochemistry to regionally assess expression of eNOS or other proteins of interest.

The results of this study suggest a number of potential applications and routes for further investigation. Though the results of this study seem to suggest that pulsatile flow is not important, many routes of exploration exist that could help elucidate the effect of pulsatility on the vascular endothelium and the organ as a whole in EVLP. Further studies must be conducted on factors suspected to be involved in vasodilatation, such as nitric oxide synthase, endothelin, and PI3K. The reduction of PVR may not contribute to oxygenation, but maintaining the patency and dilation of the vasculature still has the potential to 1) prolong EVLP and 2) improve outcomes in terms of graft dysfuction.

Immunomodulation of donor lungs ex vivo has recently been suggested. It is hypothesized that if seeded into lungs undergoing EVLP, multipotent stem cells could take up residence in the donor lungs, camouflaging them from the innate immune response, and t-cell and complement activation. This method of mitigating the rejection response could be revolutionized by EVLP. A platform for prolonged stem cell treatment and access to the pulmonary circulation has obvious advantages when compared to the traditional static preservation techniques. In a similar vein, immunmodulation and gene therapy using viral vectors could very well be potential applications for EVLP. 
EVLP as a platform for the creation of chronic cancer models has innumerable applications. Research has been hindered by the absence of a suitable animal model for research into lung cancer. If viability can be extended to times greater than 48-72 hours, EVLP potentiates the creation of a cancer model via the direct injection and incubation of cancer and tumor cell lines. From a research prospective, the ex vivo lung cancer model could provide a platform to help elucidate the underlying mechanisms behind both small and non-small cell carcinomas. From a clinical perspective, EVLP could enable the isolated treatment of lungs ex vivo while the patient is supported by ECMO. Thus, the systemic effects of chemotherapy or radiation could be avoided and the lungs returned to the body once rehabilitated. 


\section{LIST OF REFERENCES}

1. Steinbrook, R., Organ Donation after Cardiac Death. New England Journal of Medicine, 2007. 357(3): p. 209-213.

2. Association, A.L., Lung Disease Data:2008, D. Maple, Editor. 2008.

3. Prevention, C.f.D.C.a., Ntional Vital Statistics Reports, Deaths: Final Data for 2004. 2007.

4. National Heart, L. and B. Institute, Morbidity \& mortality: 2009 chart book on cardiovascular, lung, and blood diseases. Bethesda, MD: US Department of Health and Human Services, National Institutes of Health; 2009. 2012.

5. Prevention, C.f.D.C.a., National Center for Health Statistics: National Health Interview Survey, 2006. 2006.

6. Thurlbeck, W.M. and A. Churg, Pathology of the lung. 1995: Thieme.

7. Nichols, J.E. and J. Cortiella, Engineering of a complex organ: progress toward development of a tissue-engineered lung. Proceedings of the American Thoracic Society, 2008. 5(6): p. 723-730.

8. Hall, J.E., Textbook of Medical Physiology. 2011: Saunders Elsevier.

9. Weinberger, S.E., B.A. Cockrill, and J. Mandel, Principles of pulmonary medicine. 2008: Elsevier Health Sciences.

10. Hasenberg, M., S. Stegemann-Koniszewski, and M. Gunzer, Cellular immune reactions in the lung. Immunological reviews, 2013. 251(1): p. 189-214.

11. Michelle Peckham, A.K., Steve Paxton. University of Leeds Histology Guide. 2004.

12. Emery, J. and A. Mithal, The number of alveoli in the terminal respiratory unit of man during late intrauterine life and childhood. Archives of disease in childhood, 1960. 35(184): p. 544-547.

13. Pump, K.K., THe morphology of the finer branches of the bronchial tree of the human lung. CHEST Journal, 1964. 46(4): p. 379-398.

14. Mohrman, D.E. and L.J. Heller, Cardiovascular physiology. 2002.

15. Sadava, D., et al., Life: the science of biology. Vol. 3. 2009: Macmillan.

16. Fick, A., V. On liquid diffusion. The London, Edinburgh, and Dublin Philosophical Magazine and Journal of Science, 1855. 10(63): p. 30-39.

17. Dewey Jr, C., et al., The dynamic response of vascular endothelial cells to fluid shear stress. Journal of biomechanical engineering, 1981. 103(3): p. 177-185.

18. Zhou, J., et al., Regulation of Vascular Smooth Muscle Cell Turnover by Endothelial CellSecreted MicroRNA-126 Role of Shear Stress. Circulation research, 2013. 113(1): p. 4051.

19. Rossi, J., et al., Differential response of endothelial cells to Simvastatin when conditioned with steady, non-reversing pulsatile or oscillating shear stress. Annals of biomedical engineering, 2011. 39(1): p. 402-413.

20. Farcas, M.A., et al., The development of 3-D, in vitro, endothelial culture models for the study of coronary artery disease. Biomed Eng Online, 2009. 8: p. 30.

21. Saggau, W., et al., Clinical and experimental studies on pulsatile and continuous flow during extracorporeal circulation (author's transl)]. Herz, 1980. 5(1): p. 42.

22. Khambadkone, S., et al., Basal pulmonary vascular resistance and nitric oxide responsiveness late after Fontan-type operation. Circulation, 2003. 107(25): p. 32043208.

23. Naeije, R., Pulmonary vascular resistance. Intensive care medicine, 2003. 29(4): p. 526529. 
24. Hurst, J.W. and R.A. O'Rourke, Hurst's The Heart: Manual of Cardiology. 2005: McGraw Hill Professional.

25. Klingensmith, M.E., The Washington manual of surgery. 2008: Wolters Kluwer Health.

26. Cypel, M., et al., Technique for prolonged normothermic ex vivo lung perfusion. The Journal of Heart and Lung Transplantation, 2008. 27(12): p. 1319-1325.

27. Fishman, A.P., Pulmonary circulation. Handbook of physiology. The Respiratory system. Circulation and nonrespiratory functions, 1985. 1: p. 93-166.

28. Eroschenko, V.P., di Fiore's Atlas of Histology with Functional Corelations. 2005, Lippincott Williams \& Wilkins.

29. Hahn, C. and M.A. Schwartz, Mechanotransduction in vascular physiology and atherogenesis. Nature Reviews Molecular Cell Biology, 2009. 10(1): p. 53-62.

30. Birukov, K.G., et al., Intraluminal pressure is essential for the maintenance of smooth muscle caldesmon and filamin content in aortic organ culture. Arteriosclerosis, thrombosis, and vascular biology, 1998. 18(6): p. 922-927.

31. Nakata, M., et al., Augmentative effect of pulsatility on the wall shear stress in tube flow. Artificial organs, 1999. 23(8): p. 727-731.

32. Hutcheson, I.R. and T.M. Griffith, Release of endothelium-derived relaxing factor is modulated both by frequency and amplitude of pulsatile flow. American Journal of Physiology - Heart and Circulatory Physiology, 1991. 261(1): p. H257-H262.

33. Nakano, T., et al., Pulsatile flow enhances endothelium-derived nitric oxide release in the peripheral vasculature. American Journal of Physiology-Heart and Circulatory Physiology, 2000. 278(4): p. H1098-H1104.

34. Hendrickson, R.J., et al., Sustained pulsatile flow regulates endothelial nitric oxide synthase and cyclooxygenase expression in co-cultured vascular endothelial and smooth muscle cells. Journal of molecular and cellular cardiology, 1999. 31(3): p. 619-629.

35. Frangos, J., et al., Flow effects on prostacyclin production by cultured human endothelial cells. Science, 1985. 227(4693): p. 1477-1479.

36. Davies, P.F., Flow-mediated endothelial mechanotransduction. Physiological reviews, 1995. 75(3): p. 519.

37. Tarbell, J.M. and M. Pahakis, Mechanotransduction and the glycocalyx. Journal of internal medicine, 2006. 259(4): p. 339-350.

38. Pahakis, M.Y., et al., The role of endothelial glycocalyx components in mechanotransduction of fluid shear stress. Biochemical and biophysical research communications, 2007. 355(1): p. 228-233.

39. Knöll, R., M. Hoshijima, and K. Chien, Cardiac mechanotransduction and implications for heart disease. Journal of molecular medicine, 2003. 81(12): p. 750-756.

40. Fleming, I., et al., Role of PECAM-1 in the shear-stress-induced activation of Akt and the endothelial nitric oxide synthase (eNOS) in endothelial cells. Journal of cell science, 2005. 118(18): p. 4103-4111.

41. Zaritsky, J.J., et al., Targeted disruption of Kir2. 1 and Kir2. 2 genes reveals the essential role of the inwardly rectifying $K+$ current in $K+-$-mediated vasodilation. Circulation Research, 2000. 87(2): p. 160-166.

42. Gudi, S., J.P. Nolan, and J.A. Frangos, Modulation of GTPase activity of $G$ proteins by fluid shear stress and phospholipid composition. Proceedings of the National Academy of Sciences, 1998. 95(5): p. 2515-2519.

43. Wilson, P.D., Polycystin: new aspects of structure, function, and regulation. Journal of the American Society of Nephrology, 2001. 12(4): p. 834-845. 
44. Kotloff, R.M. and G. Thabut, Lung Transplantation. American Journal of Respiratory and Critical Care Medicine, 2011. 184(2): p. 159-171.

45. Van Raemdonck, D., et al., Lung donor selection and management. Proceedings of the American Thoracic Society, 2009. 6(1): p. 28-38.

46. Lama, V.N., Update in lung transplantation 2008. American journal of respiratory and critical care medicine, 2009. 179(9): p. 759-764.

47. Yusen, R.D., Lung Transplantation Outcomes: The Importance and Inadequacies of Assessing Survival. American Journal of Transplantation, 2009. 9(7): p. 1493-1494.

48. Chien, S., et al., Canine lung transplantation after more than twenty-four hours of normothermic preservation. J Heart Lung Transplant, 1997. 16(3): p. 340-51.

49. Menezes, A.Q., et al., Comparison of Celsior and Perfadex lung preservation solutions in rat lungs subjected to 6 and 12 hours of ischemia using an ex-vivo lung perfusion system. Clinics, 2012. 67(11): p. 1309-1314.

50. Chien, S., Metabolic management. Organ preservation for transplantation, 3rd edition. Austin: Landes Bioscience, 2010: p. 82-123.

51. Buhl, M. and M. Jensen, Metabolic inhibition. Organ Preservation for Transplantation. New York: Marcel Dekker, Inc, 1981.

52. Pegg, D., The biology of cell survival in vitro. Organ Preservation for Transplantation. Marcel Dekker, Inc., New York, 1981.

53. Johnson, M.J., The role of aerobic phosphorylation in the Pasteur effect. Science, 1941. 94(2435): p. 200-202.

54. Ambrosio, G., et al., Evidence that mitochondrial respiration is a source of potentially toxic oxygen free radicals in intact rabbit hearts subjected to ischemia and reflow. Journal of Biological Chemistry, 1993. 268(25): p. 18532-18541.

55. Steen, S., et al., Transplantation of lungs from non-heart-beating donors after functional assessment ex vivo. Ann Thorac Surg, 2003. 76(1): p. 244-52; discussion 252.

56. Cypel, M., et al., Normothermic ex vivo perfusion prevents lung injury compared to extended cold preservation for transplantation. Am J Transplant, 2009. 9(10): p. 2262-9.

57. Ingemansson, R., et al., Clinical transplantation of initially rejected donor lungs after reconditioning ex vivo. The Annals of thoracic surgery, 2009. 87(1): p. 255-260.

58. Kelly, R.F., et al., Low potassium dextran lung preservation solution reduces reactive oxygen species production. The Annals of thoracic surgery, 2003. 75(6): p. 1705-1710.

59. Chang, R.S., K. Wright, and R.M. Effros, Role of albumin in prevention of edema in perfused rabbit lungs. J Appl Physiol Respir Environ Exerc Physiol, 1981. 50(5): p. 106570.

60. Vollmar, B., et al., Leukocytes contribute to hepatic ischemia/reperfusion injury via intercellular adhesion molecule-1-mediated venular adherence. Surgery, 1995. 117(2): p. 195-200.

61. Fisher, A.B., C. Dodia, and J. Linask, Perfusate composition and edema formation in isolated rat lungs. Exp Lung Res, 1980. 1(1): p. 13-21.

62. Sasaki, M., et al., Influence of pulmonary arterial pressure during flushing on lung preservation. Transplantation, 1996. 61(1): p. 22-27.

63. Sanchez, P.G. and F. D'Ovidio, Ex-vivo lung perfusion. Curr Opin Organ Transplant, 2012. 17(5): p. 490-5.

64. Roman, M.A., et al., Ex vivo lung perfusion: a comprehensive review of the development and exploration of future trends. Transplantation, 2013. 96(6): p. 509-18. 
65. Health, U.S.N.I.o. Novel Lung Trial: Normothermic Ex Vivo Lung Perfusion (Evlp) As An Assessment Of Extended/Marginal Donor Lungs. 2013; Available from:

http://clinicaltrials.gov/show/NCT01365429.

66. Erasmus, M.E., et al., Normothermic ex vivo lung perfusion of non-heart-beating donor lungs in pigs: from pretransplant function analysis towards a 6-h machine preservation. Transplant international, 2006. 19(7): p. 589-593.

67. DE PERROT, M., et al., Interleukin-8 release during early reperfusion predicts graft function in human lung transplantation. American journal of respiratory and critical care medicine, 2002. 165(2): p. 211-215.

68. Kakishita, T., et al., Suppression of Inflammatory Cytokines During Ex Vivo Lung Perfusion With an Adsorbent Membrane. The Annals of Thoracic Surgery, 2010. 89(6): p. 17731779.

69. Sadaria, M.R., et al., Cytokine Expression Profile in Human Lungs Undergoing Normothermic Ex-Vivo Lung Perfusion. The Annals of Thoracic Surgery, 2011. 92(2): p. 478-484.

70. Yeung, J.C., et al., Ex Vivo Adenoviral Vector Gene Delivery Results in Decreased Vectorassociated Inflammation Pre-and Post-lung Transplantation in the Pig. Molecular Therapy, 2012. 20(6): p. 1204-1211.

71. Cypel, M., et al., Functional repair of human donor lungs by IL-10 gene therapy. Sci Transl Med, 2009. 1(4): p. 4ra9.

72. Naka, Y., et al., Enhanced Preservation of Orthotopically Transplanted Rat Lungs by Nitroglycerin but Not Hydralazine Requirement for Graft Vascular Homeostasis Beyond Harvest Vasodilation. Circulation research, 1995. 76(5): p. 900-906.

73. Jheon, S., et al. Pulmonary preservation effect of nitroglycerine in isolated rat lung reperfusion model. in Transplantation proceedings. 2004. Elsevier.

74. Guidot, D.M., et al., Inhaled NO prevents IL-1-induced neutrophil accumulation and associated acute edema in isolated rat lungs. American Journal of Physiology-Lung Cellular and Molecular Physiology, 1996. 271(2): p. L225-L229.

75. Csonka, C., et al., Classic preconditioning decreases the harmful accumulation of nitric oxide during ischemia and reperfusion in rat hearts. Circulation, 1999. 100(22): p. 22602266.

76. Colasanti, M. and H. Suzuki, The dual personality of NO. Trends in pharmacological sciences, 2000. 21(7): p. 249-252.

77. Levine, S., et al., Single lung transplantation for primary pulmonary hypertension. CHEST Journal, 1990. 98(5): p. 1107-1115.

78. Moncada, S., et al., Prostacyclin is a circulating hormone. 1978.

79. Unruh, H.W., Lung preservation and lung injury. Chest surgery clinics of North America, 1995. 5(1): p. 91.

80. Cypel, M., et al., Experience with the first 50 ex vivo lung perfusions in clinical transplantation. The Journal of Thoracic and Cardiovascular Surgery, 2012.

81. Valenza, F., et al. The consumption of glucose during ex vivo lung perfusion correlates with lung edema. in Transplantation proceedings. 2011. Elsevier.

82. Emaminia, A., et al., Adenosine $A<s u b>2 A</ s u b>$ Agonist Improves Lung Function During Ex Vivo Lung Perfusion. The Annals of thoracic surgery, 2011. 92(5): p. 18401846. 
APPENDIX I: CALIBRATION STANDARDS FOR ELISA CONCENTRATION QUANTIFICATION

\begin{tabular}{|l|r|r|r|r|r|r|}
\hline \multicolumn{7}{|c|}{ Standards (pg/ml) } \\
\hline Sample & Concentration & Wells & Values & MeanValue & Sid.Dev. & CV\% \\
\hline 1 & 1200.000 & $\mathrm{H} 1$ & 1.472 & 1.513 & 0.059 & 3.9 \\
& $\mathrm{H} 2$ & 1.555 & & & \\
\hline 2 & 600.000 & $\mathrm{G} 1$ & 0.823 & 0.856 & 0.046 & 5.3 \\
& G2 & 0.888 & & & \\
\hline 3 & 300.000 & F1 & 0.453 & 0.463 & 0.015 & 3.3 \\
& F2 & 0.474 & & & \\
\hline 4 & 75.000 & E1 & 0.130 & 0.141 & 0.015 & 10.6 \\
& E2 & 0.151 & & & \\
\hline 5 & 37.500 & D1 & 0.079 & 0.084 & 0.008 & 9.2 \\
& D2 & 0.090 & & & \\
\hline 6 & 18.750 & C1 & 0.053 & 0.045 & 0.011 & 23.4 \\
& C2 & 0.038 & & & \\
\hline
\end{tabular}

Smallest standard value: $\mathbf{0 . 0 4 5}$

Largest standard value: 1.513

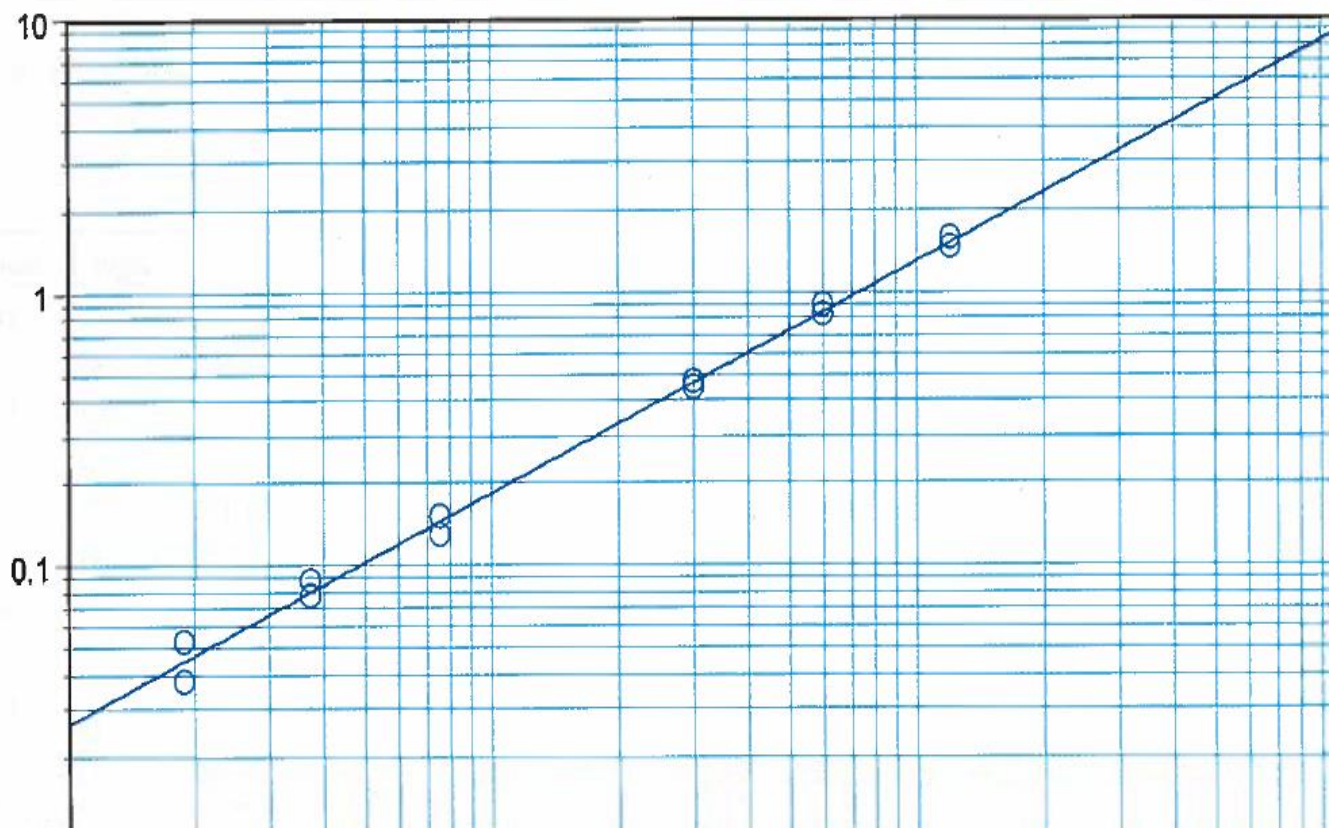




\begin{tabular}{|c|c|c|c|c|c|c|}
\hline \multicolumn{7}{|c|}{ Standards (pg/ml) } \\
\hline Sample & Concentration & Wells & Values & MeanValue & Std.Dev. & CV\% \\
\hline \multirow[t]{2}{*}{4} & \multirow[t]{2}{*}{93.800} & E1 & 0.231 & 0.224 & 0.010 & 4.5 \\
\hline & & E2 & 0.216 & & & \\
\hline \multirow[t]{2}{*}{5} & \multirow[t]{2}{*}{46.900} & D1 & 0.151 & 0.136 & 0.021 & 15.4 \\
\hline & & D2 & 0.121 & & & \\
\hline \multirow[t]{2}{*}{6} & \multirow[t]{2}{*}{23,450} & C1 & 0.065 & 0.062 & 0.004 & 5.8 \\
\hline & & C2 & 0.060 & & & \\
\hline \multirow[t]{2}{*}{ St01 } & \multirow[t]{2}{*}{1500.000} & $\mathrm{H} 1$ & 2.392 & 2.403 & 0.016 & 0.6 \\
\hline & & $\mathrm{H} 2$ & 2.414 & & & \\
\hline \multirow[t]{2}{*}{ St02 } & \multirow[t]{2}{*}{750.000} & G1 & 1.441 & 1.410 & 0.044 & 3.1 \\
\hline & & G2 & 1.379 & & & \\
\hline \multirow[t]{2}{*}{ St03 } & \multirow[t]{2}{*}{375.000} & F1 & 0.817 & 0.791 & 0.037 & 4.6 \\
\hline & & F2 & 0.765 & & & \\
\hline
\end{tabular}

Smallest standard value: $\mathbf{0 . 0 6 2}$

Largest standard value: 2.403

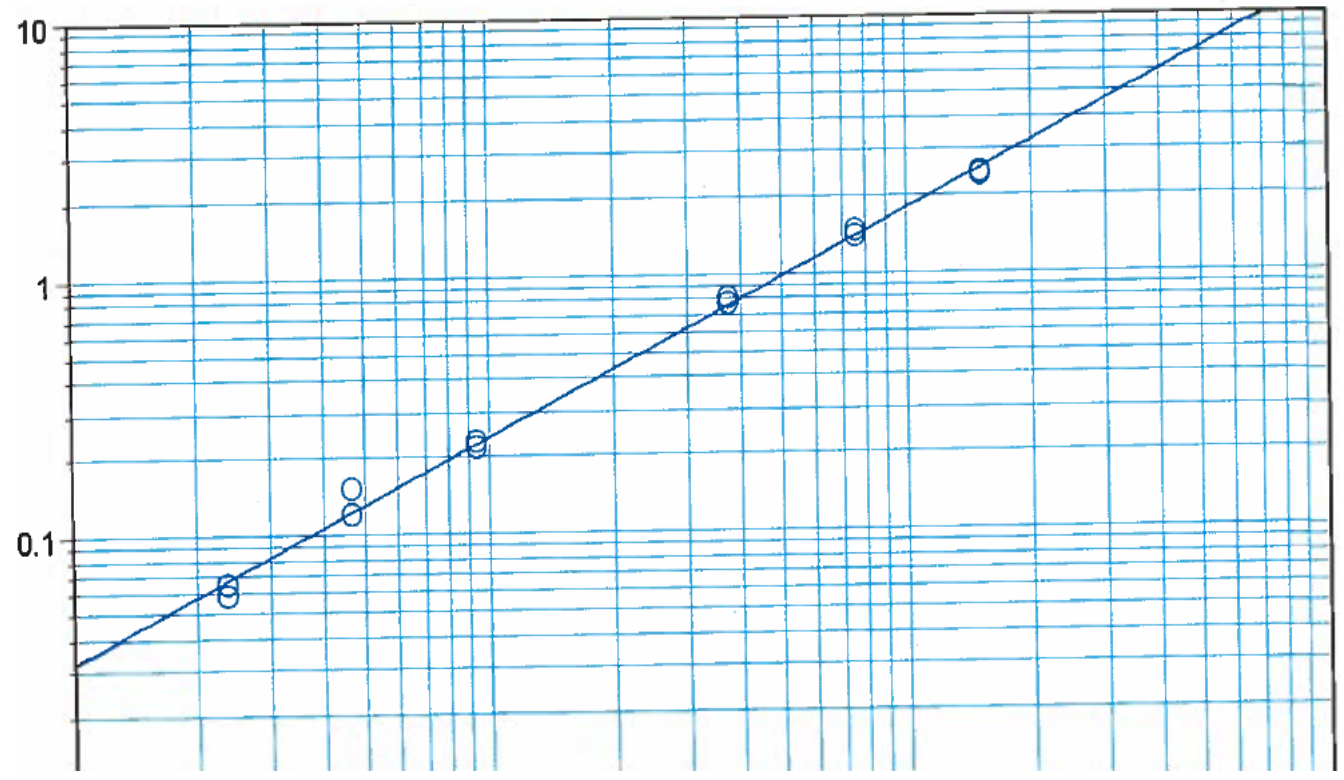




\begin{tabular}{|l|r|r|r|r|r|r|}
\hline \multicolumn{7}{|c|}{ Standards (pg/ml) } \\
\hline Sample & Concentration & Wells & Values & MeanValue & Std.Dev. & CV\% \\
\hline 4 & 250.000 & E1 & 0.127 & 0.128 & 0.002 & 1.4 \\
& E2 & 0.129 & & & \\
\hline 5 & 125.000 & D1 & 0.070 & 0.074 & 0.005 & 7.2 \\
& D2 & 0.078 & & & \\
\hline 6 & 62.500 & C1 & 0.031 & 0.029 & 0.002 & 7.7 \\
& C2 & 0.028 & & & \\
\hline St03 & 4000.000 & H1 & 1.251 & 1.254 & 0.005 & 0.4 \\
& H2 & 1.258 & & & \\
\hline St04 & 2000.000 & G1 & 0.797 & 0.700 & 0.137 & 19.6 \\
& & G2 & 0.602 & & & \\
\hline St05 & 1000.000 & F1 & 0.469 & 0.411 & 0.083 & 20.2 \\
& F2 & 0.352 & & & \\
\hline
\end{tabular}

Smallest standard value: 0.029

Largest standard value: $\mathbf{1 . 2 5 4}$

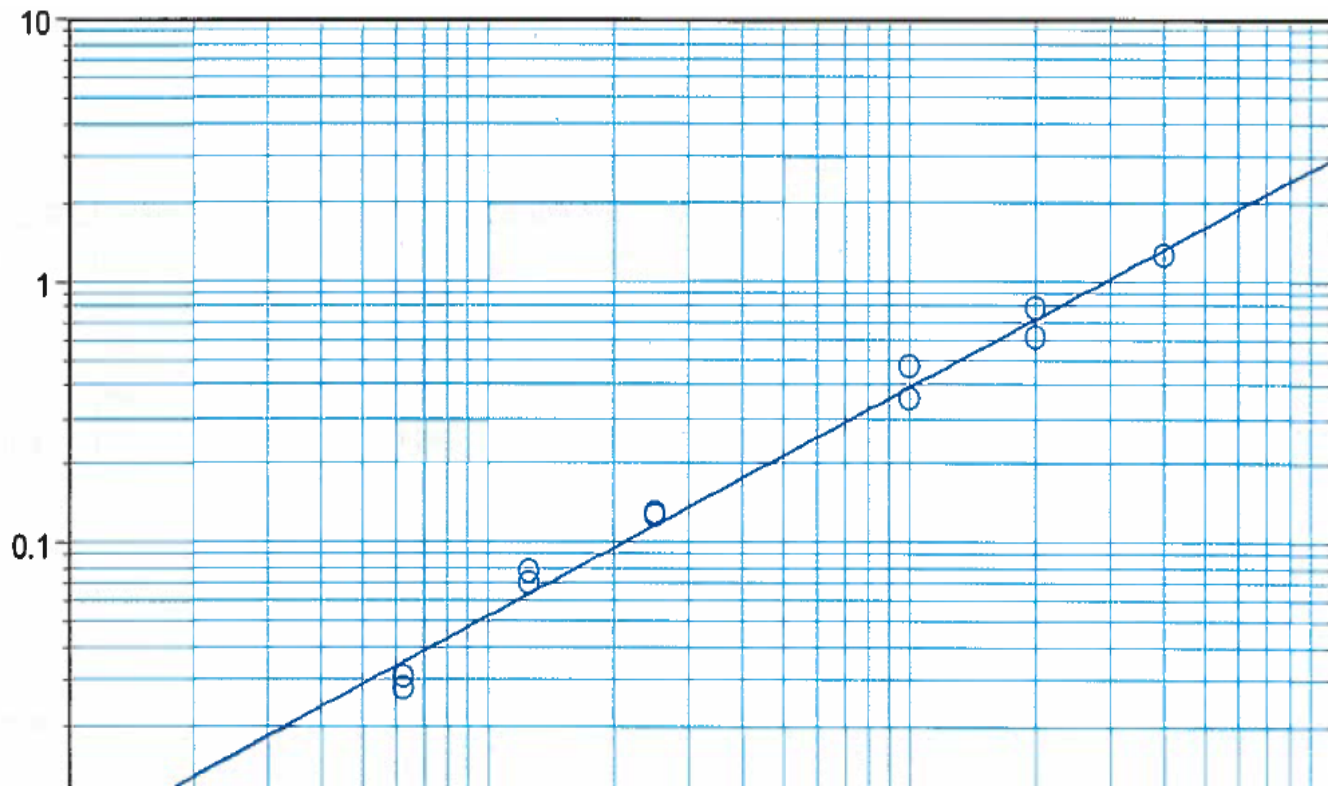




\begin{tabular}{|l|r|r|r|r|r|r|}
\hline \multicolumn{7}{|c|}{ Standards (pg/ml) } \\
\hline Sample & Concentration & Wells & Values & MeanValue & Std.Dev. & CV\% \\
\hline 1 & 2000.000 & H1 & 0.839 & 0.813 & 0.037 & 4.6 \\
\hline 2 & H2 & 0.787 & & & \\
& 1000.000 & G1 & 0.541 & 0.525 & 0.023 & 4.3 \\
\hline 3 & G2 & 0.510 & & & \\
\hline 4 & 500.000 F1 & 0.327 & 0.317 & 0.015 & 4.6 \\
& 125.000 E1 & 0.115 & 0.113 & 0.003 & 2.8 \\
\hline 5 & E2 & 0.111 & & & \\
& 62.500 D1 & 0.065 & 0.063 & 0.002 & 2.8 \\
\hline 6 & D2 & 0.062 & & & \\
& 31.250 & C1 & 0.036 & 0.034 & 0.003 & 8.8 \\
\hline & C2 & 0.032 & & & \\
\hline
\end{tabular}

Smallest standard value: 0.034

\section{Largest standard value: 0.813}

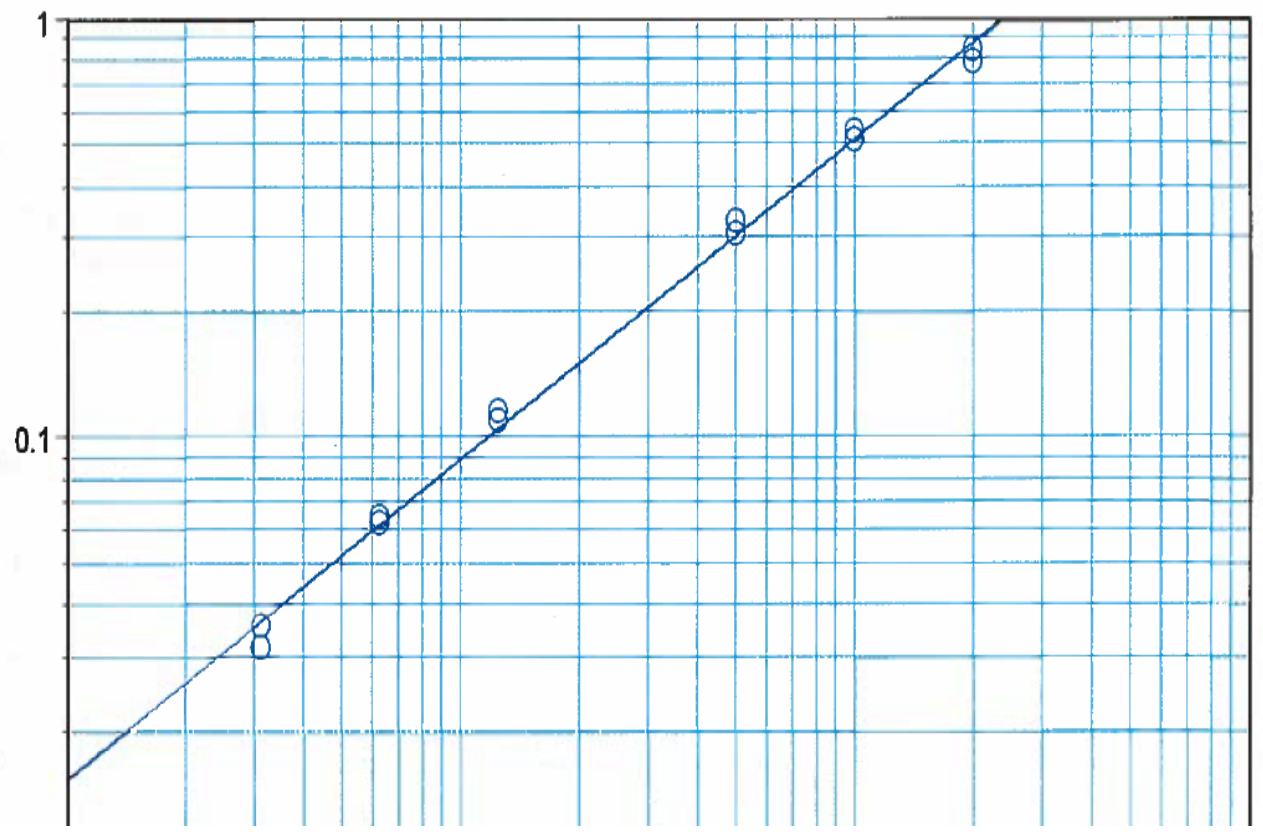




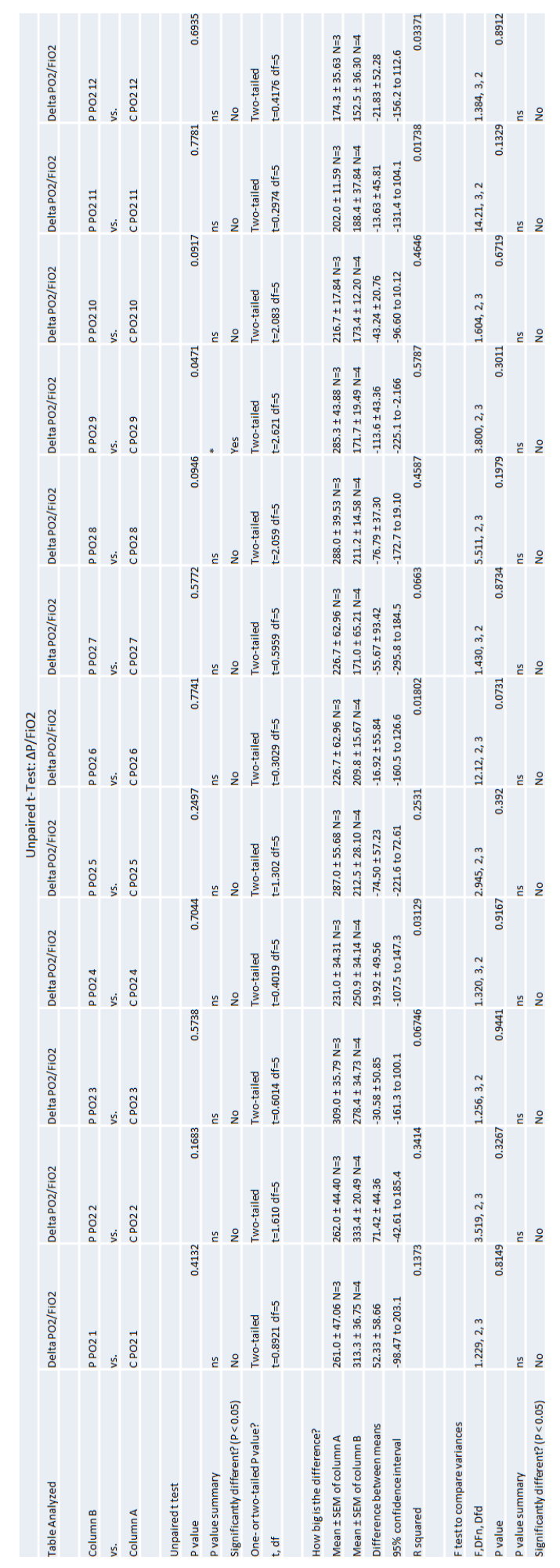




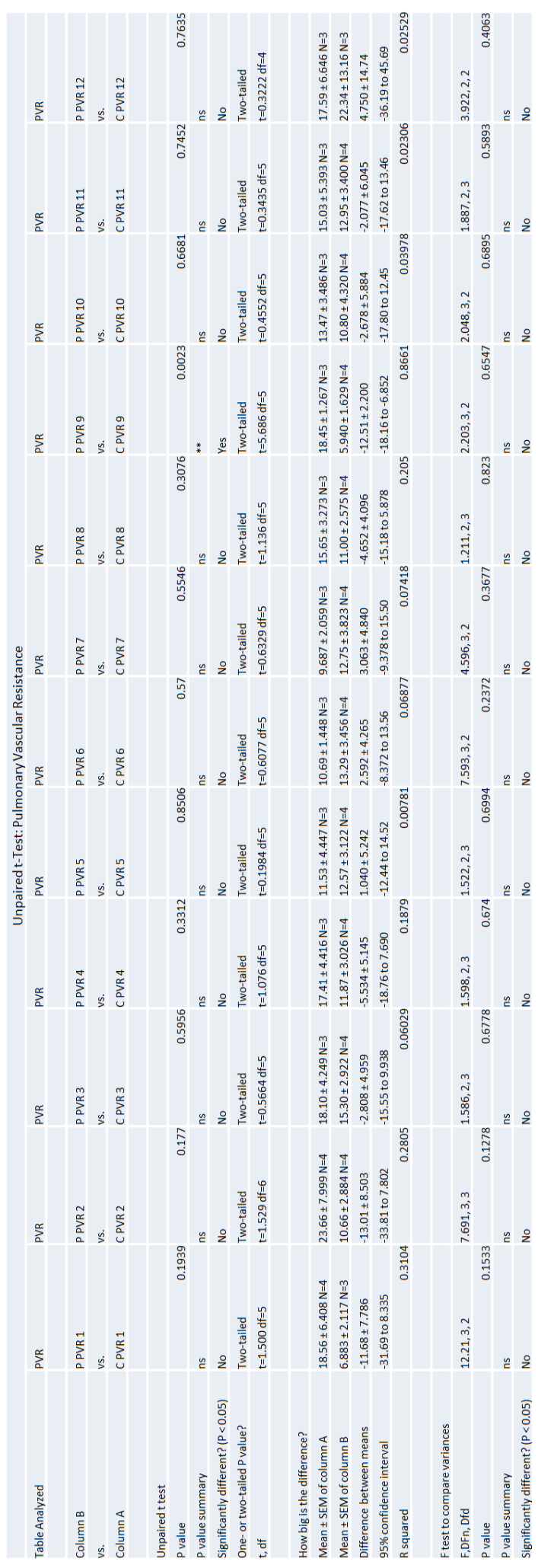




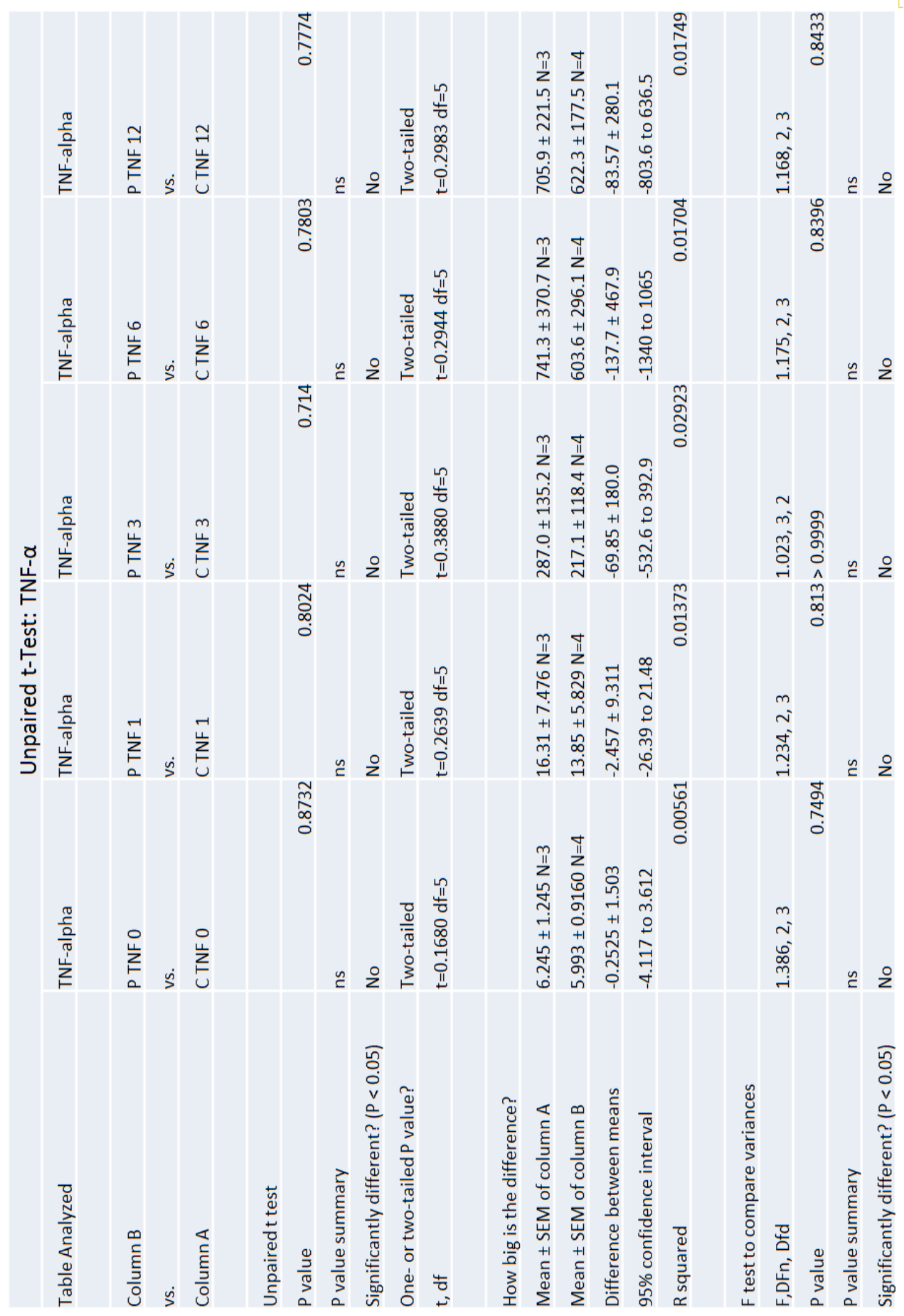




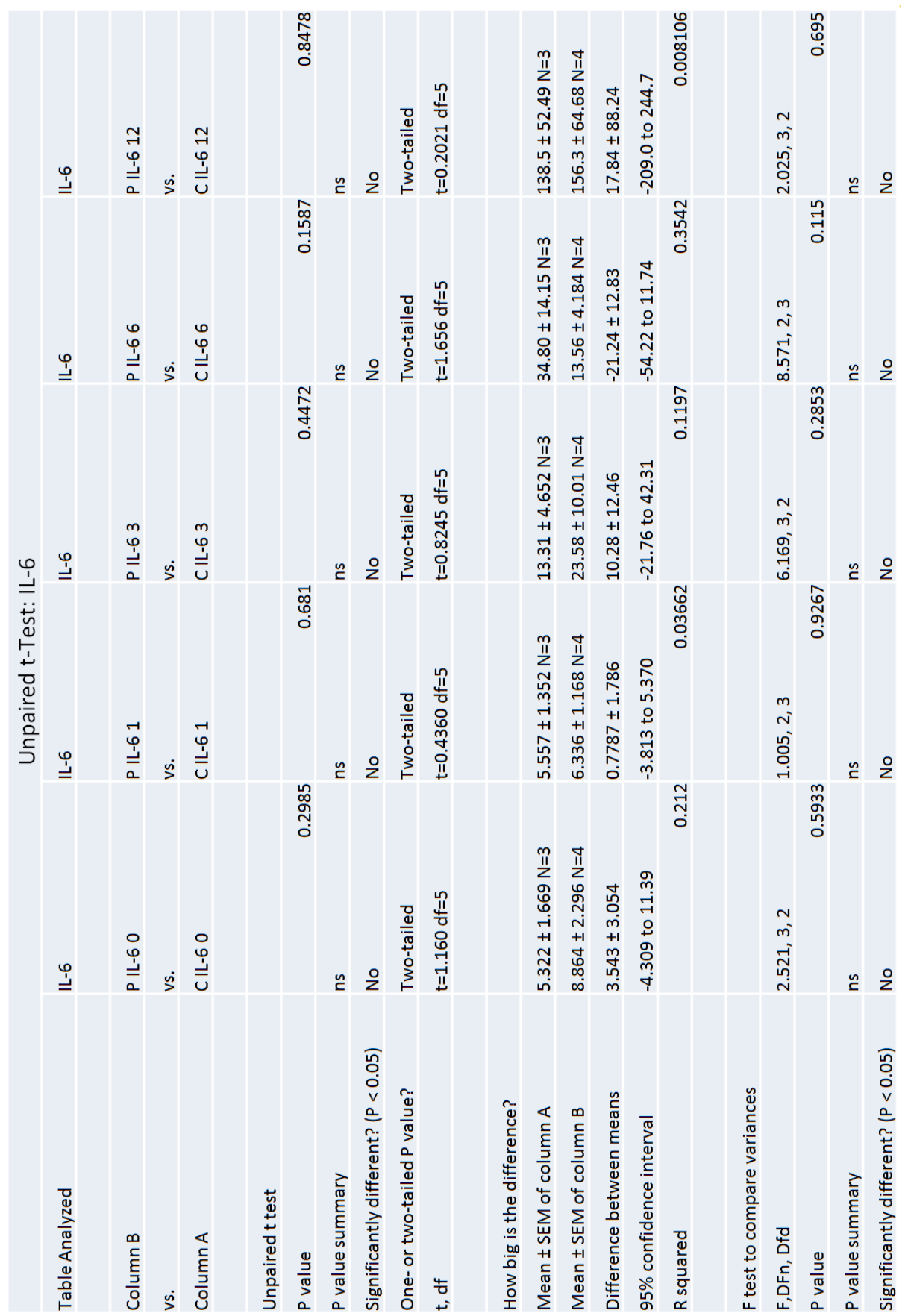




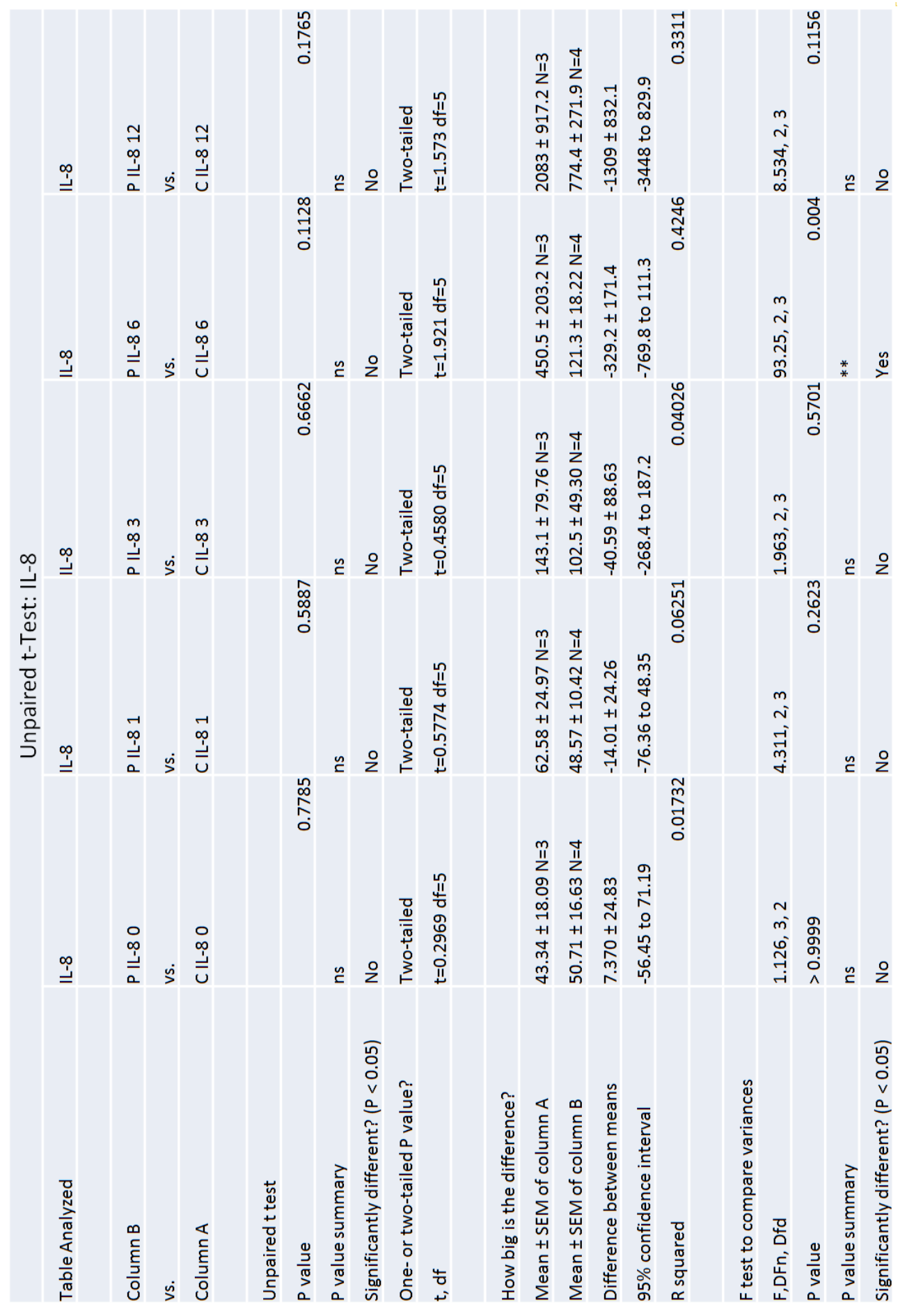




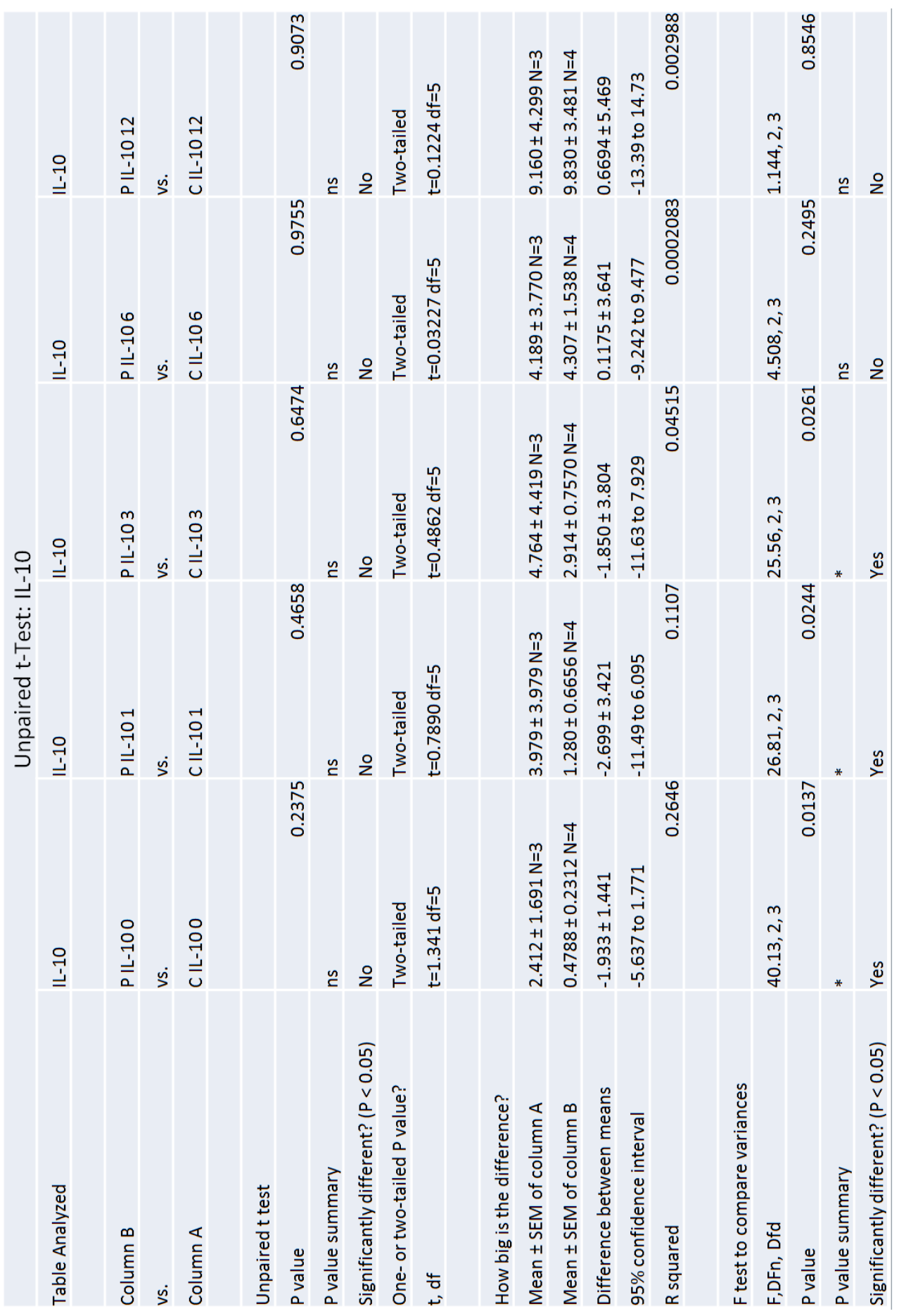




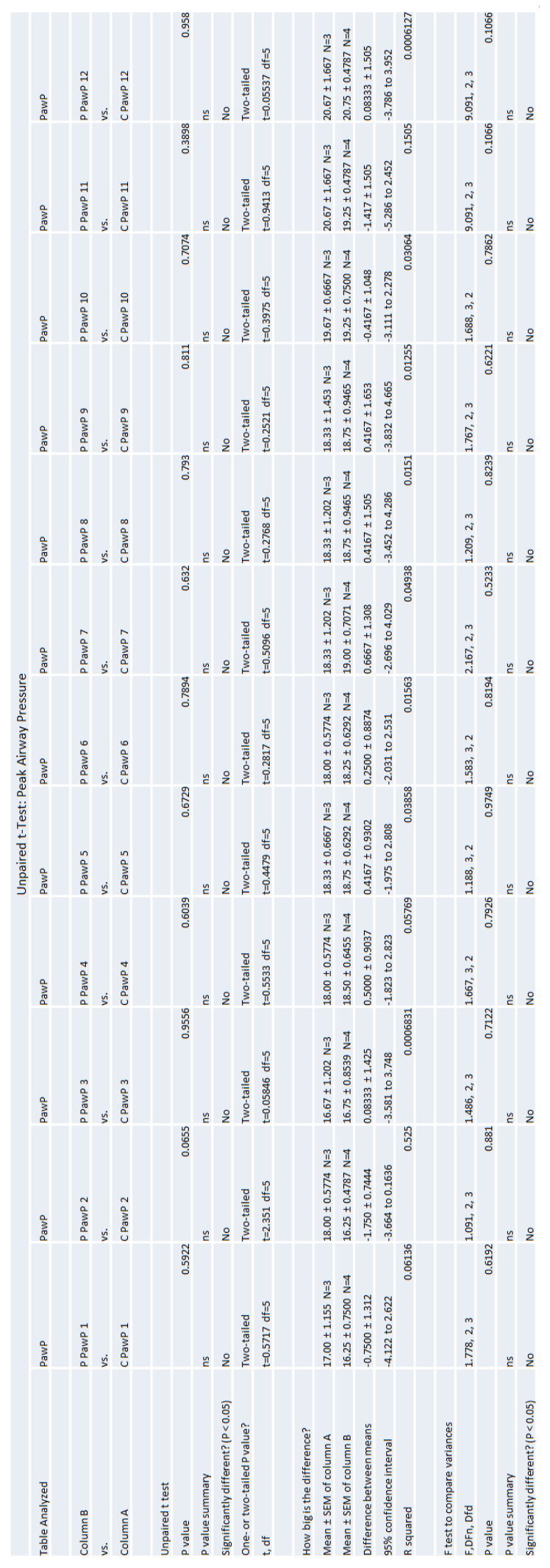


APPENDIX III: CYTOKINE DATA TABLE

\begin{tabular}{|c|c|c|c|c|c|}
\hline \multirow{2}{*}{$\begin{array}{l}\text { 굴 } \\
\text { 혼 }\end{array}$} & 늠 & 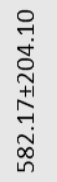 & 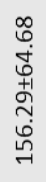 & 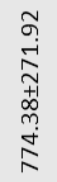 & 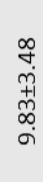 \\
\hline & U & 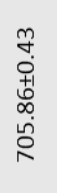 & 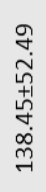 & 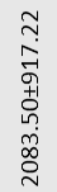 & 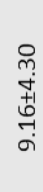 \\
\hline \multirow{2}{*}{$\begin{array}{l}0 \\
\text { 호 } \\
\text { L }\end{array}$} & 늠 & 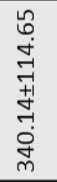 & 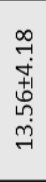 & 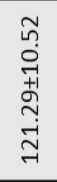 & 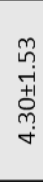 \\
\hline & ঊ & 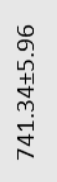 & 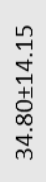 & 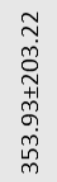 & 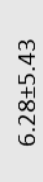 \\
\hline \multirow{2}{*}{ 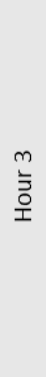 } & 늠 & 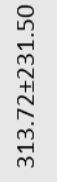 & 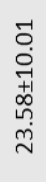 & 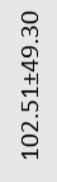 & $\begin{array}{l}\stackrel{0}{0} \\
\stackrel{0}{+1} \\
\stackrel{2}{N}\end{array}$ \\
\hline & u & 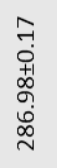 & 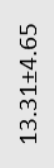 & 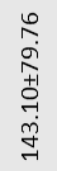 & 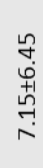 \\
\hline \multirow{2}{*}{ 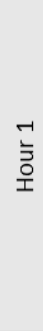 } & 늠 & 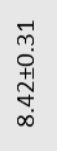 & 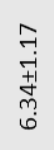 & 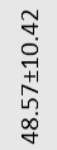 & \begin{tabular}{l}
$\stackrel{N}{N}$ \\
+1 \\
\multirow{2}{*}{} \\
i
\end{tabular} \\
\hline & む & $\begin{array}{l}\stackrel{0}{+} \\
\stackrel{+}{+} \\
\stackrel{1}{m} \\
\stackrel{m}{\oplus}\end{array}$ & 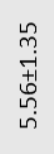 & 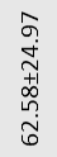 & 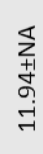 \\
\hline \multirow{2}{*}{$\begin{array}{l}\text { ○ } \\
\text { 호 }\end{array}$} & 늠 & 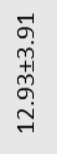 & 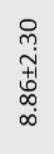 & 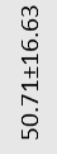 & 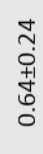 \\
\hline & ঊ & 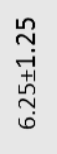 & 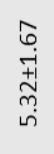 & $\begin{array}{l}\text { ò } \\
\infty \\
0 \\
+ \\
+ \\
m \\
m \\
y\end{array}$ & 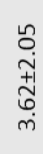 \\
\hline & & 站 & $\stackrel{\varphi}{=}$ & $\stackrel{\infty}{\stackrel{P}{=}}$ & $\stackrel{\stackrel{ }{I}}{=}$ \\
\hline
\end{tabular}


Curriculum Vitae

Keith Armand Zoeller

Telephone: (502) 650-5772

Email: Kazoel01@louisville.edu

\section{Education}

2008 Ballard High School

2012 University of Louisville

2013 University of Louisville
High School Diploma

Bachelor of Science

Master of Engineering
Bioengineering

Bioengineering

\section{$\underline{\text { Academic and Professional Experience }}$}

2007-2008 Part-time Employment, Medastat USA

- Tasked with repair, sanitization, shipping and receiving of specialty healthcare devices including mobility devices, bariatric support devices and patient handling equipment.

2007-2008 Independent Research, Ballard High School/University of Louisville

- Created microfluidic lab-on-chip devices for cell culture and high-throughput reagent analysis

- Regional Science Fair $3^{\text {rd }}$ place awarded for project entitled "Fabrication of a Microfluidic Cell Array for Treatment of Glioblastoma of the Brain"

2010 Industry Co-op Research Technician, Allylix Inc

- Used polymerase chain reaction (PCR) to engineer a genomic vector suitable for large scale production of nootkatone in S. cerevisiae.

- Tasked with DNA amplification in E. coli, fermentation, chemical extraction and product analysis using gas chromatography.

2011 Academic Research Co-op, UofL Institute of Molecular Cardiology

- Tasked with isolation and purification of HMG53 protein from E. coli for analysis of cardioprotective effects.

- Developed proficiency in culture of bacterial and human cell lines, as well as routine analytical laboratory techniques

2011-2013 Part-time Employment, Advanced Heart Failure Research 
- Fed, administered medication, and tended to the medical needs of bovine subjects undergoing device therapy for ischemic heart failure.

- Developed auscultation skills, working pharmacological knowledge, and diagnostic and therapeutic measures for symptomatic heart failure.

2012 Academic Research Co-op, Advanced Heart Failure Research

- Provided technical support for many grant and industry sponsored studies, including hemolysis testing for mechanical circulatory support devices.

- Assisted with instrumentation and data collection during open-heart surgery on bovine subjects.

- Observed VAD operations and collected myocardial samples for analysis in conjunction with the study protocol

2012-Present Graduate Bioengineering Student, University of Louisville

- Developed study protocol, acquired funding and IACUC approval for ex vivo lung perfusion project.

- Research seeks to discern a difference in pulmonary function when perfused under continuous and pulsatile flow modes.

2013-Bioengineer, Advanced Heart Failure Research

- Assist in in the research and clinical development of mechanical circulatory support devices.

- Provide engineering support in post-operative recovery clinic, operating room, and laboratory.

- Participate in collection and analysis of data collected in numerous animal, cadaver, and human studies.

\section{Professional Societies}

Member of Biomedical Engineering Society

2009-2012

- Served as President from 2011-2012.

- Organized research showcase and banquet featuring over 20 research projects and key note address from bioengineering department chair, Dr. Robert Keynton. Over 200 were in attendance.

Member of Pi Kappa Alpha Fraternity

2009-2012 
- Served as pledge class president, Sargent at Arms, membership development, and scholarship chairs.

- Gave weekly speeches, led judiciary committees, and maintained order in room of 60 individuals.

- Performed over 50 hours of community service with proceeds going to organizations such as Harbor House of Louisville, Special Needs Kentucky, and Prevent Child Abuse America.

\section{Research Funding}

Advanced Heart Failure Research $\quad 11 / 1 / 2012-11 / 21 / 2013 \quad \$ 40,000$

Comparison of Continuous and Pulsatile Flow in ex vivo Lung Perfusion

- Comparatively analyzed pulsatile and non-pulsatile flow in a swine model of $e x$ vivo lung perfusion.

\section{Volunteering, Community Service, and Leadership Activities}

Harbor House of Louisville

- Assisted in the coordination and clean up in the Kenducky Derby.

Portland Elementary School: Street Academy

- Mentored and tutored youth from disenfranchised homes in Louisville at Portland Elementary School.

Pike University Leadership Summit

- Attended a weekend-long education seminar on how to be an effective leader and organizer.

Special Olympics Kentucky

- Participated in Special Olympics Kentucky presents: The Polar Plunge.

Advanced Heart Failure Research

- Volunteered over 40 hours in the post-operative care facility at Advanced Heart Failure Research.

\section{$\underline{\text { Academic and Professional Awards }}$}

Nominated for J.B. Speed School of Engineering Outstanding Student Award 


\section{$\underline{\text { Posters }}$}

J.B. Speed School of Engineering Homecoming Student Research Showcase

- Feasibility of Pulsatile Flow in Ex Vivo Lung Perfusion

UofL BMES $100^{\text {th }}$ Coulter Anniversary and Student Research Showcase

- Feasibility of Pulsatile Flow in Ex Vivo Lung Perfusion

\section{$\underline{\text { Publications }}$}

1. Schumer E, Zoeller K, Linksy P, Monreal G, Sobieski M, Koenig S, Slaughter M, van Berkel V. Pulsatile flow does not improve efficacy during prolonged ex vivo lung perfusion, ISHLT, 2013 (in review) 